$\frac{80}{-19.85} .570$

$$
223000 \text { (39) } D R^{* 12939-9}
$$

UNITED STATES GEOTHERMAL TECHNOLOGY

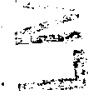
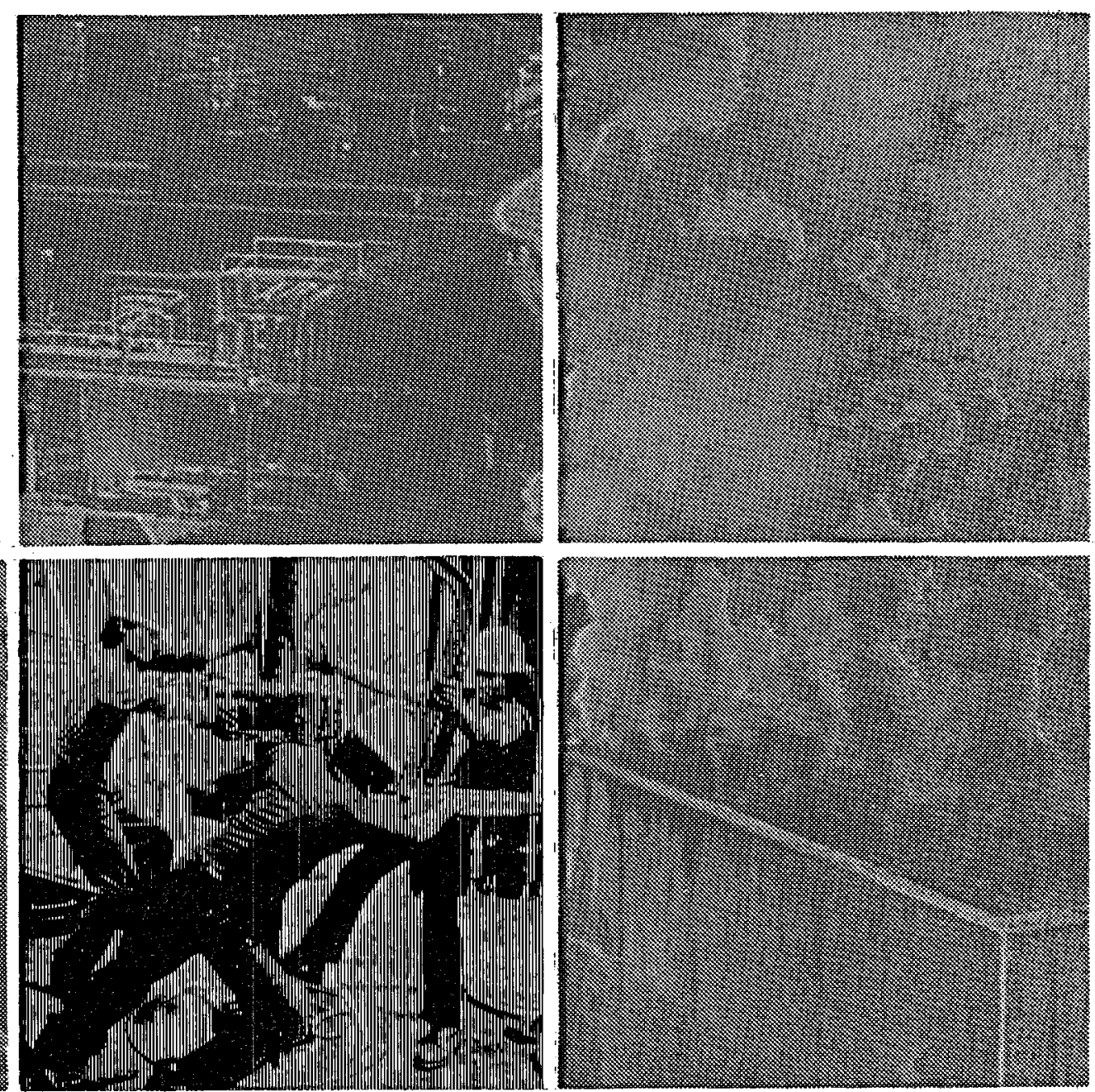

$=\infty$

3 แI

$=1$

$x \rightarrow \infty$

$-\infty$

$\infty$

2

8

\title{
EQUIPMENT \\ AND \\ SERVICES \\ FOR \\ WORLDWIDE APPLICATIONS
}

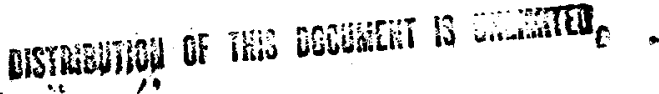




\section{DISCLAIMER}

This report was prepared as an account of work sponsored by an agency of the United States Government. Neither the United States Government nor any agency Thereof, nor any of their employees, makes any warranty, express or implied, or assumes any legal liability or responsibility for the accuracy, completeness, or usefulness of any information, apparatus, product, or process disclosed, or represents that its use would not infringe privately owned rights. Reference herein to any specific commercial product, process, or service by trade name, trademark, manufacturer, or otherwise does not necessarily constitute or imply its endorsement, recommendation, or favoring by the United States Government or any agency thereof. The views and opinions of authors expressed herein do not necessarily state or reflect those of the United States Government or any agency thereof. 


\section{DISCLAIMER}

Portions of this document may be illegible in electronic image products. Images are produced from the best available original document. 
Prepared for the U.S. Department of Energy by Meridian Corporation, Falls Church, Virginia, under subcontract to the Idaho National Engineering Laboratory, EG\&G Idaho, Inc., Idaho Falls, Idaho.

\section{Notice}

This digest was prepared as an account of work sponsored by an agency of the United States government. Neither the United States nor any agency thereof, nor any of their employees, makes any warranty, express or implied, or assumes any legal liability or responsibility for the accuracy, completeness, or usefulness of any information, apparatus, product, or process disclosed, or represents that its use would not infringe privately owned rights. Reference herein to any specific commercial product, process, or service by trade name, trademark, manufacturer, or otherwise, does not necessarily constitute or imply its endorsement, recommendation, or favoring by the United States government or any agency thereof to the exclusion of others that may be suitable. The views and opinions of authors expressed herein do not necessarily state or reflect those of the United States government or any agency thereof.

Cover Photos:

Background: The 135-MWe Unit 13 power plant located at The Geysers, California is the largest geothermal generating unit in the world. Courtesy of Pacific Gas and Electric Company, San Francisco, California.

Inset: Drilling a geothermal exploration well on the island of Java in Indonesia. Courtesy of Unocal Corporation, Los Angeles, California. 
DOE/ID--10130

DE85 018007

DOE/ID-10130

Distribution Category: UC-66

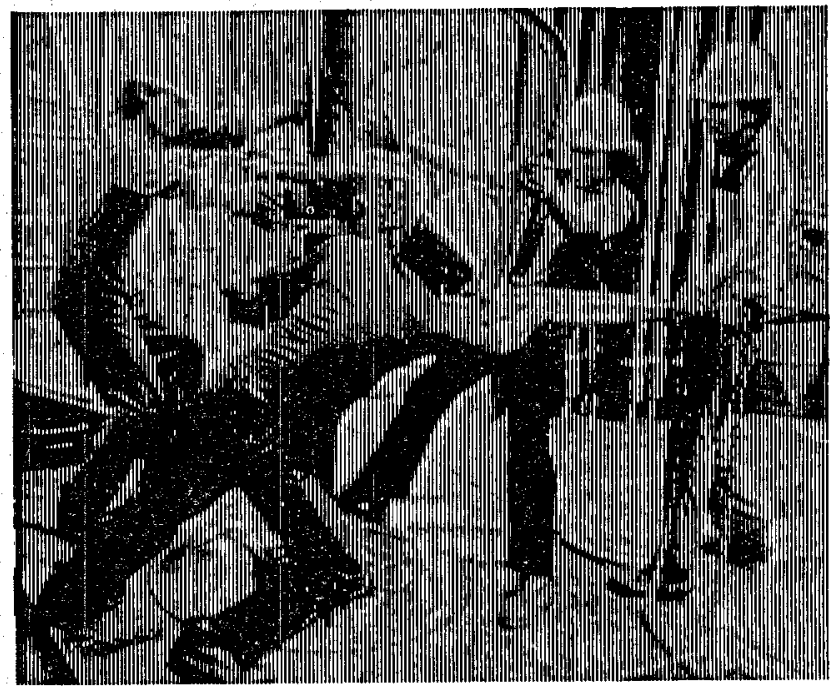

\section{EQUIPIMENT AND SERVICES}

$\frac{1 \%}{8 \%}$

WORLDWIDE APPLICATIONS

\section{MASTER}

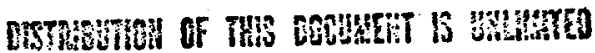


To The Reader:

The United States Department of Energy has prepared this digest to present the status of geothermal energy technology and how it can help meet worldwide energy needs. The Department of Energy is committed to the development of renewable energy technologies that are economically, socially, and environmentally acceptable. Geothermal energy, one of these technologies, has received U.S. Government research and development support since 1971.

Many geothermal energy technologles are ready now for worldwide applications. Almost fifteen years of U.S. research and development on both geothermal electric and direct-use-of-heat technologies have produced system improvements and cost reductions well beyond the expectations of the early 1970's. These technical improvements apply both to energy extraction wells and to geothermal energy conversion and conditioning equipment.

A sophisticated U.S. geothermal exploration, production, and applications industry has grown from that technology base. This industry includes a full range of equipment manufacturers, exploration analysis servicers, power plant designers, and project managers and constructors.

These technologies are being applied rapidly to geothermal energy utilization at a large number of U.S. and international sites. The industry is constantly improving the state of the technology through its domestic and international project experience and through cooperative research with U.S. Government programs.

These projects have also provided an experience base sufficient to allow industry and government to find practical ways to achieve integration of geothermal energy systems with local socio-economic contexts, adequate safety provisions, inexpensive environmental controls, and practical ways to finance geothermal projects.

The U.S. geothermal energy experience base is fully extendable to worldwide applications. American firms are now the world leaders in discovering and exploiting economical geothermal energy in a variety of physical and cultural settings. This digest seeks to share that experience with you.

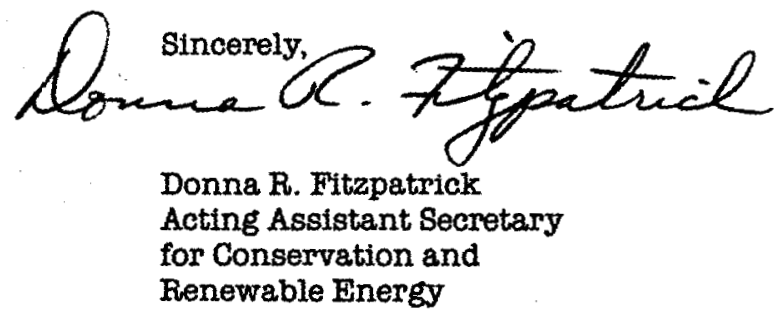




\section{Geothermal Energy Technology Today}

\begin{abstract}
$\boldsymbol{F}$
or many years, it was clear that geothermal energy, heat from the Earth, held great promise as an energy source. Many people believed that vast subterranean pools of steam and hot water could somehow, and some day, be put to use in electric generators, industrial processes, and district space heating systems.

Until recently, however, the "how" and "when" of widespread geothermal energy use were not at all clear. Geothermal technologies were being fabricated and tested, but they encountered severe problems with component failures at high temperatures, corrosion, scale deposition, and unacceptable levels of environmental emissions. The economic systems consisted of electricity production from several dry steam reservoirs and a few hundred small direct-heat applications scattered around the world. It was not clear when the technologies needed for widespread use of hot water and wet steam geothermal energy would be practical.
\end{abstract}

In recent years, U.S. industry experience and government-sponsored research have created technologies needed to exploit a large fraction of known geothermal reservoirs and to discover and confirm more resources. Today:

- Geothermal energy is being developed rapidly, for both electricity and direct heat uses.

- The most important accomplishment is that many liquid-dominated, moderate-temperature reservoirs can now be exploited economically for electricity production. Flash-steam technology, which uses high quality steam separated from superheated water, has arrived. "Binary" technology, which uses organic fluids to drive turbogenerators from lower-temperature geothermal resources, is not far behind.

- The major brine handling and potential environmental pollution problems have been solved. Corrosion, scaling, injection-well plugging, and environmental control are no longer fundamental barriers to economic development of geothermal systems.

- Direct heat projects have become increasingly attractive as their economics become better understood. Larger projects are now being developed in places where geothermal reservoirs are located near a population base.

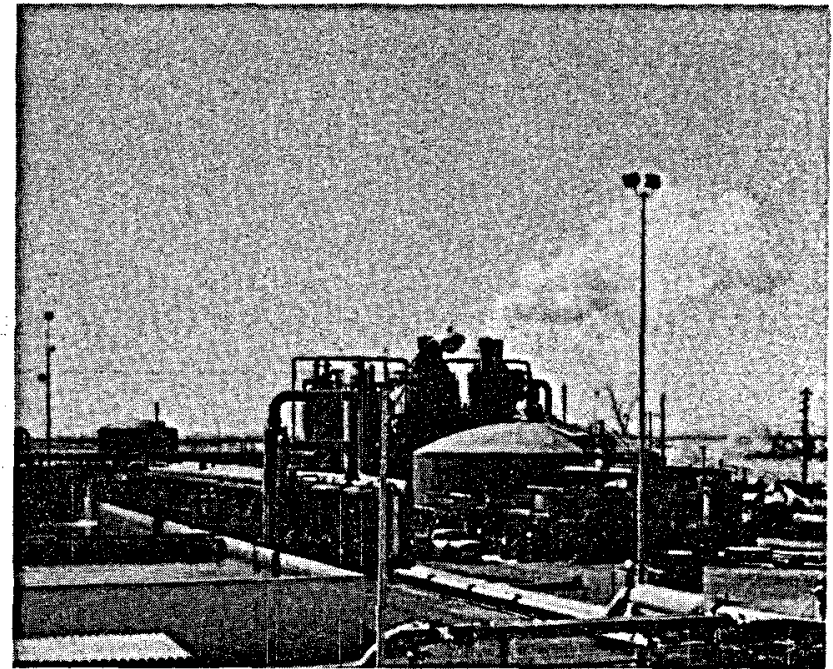

Thls 10-MWe electric plant at

Safton Sea, California, uses flash

steam technology to tap energy

from a liquid-dominated resource. Initial problems with handling

brines containing 20 percent

dissolved solids and highly

corrosive chemicals have been

solved. The plant is located in the

middle of a highly productive and

environmentally sensitive Irrigated

ogricultural area. 
U.S. geothermal technology-equipment, process design, services, and technical expertise-has been improved and proven to the point where it provides the foundation for rapid economic exploitation of geothermal energy in many places in the world. Many nations are taking advantage of this technology.

\section{Geothermal Electric Power On-line as of June 1984}

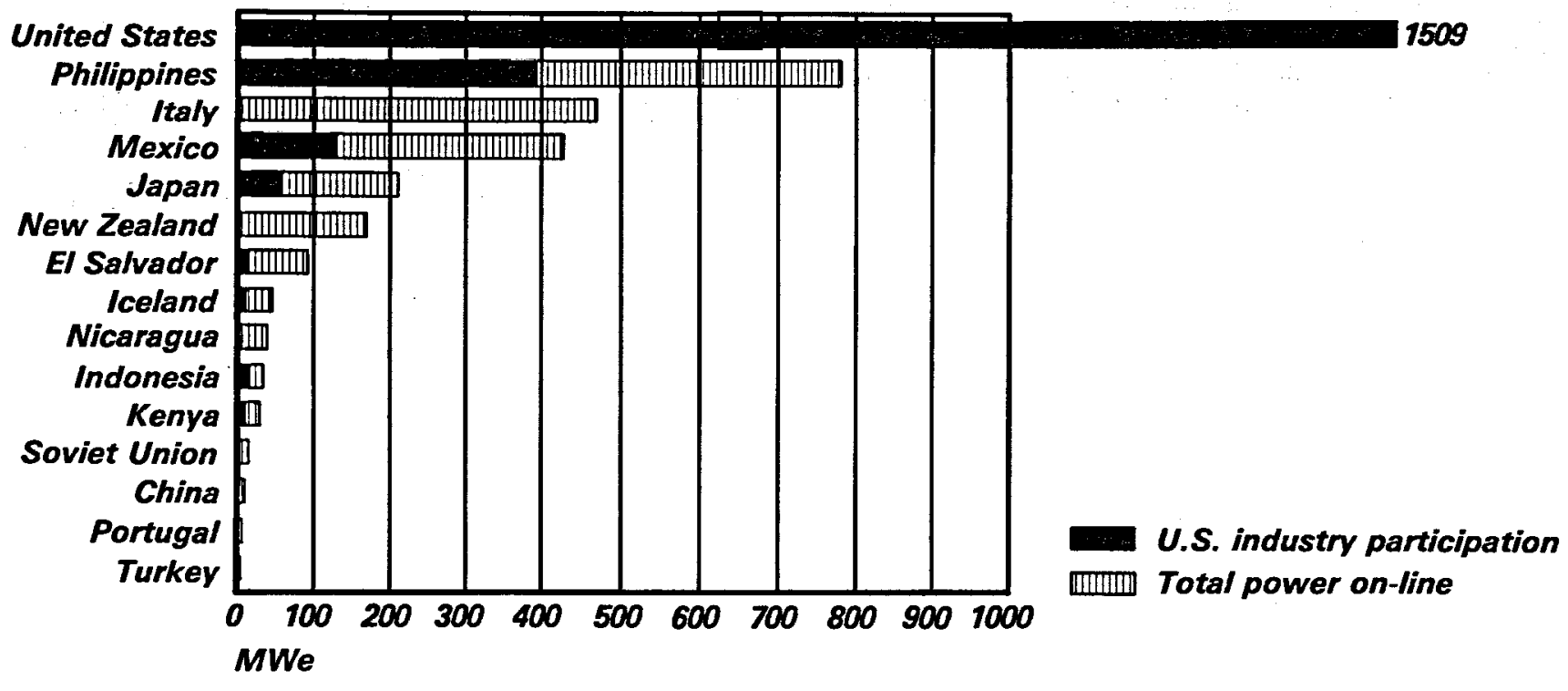

The U.S. geothermal industry has been selected by more than half of the countries with installed capacity to participate in their geothermal development. This represents about 2,120 MW of the 3.825 MW of worldwide installations and clearly establishes the U.S. as the leading producer of geothermal technology. The primary areas of U.S. exported technologies are in geothermal production field analysis and field development. U.S. organizations are today involved in major geothermal field design and development projects in Japan, Indonesia, Mexico, and the Philippines. 


\section{World Wide Locations of Major Geothermal Systems}

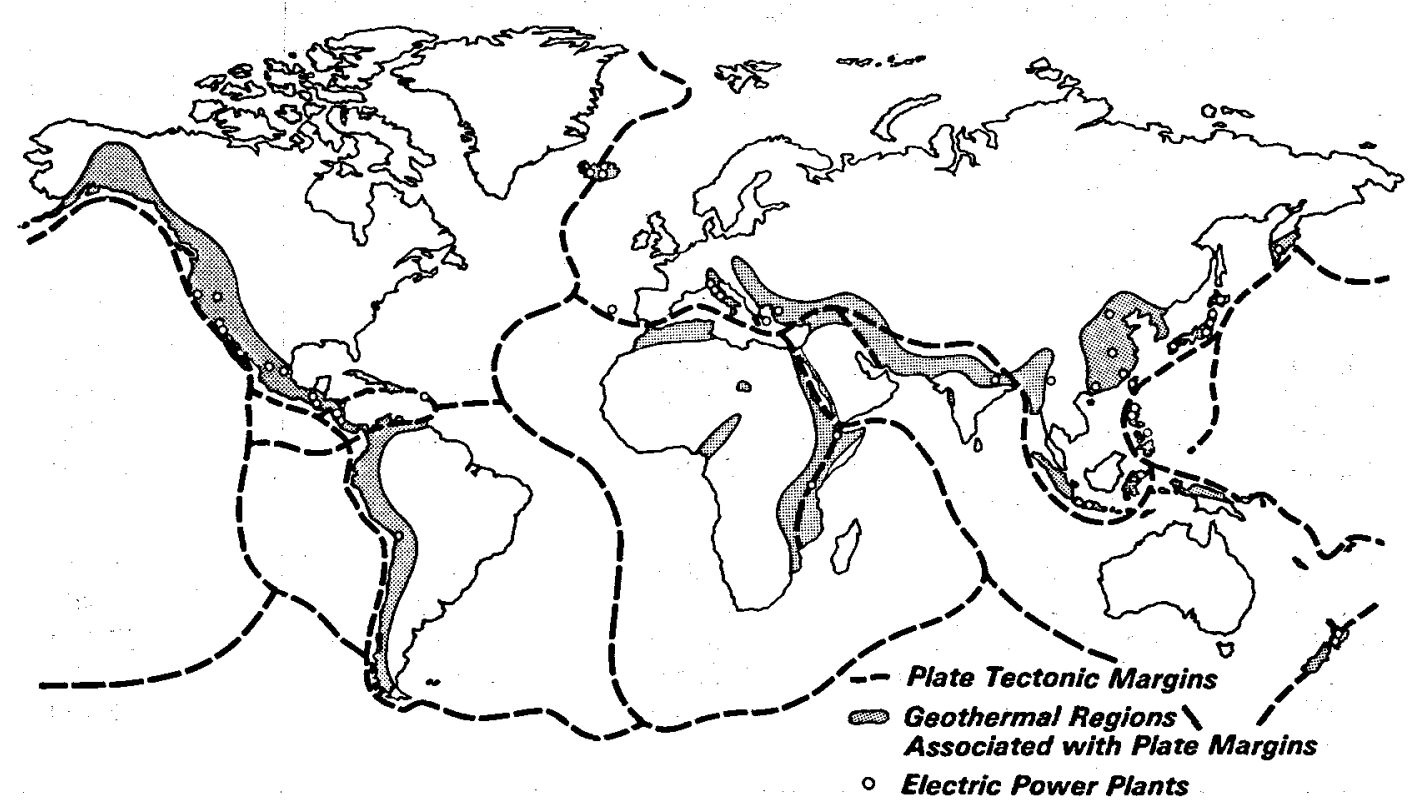

$G$ eothermal energy, like most energy resources, is distributed unevenly across the Earth. Some regions and nations are more favored than others.

High-grade geothermal resources-those most favorable for electricity generation or industrial process heating-occur where geophysical activity allows hot or molten rock to approach the earth's surface. Lower grade resources are distributed rather broadly and are not fully depicted on the map.

The high-grade recoverable geothermal resources available to specific countries for power generation far exceeds (by several orders of magnitude) the development to date. Many countries have potentials in excess of 100,000 MWe which would fulfill a considerable portion of their electricity requirements for many years.

Geothermal fields are distributed within well defined "belts" of geologic activity. This activity is manifested as earthquakes, recent volcanism, hot springs, geysers, and fumaroles. Geothermal belts are associated with the margins of the earth's nine major crustal plates. The most notable of these belts is the Circum-Pacific Belt which totally rings the Pacific Ocean, and has one branch which penetrates the Asian continent across northern India and continues into the Mediterranean area.
Hot crustal material also rises at mid-ocean spreading ridges such as the East Pacific Rise and the Mid-Atlantic Ridge. Spreading ridges within the interior of continents produce elongated zones of subsidence or "rifts." Within the "rift" zone, molten rock, or magma, can rise near the surface. Examples of geothermal areas associated with mid-ocean ridges are Iceland, the Azores, and Ascension Island. Examples of continental rift zones are the East African Rift and the Rio Grande Rift.

Geothermal resources can also be found associated with (1) local "hot spots" (such as Hawaii and Yellowstone, Wyoming), (2) regions of conductively heated groundwater aquifers, and (3) geopressured sedimentary basins.

The most commonly used geothermal resource is hydrothermal, which consists of water and steam trapped in fractured or porous rocks. Hydrothermal systems can be categorized as either liquid-dominated (hot-water) or vapor-dominated (steam). The temperature of these fluids varies considerably but is generally below $350^{\circ} \mathrm{C}$. Relatively young volcanos or a thinning of the earth's crust are associated with many of the higher temperature resource sites. 
Estimates of Worldwide Geothermal Electric Energy Potential

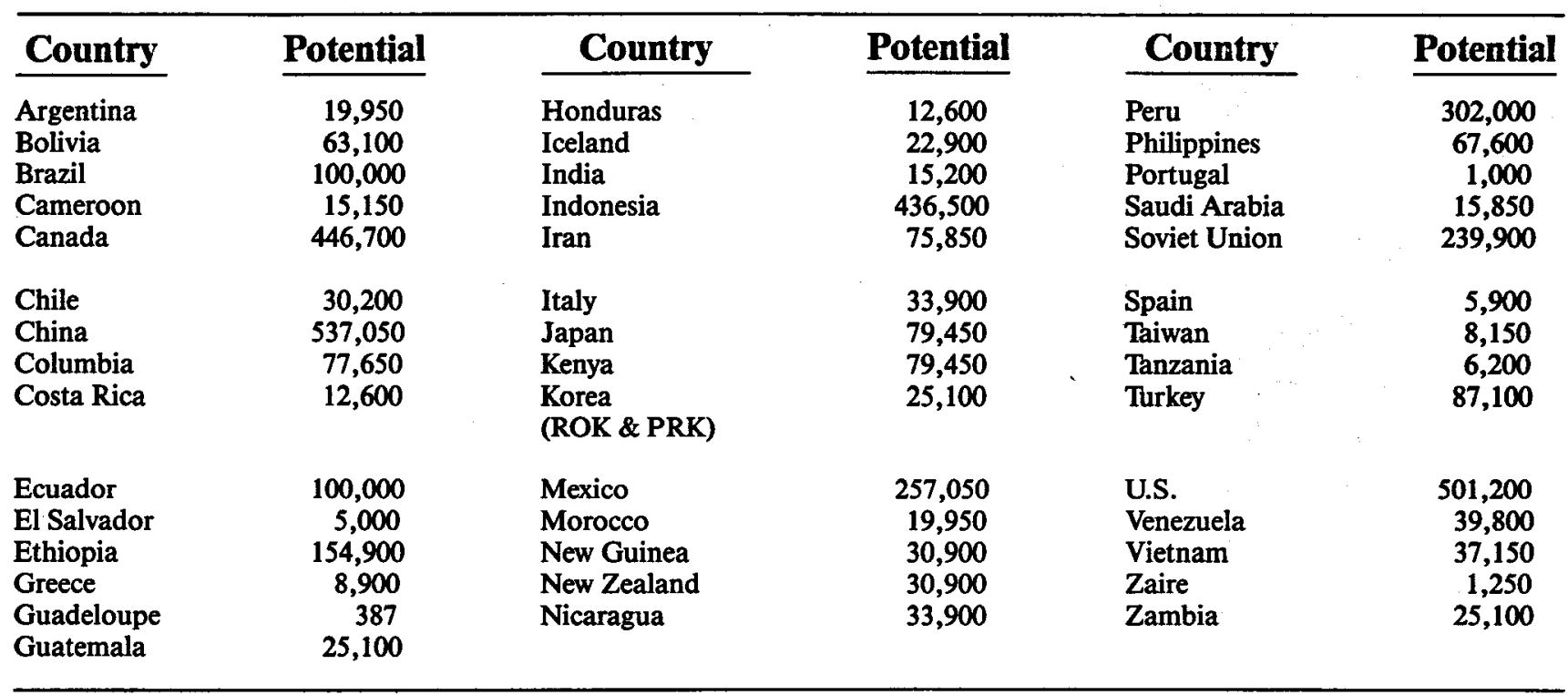

The higher-temperature hydrothermal fields often have low-to-moderate-temperature fluids at their margins. Those fluids are suitable for binary technology or direct applications. The total energy contained in low-to-moderate-temperature systems is many times that which is present in high-temperature resources.

In the past, the widespread availability of inexpensive fossil fuels precluded the need to locate and develop alternative sources of energy, including geothermal energy. However, since the mid 1970's, increases in conventional fuel costs have made geothermal energy more economically attractive and opened up previously unexplored or partially explored regions of high potential. Advances that have already occurred in U.S. exploration methodology and reservoir development technology enhance the attractiveness of the explored areas and will undoubtedly assist in assessing the resource potential of unexplored regions.
The estimated "potential" is measured in units of MWe capacity that could be sustained in continuous operation for 30 years - the typical life of a geothermal electric plant. The estimates were made by the Electric Power Research Institute in 1978.

These estimates are presented for comparison purposes only. They are based on assumptions and calculations that may overstate or understate actual resources. For example, the U.S. Geological Survey estimate for the U.S. is 95,000-150,000 MWe for 30 years. This estimate is based on a systematic assessment of geothermal resources using geologic and surface data developed by the Geological Survey, industry, academic institutions, and state agencies. Similar assessments of the resources of other countries will establish a more precise data base for use in both short- and long-range geothermal development strategies. 


\section{The Geothermal Role in Energy Development}

$G$ eothermal energy can be used in two highly economic ways: electricity generation and direct use of heat.

- Electricity: Generally, the most attractive use of geothermal fluid is electricity generation. Electricity can be produced from reservoirs with wellhead fluid temperatures as low as $100^{\circ} \mathrm{C}$, but economics are usually most favorable when the temperature is above $200^{\circ} \mathrm{C}$. Electricity is of special interest for geothermal development because it can be transported cheaply. This is important since high-quality geothermal reservoirs are often located at some distance from energy markets.

- Direct heat: A geothermal well can supply heat economically to any application whose process requirements are matched to the well's temperature and flow rate. Important uses are:

- Process heating, especially for food processing and crop drying.

- Space and water heating for buildings, including district heating systems.

- Agriculture and aquaculture.

- Snow and ice removal.

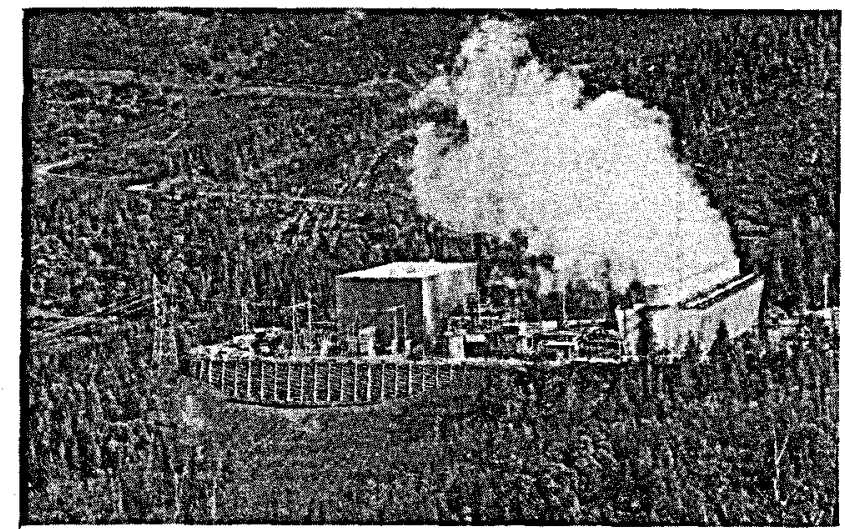

Pacific Gas and Electric's 110-MWe Unit 18 at The Geysers, California. Electricity is produced in the turbine-generator on the left. Spent steam is condensed to hot water, which goes to the cooling tower on the right before being injected into the earth. To date, electric projects dominate the use of geothermal energy resources.

\section{Geothermal Advantages}

Geothermal energy is especially attractive as a source of baseload electricity, or for direct heat projects that need heat around the clock for many days per year. It is not usually attractive as a source of peaking power, or for direct heat projects that use the available energy only a few days per year. In the simplest terms, geothermal electric plants compete with coal and nuclear plants in meeting baseload capacity needs. Direct heat plants are very competitive with all other sources of energy for many agricultural and industrial processing applications.

Some of the specific advantages of geothermal systems are:

- Resource Size: In those nations and regions that have geothermal resources, the resources tend to be large. This energy may thus be able to meet a substantial fraction of regional energy needs for many years.

- Indigenous Energy: The energy source for geothermal systems is locally extracted through capitalized wells. There are no additional costs for fuel, except for small amounts of electricity to drive pumps in direct heat systems. Geothermal energy can help a nation gain independence from imported oil, gas, coal, or nuclear fuels.

- Renewability: Most geothermal reservoirs recharge themselves with liquid and/or heat. Thus, most reservoirs are truly renewable energy systems, although the pressure of some reservoirs decreases with use.

- System Size: Geothermal energy systems cover a very broad range of capacities. Some are as small as 20 thousand $\mathrm{Btu} / \mathrm{hr}$ for heating a single house, while the largest stand-alone geothermal electric plant in the world, 135 MWe at The Geysers, California, has an input of about 2-1/2 billion Btu/hr. The Geysers now has plants totaling 1,500 MWe of electric capacity, equivalent to 17 million barrels of oil per year. The Imperial Valley region of California supports about $150 \mathrm{MWe}$, and is thought capable of powering about 4,000 MWe when fully developed-the equivalent of four large nuclear plants.

- Modularity: A single high-quality well will support between 3 and $10 \mathrm{MWe}$ (net) of electric capacity for 10 to 20 years. It can take as little as one year to install a 3- to 5-MWe plant, and about 2 years to install a 50-MWe plant. 
- Hybrid Systems: If an application requires a higher temperature than that available from the geothermal fluid, supplemental fuels such as oil, natural gas, or biomass can be used to achieve the needed temperature. Geothermal fluid can provide copious quantities of economic heat in such hybrid systems.

- Availability: Fluid production and conversion equipment are extremely dependable. Availability is very high; 90 to 95 percent is not uncommon in either electric or direct use systems.

- Operating \& Maintenance Costs: Direct use systems usually have no moving parts, except for a single pump impeller. Therefore, they are very reliable and have very low maintenance costs. Electric system annual O\&M costs are typically about 5 to 8 percent of the capital cost.

- Cooling Water: Many systems, especially direct heat applications, require no cooling water. This is an advantage where water is scarce.
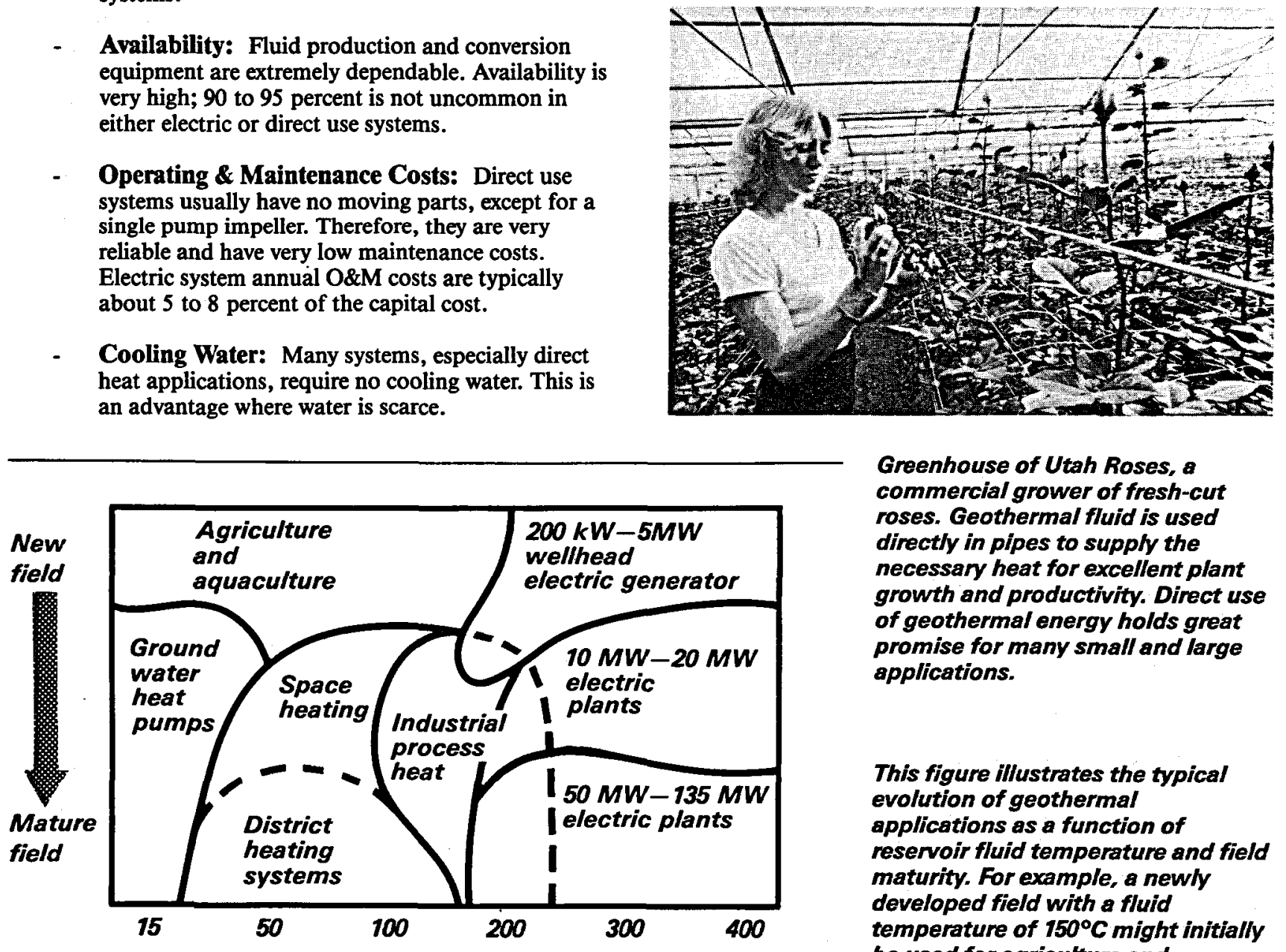

Greenhouse of Utah Roses, a commercial grower of fresh-cut roses. Geothermal fluid is used directly in pipes to supply the necessan heat for excellent plant growth and productivity. Direct use of geothermal energy holds great promise for many small and large applications.

This figure illustrates the typical evolution of geothermal applications as a function of reservoir fluid temperature and field maturity. For example, a newly developed field with a fluid temperature of $150^{\circ} \mathrm{C} \mathrm{might} \mathrm{initially}$ be used for agriculture and aquaculture purposes. As successful field production is demonstrated, space heating applications would be realized and finally, industrial process heating might be implemented. For a new resenvoir with fluids at $300^{\circ} \mathrm{C}$, electricity production would begin with wellhead generators of 0.2 to 5 MW capacity which could eventually lead to large 50 to 135-MW electric plants. 


\section{Other Factors}

A number of technical factors affect the decision of how best to use a discovered geothermal resource, or whether to explore for resources to meet specific energy needs:

- Temperature: Useful geothermal fluid temperatures range from 30 to more than $300^{\circ} \mathrm{C}$. In general, the higher the temperature, the better the economics of the system.

- Heat Rates: The amount of heat economically extractable from the fluid depends on its temperature and flow rate. The useful output per well can range from a few thousand Btu/hr for a shallow low-temperature well to 250 million $B t u / h r$ for a deep high-temperature well.

- Utilization Factors: Because of the capital investment in drilling, baseload applications-those with nearly continuous flow, or high "utilization". or "capacity" factors-are generally more economic than applications with low utilization factors. economically feasible, provided that the resource temperature and fluid flow rate are both high. Wells in use today range from 60 to 4,000 meters.

- Energy Transport: Electricity can be transported cheaply over long distances. A geothermal electric plant can thus serve customers that are not located near the well. Heat, on the other hand, cannot be transported cheaply unless the system capacity is very large. In practical terms, direct heat applications should be sited within $1 \mathrm{~km}$ of the wellhead.

- Well Depth: The deeper a geothermal well, the more it costs. Wells as deep as $4 \mathrm{~km}$ are

\section{Comparative Costs of Producing Electricity}

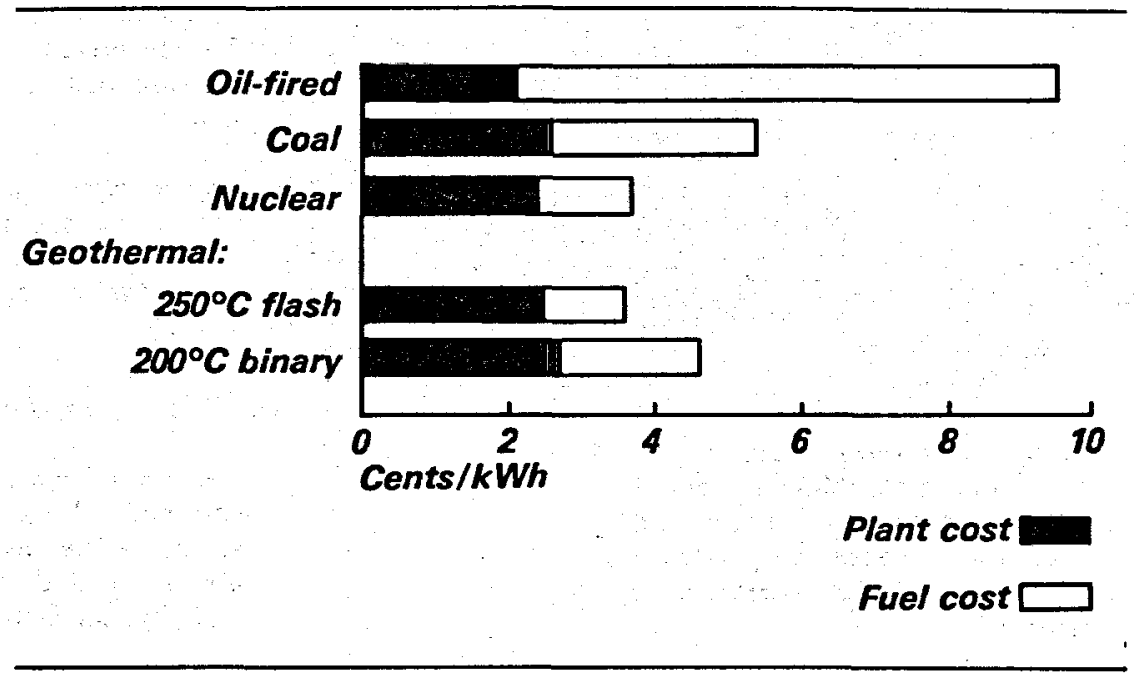

These costs are from U.S. 


\section{Technology Overview}

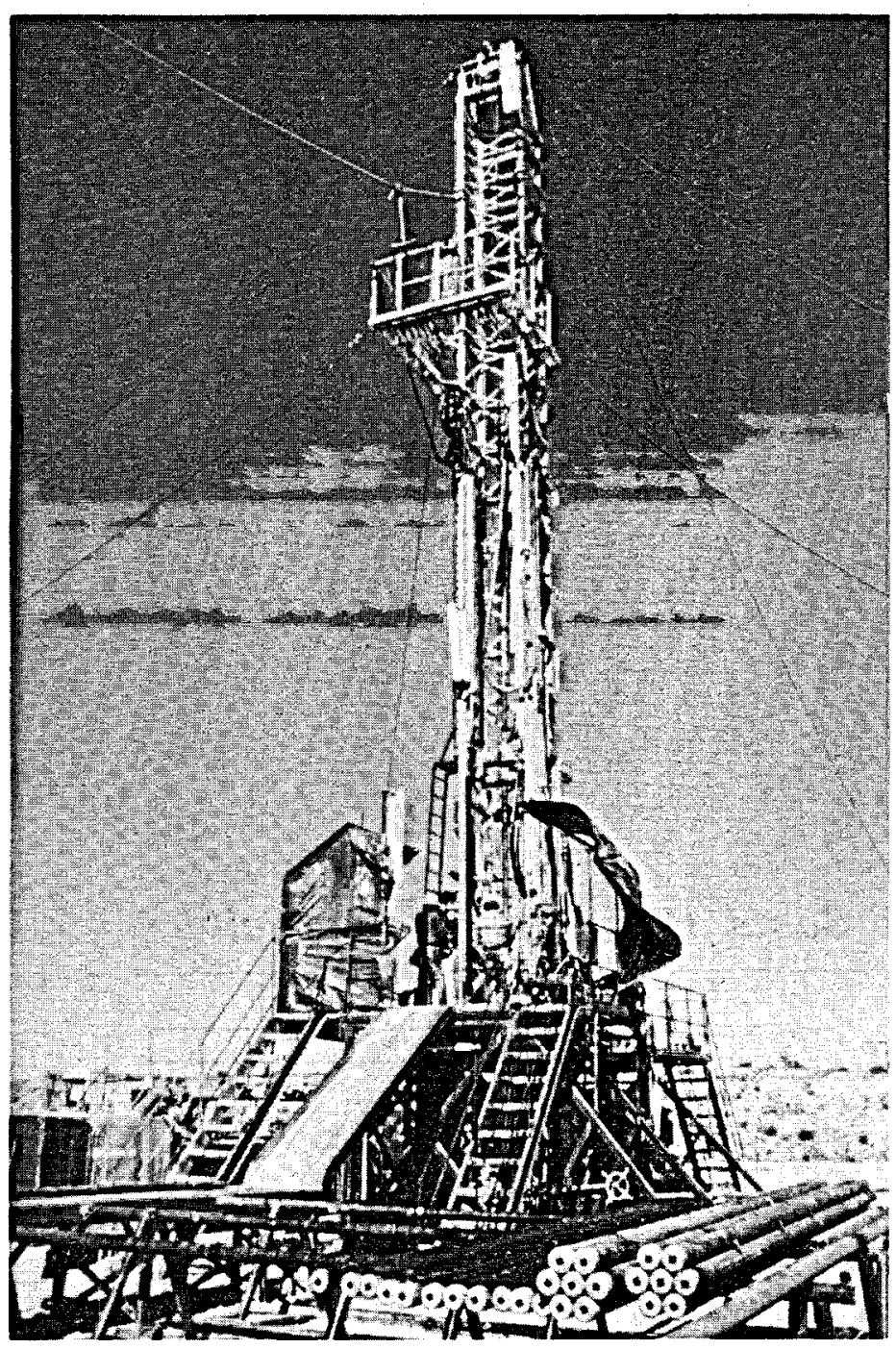

Drill rig operating at a deep geothermal well. Wells as shallow as 60 meters and as deep as 4,000 meters are the essential production technology for geothermal energy systems.

\section{Production Technology}

Geothermal production technology is drawn in large part from oil and gas technology. It requires increasingly stringent engineering practices as exploited resources become hotter, deeper, and more difficult to drill.

Geothermal development begins with exploration, to find a reservoir with economically exploitable temperature, depth, and volume. Exploration now relies increasingly on surface measurements of subsurface geological and geophysical properties to evolve an X-ray-like picture of what is underground.

The next step is the development of the geothermal resource field. This requires the drilling of wells to: (1) measure subsurface temperatures and heat flow rates; (2) confirm that a potential reservoir contains economically useful heat and/or fluid; (3) produce the geofluid; and (4) dispose of the used geofluid by subsurface injection.

Most wells are drilled using a rotary rig. The rig rotates a string of pipe, to which is fixed a drill bit that crushes or scrapes rock from the well bottom. Pumps on the rig drive a drilling fluid-air, water, or a water-solid mixture called "drilling mud"-down the center of the rotating pipe, through the bit, and back up between the pipe and the wellbore. This fluid removes rock cuttings and heat from the hole.

Well completion is the final step in the drilling operation. Casing pipes are lowered into the hole and cemented permanently in place. The formation may be treated by high pressure fracturing operations to increase the flow rate of the well.

Proper reservoir engineering is required to optimize reservoir exploitation and maximize life-time economic productivity. Major design elements are the locations, depths, configurations, and flow rates of production and injection wells.

\section{Conversion Technology}

Geothermal conversion technologies are derived from conventional space heating and cooling, process heat, and steam turbine/electric generator technologies. Choice of application and system design depend on the production cost and physical characteristics of the geofluid. 
In this flash steam electric plant, a substantial portion of the geothermal fluid "flashes" into steam, which drives the turbogenerator. The condenser and cooling tower optimize cycle efficiency by reducing the back pressure at the turbine outlet. Unflashed brine and condensate are typically injected to the formation, but can be cascaded to direct heat applications.

This technology is economic at many locations, and is being developed in unit sizes of 10 to 55 MWe as industry gains confidence with it. Other plant cycle designs include Dry Steam, Binary, and Hybrid-as described in the section on large electric plants.
Proven electrical power plant designs and components are available for resource temperatures of $150^{\circ} \mathrm{C}$ and higher, and for sizes from $50 \mathrm{kWe}$ to $135 \mathrm{MWe}$.

Another aspect of conversion technology deals with chemical constituents of geofluids. The chemicals can cause scaling, corrosion, or mechanical erosion of well and surface plant components, and require special materials and process treatments.

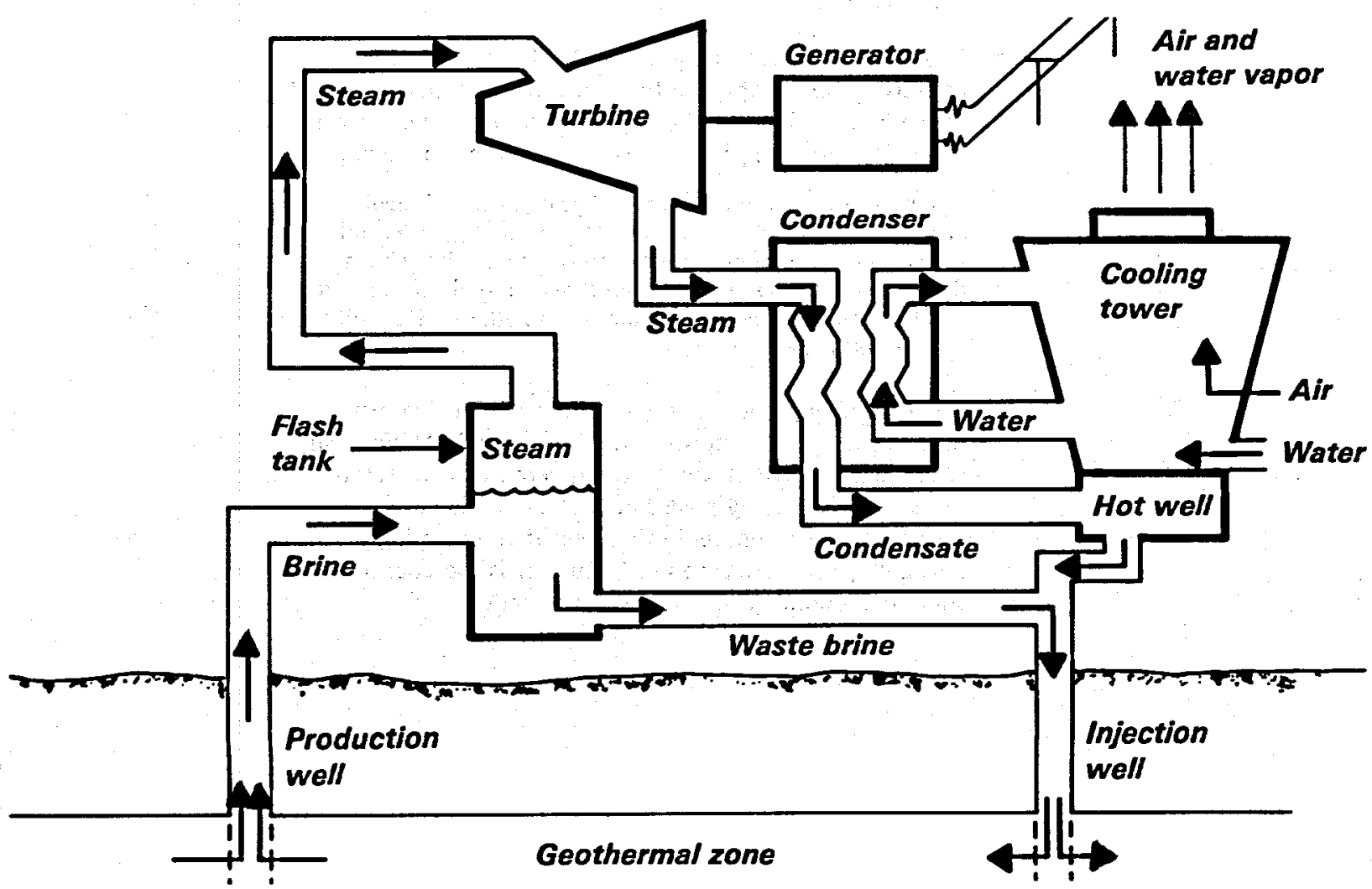




\section{Other Technologies}

Geothermal energy has environmental considerations which include land use, geology and soils, water resources, air quality, noise, and solid wastes. The development and use of environmental control technologies to meet stringent U.S. standards have resulted in a safe, environmentally acceptable geothermal industry. Some geothermal fluids have considerable potential value as a source of minerals and extraction processes have been developed.

The technologies are described more fully in later sections of this Digest. They are available for use now, yet research, development, and product improvement are continuing to improve performance and lower costs.

\section{Project Phases and Rísks}

The roles of specific technologies and technical advances are best understood in the context of how geothermal energy projects proceed. The economic use of technology depends on applying specific technical expertise using effective project management.

U.S. geothermal experience since 1975 has resulted in an effective phased approach to project development, pictured in the box on the opposite page. Different technologies and specialists have varying degrees of importance at each phase.

The need for such phasing arises because the technical attributes and economic quality of a specific geothermal reservoir are uncertain until one to three wells have been drilled and flow tested. U.S. well costs are typically $\$ 360$ to $\$ 720$ per meter, and thus can amount to $\$ 0.7$ to $\$ 1.4$ million for a 2,000-meter well.

The phased approach is very useful in minimizing project investment risk. As shown in the box for a 50-MWe flash steam electric project, only 5 to 50 percent of the total investment is initially placed at risk. Economic losses are thus held to a minimum in the event that a seemingly desirable reservoir has too little fluid or is too cool to support economic heat or power production. 


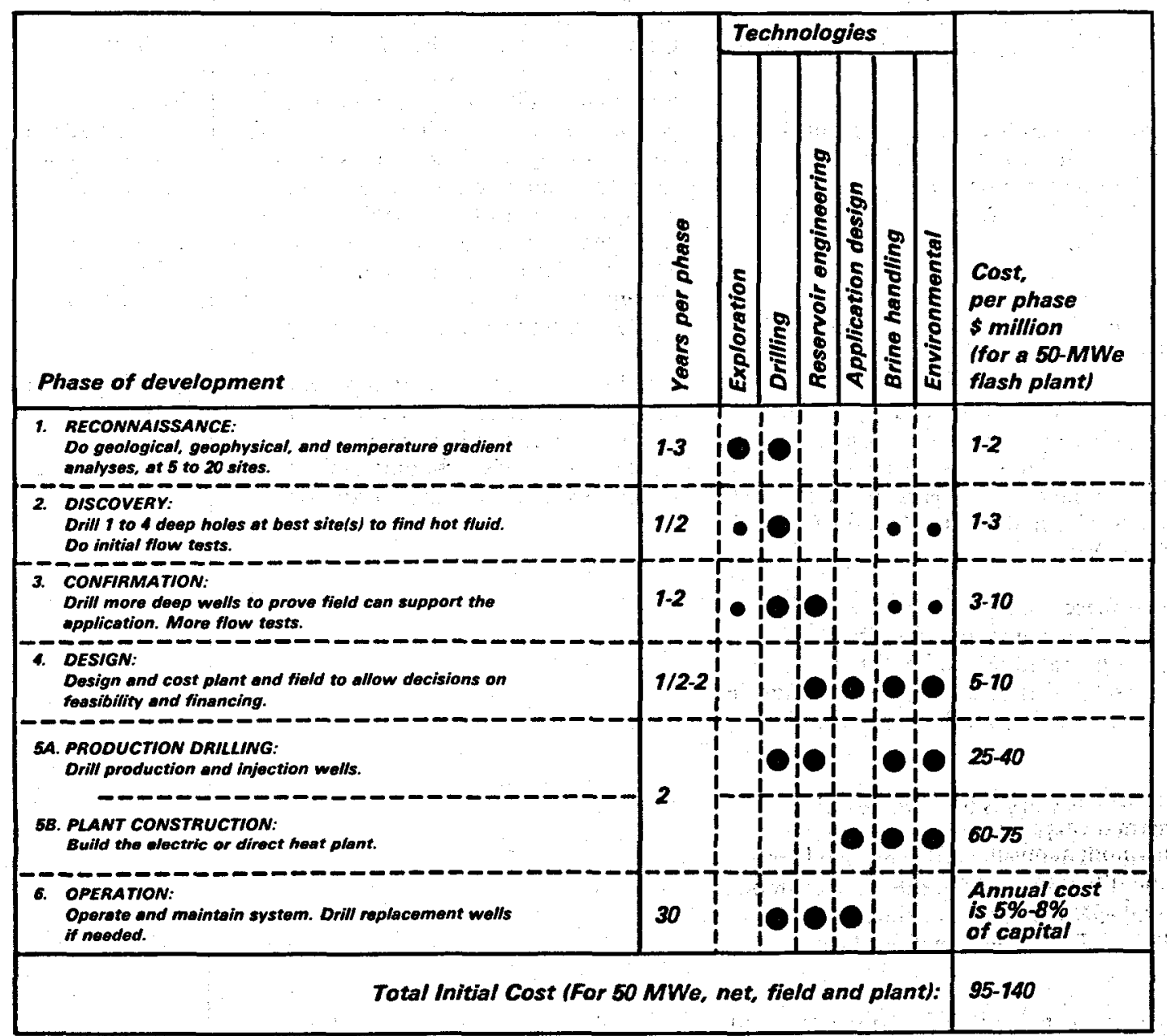

The relative importance of different technologies at each phase of development is indicated by the size of the dots.

For a wellhead electric unit, at 0.3 to 3 MWe capacity, phases 3 and 5 A are unnecessary if the first well is successful. The costs of phases 4 and $5 B$ combine to about $\$ 1.2$ to $\$ 2.0$ million per $M W$.
Direct heat projects often use onhy one or two wells. In some cases, interest in the application, e.g., a crop drying plant, does not arise until a reservoir has been confirmed. The Investors in the surface plant have no Interest in phases 1 and 2, but are very interested in the results of phase 3. When the end use, e.g., heating buildings, already exists, phases 2 and 3 are most important, and phases 4 and 5 are reduced to retrofit work.

Annual $08 M$ costs are 4 to 6 percent of plaint capital costs, and 6 to 10 percent of field capital costs, and thus are 5 to 8 percent of total caphtal costs. 


\section{The Future}

\begin{abstract}
$\infty$ ince its inception at Larderello, Italy, in 1904, exploitation of geothermal energy for modern applications has been developed in incremental steps. This development will continue because geothermal energy is a proven viable technology and an important contributor to the world's total energy supply.
\end{abstract}

The total installed capacity of geothermal power plants is a significant measure of the utilization of geothermal energy throughout the world. Worldwide capacity increased from $1,760 \mathrm{MW}$ in June 1979 to $3,820 \mathrm{MW}$ in June 1984 with an annual growth rate of $16.5 \%$.

Worldwide generating capacity is expected to increase by $45 \%$ to 5,530 MWe in 1986, and the U.S. geothermal industry is in the forefront of this growth.

The countries installing most of this new capacity are the United States, the Philippines, Mexico, and Indonesia. Italy, Japan, Kenya, Nicaragua, and Turkey will also make significant contributions in the next few years. It is estimated that by 1995 worldwide geothermal electrical production will increase to over 10,000 MWe.

The greatest geothermal success story to date is electrical production from steam-dominated reservoirs. Electricity production from liquid-dominated reservoirs, using flash-steam and binary technologies, is a success story now in the making. New projects are being announced in the U.S. every month.

A third, longer-range, success story is likely to be direct applications of geothermal energy. Direct applications are technically simple, thermodynamically efficient, and highly adaptable to worldwide situations. By far, the greatest amount of accessible geothermal energy lies at temperatures below $150^{\circ} \mathrm{C}$, where the fluids are most useful in direct heat applications.

The expansion of geothermal energy in the world market will continually evolve from the advancement of technologies. Among the improvements in fluid production will be: (1) optimization of the drilling and completion of wells by the upgrading of drill bits, downhole instrumentation, downhole motors, and properties of drilling fluids; (2) improvements in reservoir management; and (3) advancements in overall technology that will apply in the geothermal environment, such as robotics and advanced materials. Improvements in conversion technologies will increase the efficiency of energy produced for a given resource type. Examples of this include second generation binary electric plants for moderate-temperature resources, and hybrid electric plants using supplemental biomass or fossil fuels.
Geothermal energy can complement conventional energy resources. Through its diversity, the utilization of geothermal energy will reduce the risks of sudden energy supply interruptions or price increases of conventional fuels. Geothermal technologies offer the flexibility of direct matching of various energy requirements with locally-available energy sources. The modularity of geothermal energy equipment allows additions to be made in comparatively small increments, resulting in short lead times, reduced planning uncertainties, comparatively small capital outlays over short time periods, and small social/environmental impacts to surrounding communities. This modularity will offer significant economic benefits to energy producers and consumers, particularly when used in concert with the direct use energy option.

Geothermal is a "here and now" energy supply that offers an exceptional opportunity to those nations which are geographically fortunate enough to have such natural resources. Today's technologies work well-the technologies of tomorrow are even more promising. 


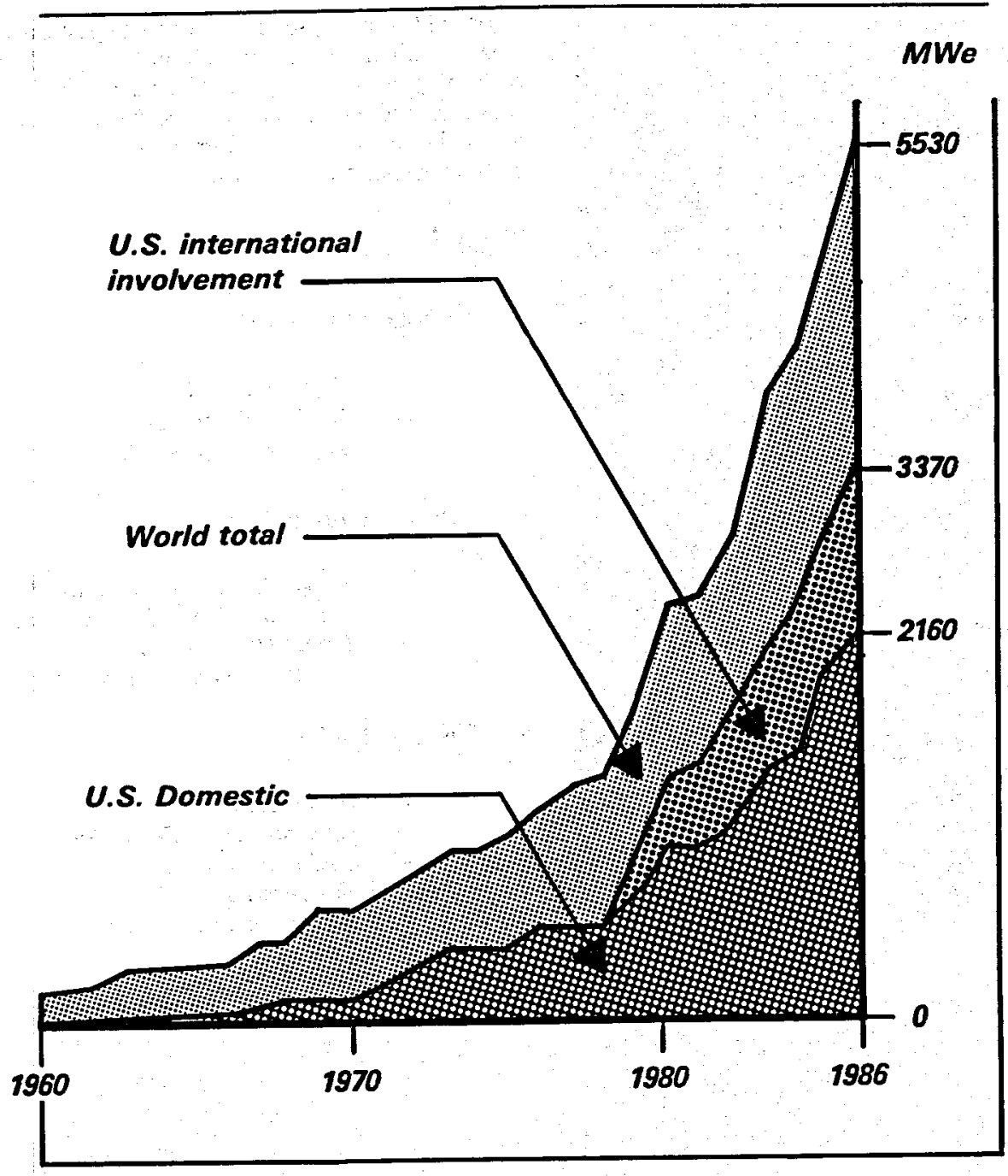

The growth of geothermal electric capacity has accelerated markedly since the late 1970's. U.S. technology Improvements, development expertise, and Investment have paced this growth, both domestically and internationally. 


\section{Geothermal Technology Specifics}

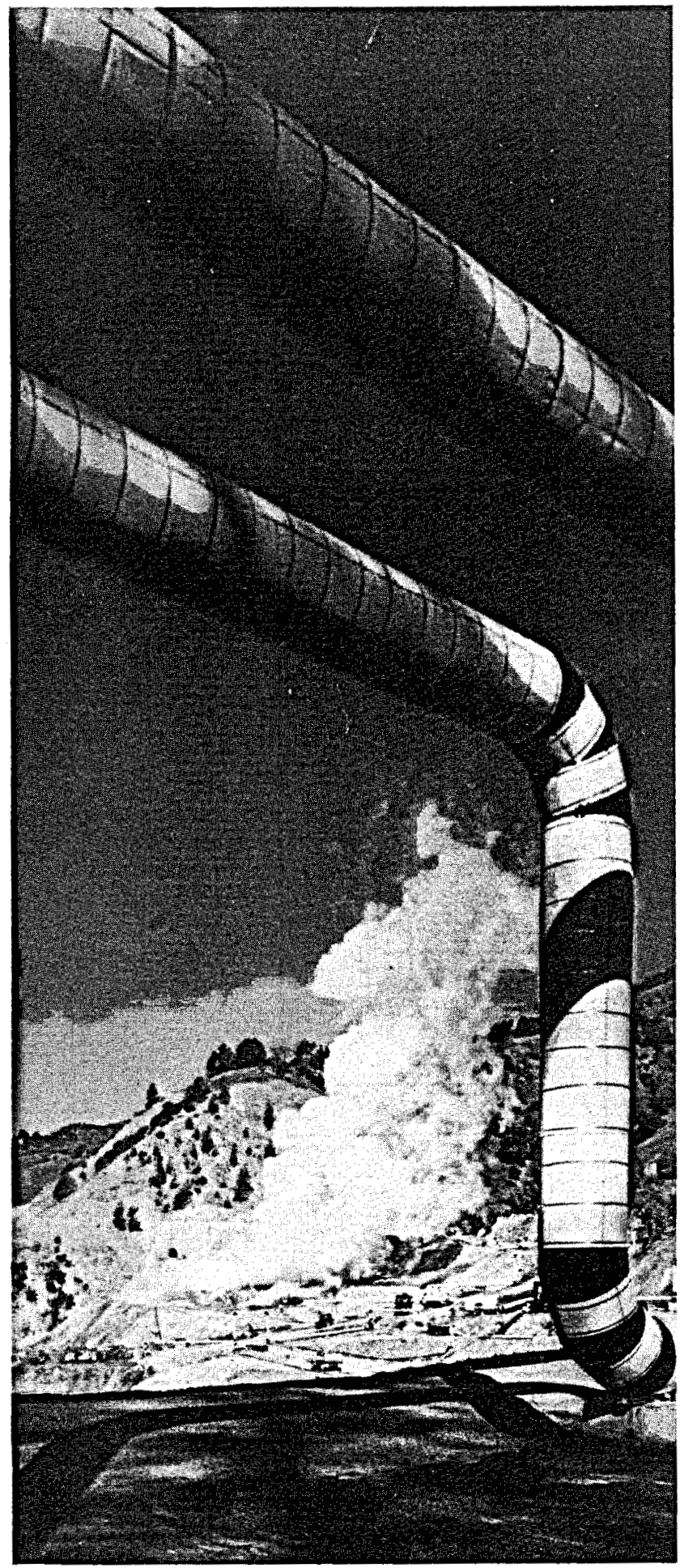

he following sections of this Digest provide more
detailed information about U.S. geothermal technologies. The purpose is to clarify, for energy system planners and engineers, how geothermal technology can be applied under specific circumstances of resource characteristics and energy needs.

Subject Page

- Energy Production

- Exploration Technology

- Drilling Technology

- Reservoir Engineering and Development

- Energy Applications

- Large-Scale Electric Technology

- Small Geothermal Generators

- Direct Use Systems

- Agriculture and Aquaculture

- General Topics

- Brine Handling

- Environmental Technology

- Socio-Economics

- The International Scene

- Advanced Technology 


\section{Exploration Technology}

\begin{abstract}
$G$ eothermal exploration in the U.S. has come of age with advances in the tools and techniques needed for application to geothermal reservoirs. As reported by the Petroleum Information's National Geothermal Service, in 1984,10 geothermal wells classified as "wildcat" or "exploratory" were drilled in the U.S. All 10 of these were completed as potential producers-none was classified as "unsuccessful:"
\end{abstract}

In geothermal exploration, a "discovery" is not limited to finding a geothermal manifestation, but must include confirmation that the resource exists at economically exploitable temperatures and quantities and in economically accessible formations. In the development of U.S. geothermal exploration technology, refinements have been made to existing oil and gas technologies and innovative new methods have been developed which industry is using successfully both in the U.S. and abroad.

Due to the uniqueness of individual geothermal reservoirs, there is no one exploration method or series of methods that can be applied universally. Typically, the initial step in geothermal exploration is reconnaissance where large areas (in some cases, up to a million acres) are screened with inexpensive techniques. As long as favorable indicators continue to be found, exploration becomes increasingly detailed, site-specific, and costly.

The information developed in the initial reconnaissance is used as the basis for designing a specific exploration program. Sources of this information include:

- Available geologic reports on the area

- Regional geologic maps

- Aerial photography and aeromagnetic maps

- Satellite imagery

- Measurements of thermal gradients in existing holes (e.g., water or oil and gas wells)

- Geochemical sampling of surface waters

- Analysis of surface rocks and soils.
The next step in geothermal exploration is prospect

reconnaissance that are now given priority. Detailed geologic maps are prepared to guide subsequent exploration activities. Downhole temperature gradient measurements provide the most fundamental data in early hydrothermal exploration. Drill cuttings and cores provide information on other subsurface characteristics such as thermal conductivity. The geochemistry of trace elements (e.g., mercury and arsenic) in surface soils helps define the "plumbing system" of faults and the zoning of alteration minerals. Detailed geophysical surveys and geophysical logging of drill holes may be carried out. When this prospect-specific information is integrated with the reconnaissance data, the parameters identified include the potential reservoir's: temperature, lateral extent, depth, "caprock", and heat source. The final product of this stage of exploration is an initial conceptual geologic model of the prospect.

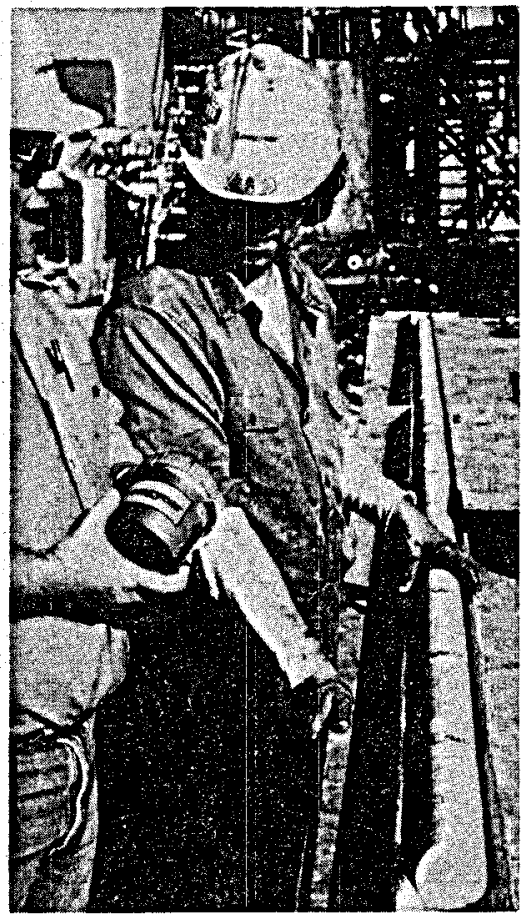

Core sample from a geothermal well. Subsurface rock is collected by substituting a core barrel for the drill bit and retrieving a cylindrical rock sample for geoscientific studies of reservoir characteristics. 


\author{
Maps of geological structures play \\ dominant roles in geothermal \\ exploration. This one shows \\ relationships between geothermal \\ systems in the Imperial Valley, \\ California, and Cerro Prieto, \\ Mexico.
}

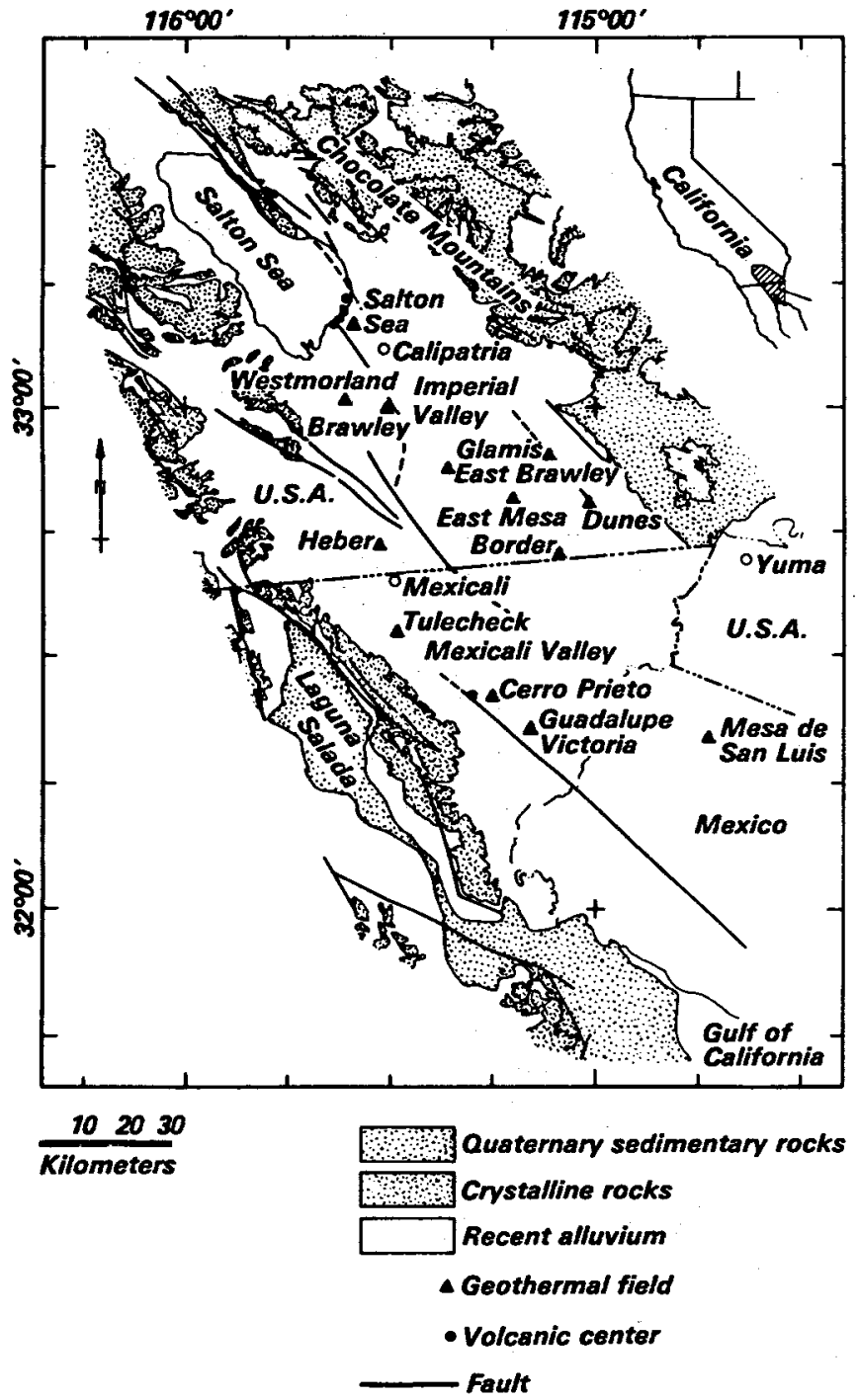

In order to site intermediate depth (500-800 meters) test holes, the prospect is further delineated through:

- Detailed geologic mapping, perhaps utilizing low-altitude color aerial photography

- Geophysical surveys to extend the mapping to depth and define fluid/flow characteristics

- Numerical modeling of geophysical and thermal data to improve the conceptual geologic model.

Intermediate test drilling yields cuttings and fluids which permit prediction of reservoir temperature, estimation of permeability and, possibly, identification of the source of recharge. From this information, detailed geologic cross sections can be drawn that integrate the accumulated data and refine the conceptual model of the reservoir.

A drill-targeting model is then defined to: select the site for deep exploratory drilling, to design the drilling and completion program, to estimate the depth to specific geologic strata, and to predict well temperatures.

Production test (wildcat) wells are drilled until the geothermal resource is discovered and confirmed, or the prospect is abandoned. Drill cuttings, core, lithologic, and geochemical analyses are repeated. Results are integrated with surface mapping, cross sections, and geophysical profiles to correlate lithologies, identify structures that control fluid flow, and define alteration. Hydrothermal mineral alteration patterns yield important information on the location and permeability of production zones, and the chemical/thermal history of the system.

Downhole temperatures and pressures recorded during flow tests are the first direct measurements of the reservoir. These data will confirm estimated reservoir temperatures, indicate fracture porosity and permeability, locate hot and cold fluid entries in the well, and identify reservoir rock and fluid properties. As step-out wells confirm the discovery and identify the boundaries of the reservoir, reservoir engineering begins in order to evaluate the resource and select a cost-effective strategy for its exploitation. 


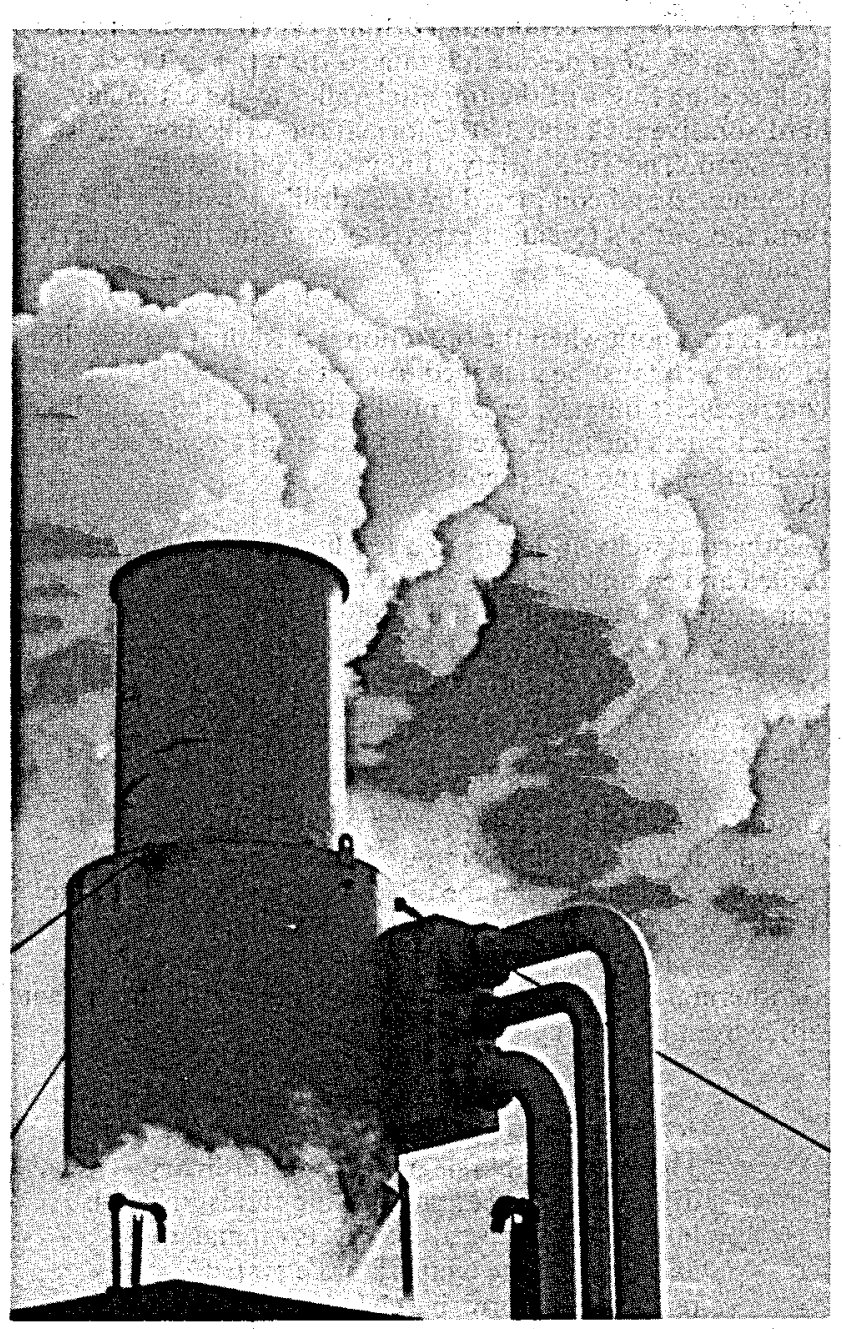

Steam exiting from a nolse muffler during a well test. Geothermal wells are tested for production by allowing the well to vent to the surface. Temperature, pressure, flow rates of both mass and heat, and fluid composition are measured.

\section{Geothermal Exploration Techniques}

Surface Geological Survey-Map the surface distribution of rock varieties, age relationships and structural features.

Geothermometers-Estimate subsurface temperature through mathematical calculations using the concentrations of dissolved chemical species in surface waters.

Magnetic Survey - Map variations in the earth's magnetic field to detect anomalies which may be due to temperature variation.

Passive Seismic Survey-Detect microearthquakes (frequently associated with geothermal occurrence) through instruments implanted just below the surface.

Active Seismic Survey-Provide information on the composition and structure of the subsurface through artificial generation of elastic shock waves.

Self-Potential Technique-Measure variations in the natural dc voltage which result from high geothermal gradients or from movements of fluids.

Resistivity Technique-Measure the distribution of the electrical resistivity in the subsurface.

Magnetotelluric Method-Measure natural electric and magnetic fields deep in the earth's crust.

Thermal Gradient Holes-Determine the rate of increase or decrease in temperature with distance; typically 30-160 meters.

Intermediate Test Holes-Provide a preliminary test of the conceptual geologic model of the reservoir and evaluate cold water masking or mixing and shallow thermal aquifers.

Wildcat Drilling-Provide the first information available on the producibility/permeability of a reservoir.

Confirmation Drilling-Provide sufficient understanding of the reservoir to guide routine developmental drilling. 


\section{Drilling Technology}

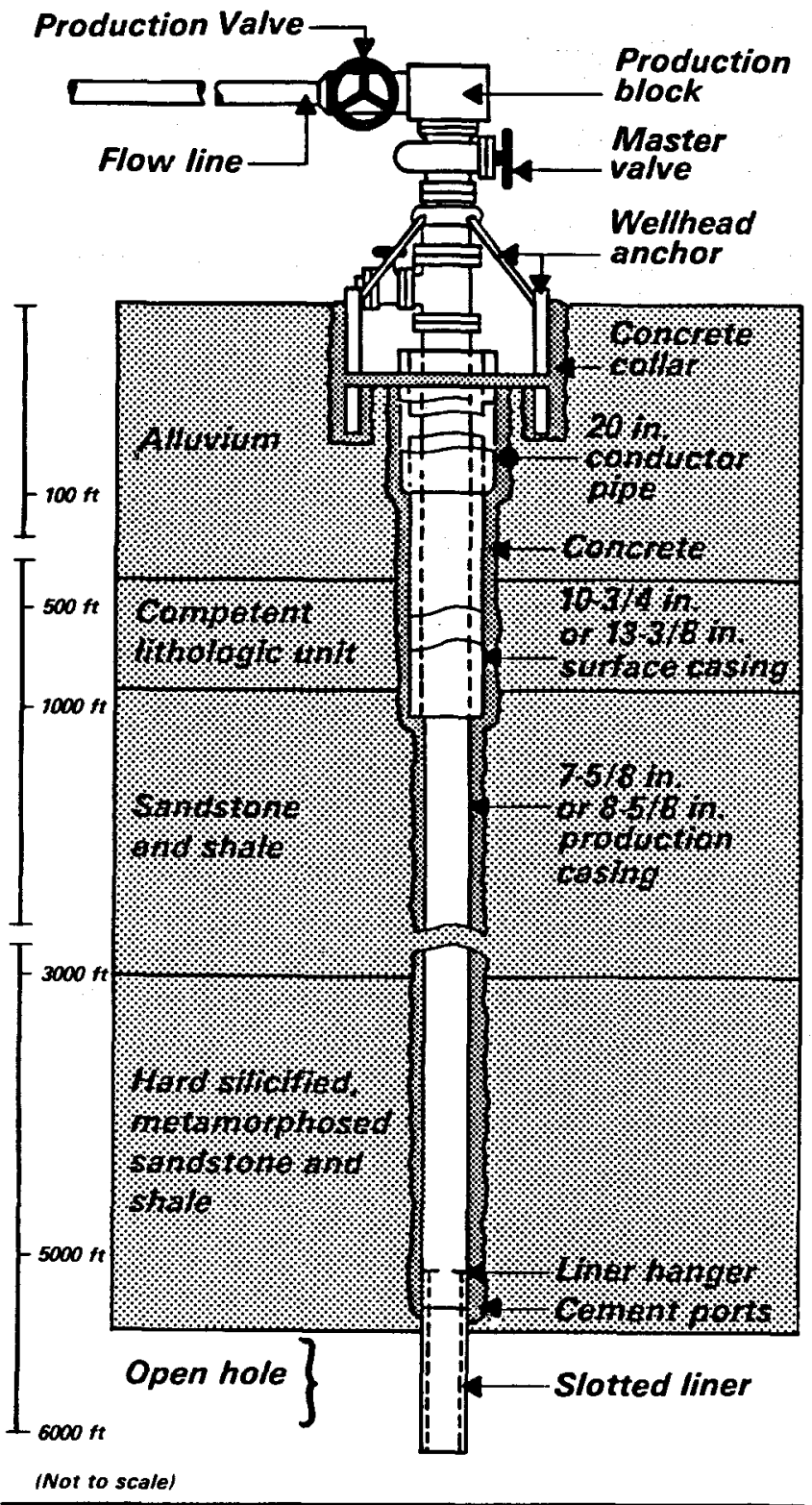

Geothermal well designs, materials, and drilling practices must be closely matched to formation and fluid characteristics. Substantial drilling experience is the best guarantee of success. U.S. firms have completed successful production wells at over 30 diverse worldwide locations.
U.S. geothermal drilling experience in the past decade has ranged from the soft rock and high-scaling fluids of the Imperial Valley to the extremely hard abrasive rock and $340^{\circ} \mathrm{C}$ formations drilled on the island of Hawaii. The wide variety of physical conditions encountered and conquered by U.S. drilling firms have made them the world's foremost experts at cost effective geothermal drilling.

This is true both when the operation is a wildcat exploration effort which must be managed to meet a great variety of contingencies quickly, or is a production-oriented multi-hole project where the objective is the greatest aggregate energy production at the lowest cost.

Geothermal wells of depths to a few hundred meters are drilled and completed (casing and wellheads installed) using conventional water-well drilling equipment. These wells are used in low-temperature direct heat projects. They are unusual only in that casing materials must be chosen to avoid the anodic loss of metal from the chemical activity of some geothermal brines.

On the other hand, sizeable power plants require multiple deep production and injection wells. Rotary drilling technology adapted from the oil and gas industry is used to develop these fields.

Geothermal deep wells encounter four major conditions that differ from oil drilling:

- Geothermal fluid temperatures may reach $400^{\circ} \mathrm{C}$ as compared to $200^{\circ} \mathrm{C}$ for oil and gas. This causes rapid degradation of ordinary drilling equipment and drilling fluids, through both direct temperature effects on materials, and through the temperature-elevated reactivity of corrosive chemicals in the rock and brines. Chemical corrosion can be a problem with some brines, even at low temperatures.

- Geothermal formation rocks are usually more abrasive and/or harder than petroleum formation rocks. This is extremely degrading on bits and tubular goods, especially when air is used as the drilling fluid.

- The producing formations are often underpressured. They can become plugged if ordinary drilling muds are used. 
- Geothermal fluid production rates are very high: 100,000 to $300,000 \mathrm{~kg} / \mathrm{hr}$ as compared to 100 to $6,500 \mathrm{~kg} / \mathrm{hr}$ for oil and gas. Geothermal wells must have wider bores at depth than oil wells, and be cased in ways that minimize the effects of sand scouring.

U.S. drilling engineers and equipment manufacturers are making steady progress in overcoming the unique conditions associated with geothermal drilling. More efficient techniques and better equipment have reduced rig time on location by about 10 percent per well from 1980 levels. However, the rate at which geothermal-specific well technology is improving is moderate because relatively few (about 150) deep geothermal wells are drilled per year. In the U.S., and worldwide, one deep geothermal well is drilled per thousand oil and gas wells. It is therefore important to utilize drillers with experience in producing geothermal wells.

Present deep geothermal well drilling costs in the U.S. are about $\$ 360$ to $\$ 720$ per meter. Footage costs range from two to four times oil well costs, and tend to change annually in proportion to oil well footage costs. American Petroleum Institute statistics indicate that U.S. onshore drilling costs declined by 30 percent from early 1983 to early 1985 , due to the fall-off in oil exploration activities which produced a surplus of available drilling equipment. This recent deescalation, especially when combined with technology improvements, has resulted in geothermal well costs that are now slightly less than thev were in 1980.

A polycrystalline diamond compact

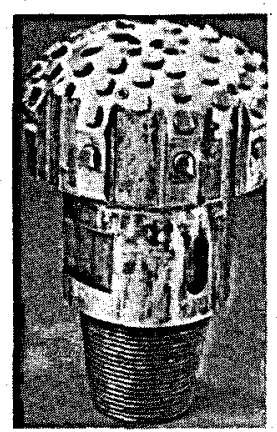
drill bit. The ability to make manmade diamond cutters in any shape, pioneered by General Electric and supported by the U.S. DOE Geothermal Program, has resulted in a bit that cuts many formations much faster than conventional tricone bits, lasts twice as long, and is still controllable. These bits are now finding extensive use in deep ofl and gas drilling.

\section{Drilling Hardware}

Drilling Bits: Oil well tricone bits with

temperature-hardened cutter, body, and bearing materials are available from a number of manufacturers. Cavitating jet nozzles can double the penetration rates in some formations. Recent improvements have reduced the excessive wear of the bit's outer diameter that occurs in highly abrasive geothermal formations.

Bearing Seals: After a long search, an EDPM-based elastomer has been found that retains desirable bearing seal properties in long service at temperatures up to $200^{\circ} \mathrm{C}$. This material is now used to seal the bearings of tricone drill bits, and is finding additional applications in downhole packers and as electrical connector seals. Metal-on-metal seals for applications up to $400^{\circ} \mathrm{C}$ are in hand, but their size often requires the redesign of equipment in which they are used.

Drilling Fluids (Muds): Conventional bentonite clay muds gel at geothermal drilling temperatures, so alternative clays such as sepiolite are used. If their temperatures exceed $75^{\circ} \mathrm{C}$, muds must be cooled on the surface using mud-to-air heat exchangers. Any source of oxygen in the mud requires oxygen-stripping chemicals be included to prevent oxygen-induced corrosion.

Pipe and Casing Materials: Steels are available that maintain their strength when exposed to high temperatures and $\mathrm{H}_{2} \mathrm{~S}$. Pipes made of polymerconcrete mixtures are useful in some direct heat applications. Polymer-concrete steam separators have endured a one-year exposure at Krafla, Iceland, with no corrosion. Polymer-lined pipes for geothermal wells survive $250^{\circ} \mathrm{C}$ with no cracking, corrosion, or delamination.

Cements and Cementing: A cementing job with well-centered casing and no cement gaps is essential to prevent casings from buckling or rupturing when geothermal wells are turned on and off. Silica flour is the primary constituent added to reduce the degradation of compressive strength that occurs in ordinary cements at elevated temperatures. Perlite and pozzolan are used to reduce cement density, to keep it from penetrating into underpressured zones and fissures. A full battery of cementing tools (e.g., centralizers, scratchers, plugs) is available.

Logging Equipment: The development of high-temperature (to $275^{\circ} \mathrm{C}$ ) electronic components has enabled almost all existing well-measurement procedures to be applied to geothermal wells. Equipment and services for measuring downhole temperature, pressure, formation characteristics, flow rates, etc. are available. An acoustic borehole-televiewer for imaging geothermal production fractures is in advanced stages of development. 
Lost Circulation Control: Since geothermal fluid production zones are relatively underpressured, and often occur as random fractures, care must be taken to prevent mud from plugging production zones and from being lost in intermediate-depth fractures. This is usually accomplished by low-density muds whose properties are adjusted when drilling different portions of the hole. A great variety of "lost circulation materials" are available for plugging undesirable fissures. However, cementing of selected intervals is often required to seal off intermediate zones of lost circulation.

Directional Control: Wellbore deviation must be controlled to minimize unwanted contacts between drill pipe and the formation. It is also increasingly common that multiple geothermal wells are slanted out from a single drilling pad. This practice reduces land use, and saves rig moving time. Directional control technology is adequate for soft and medium formations, but improvements for harder formations are needed.

The section on "Brine Handling" describes other developments that cross impact with production technology.

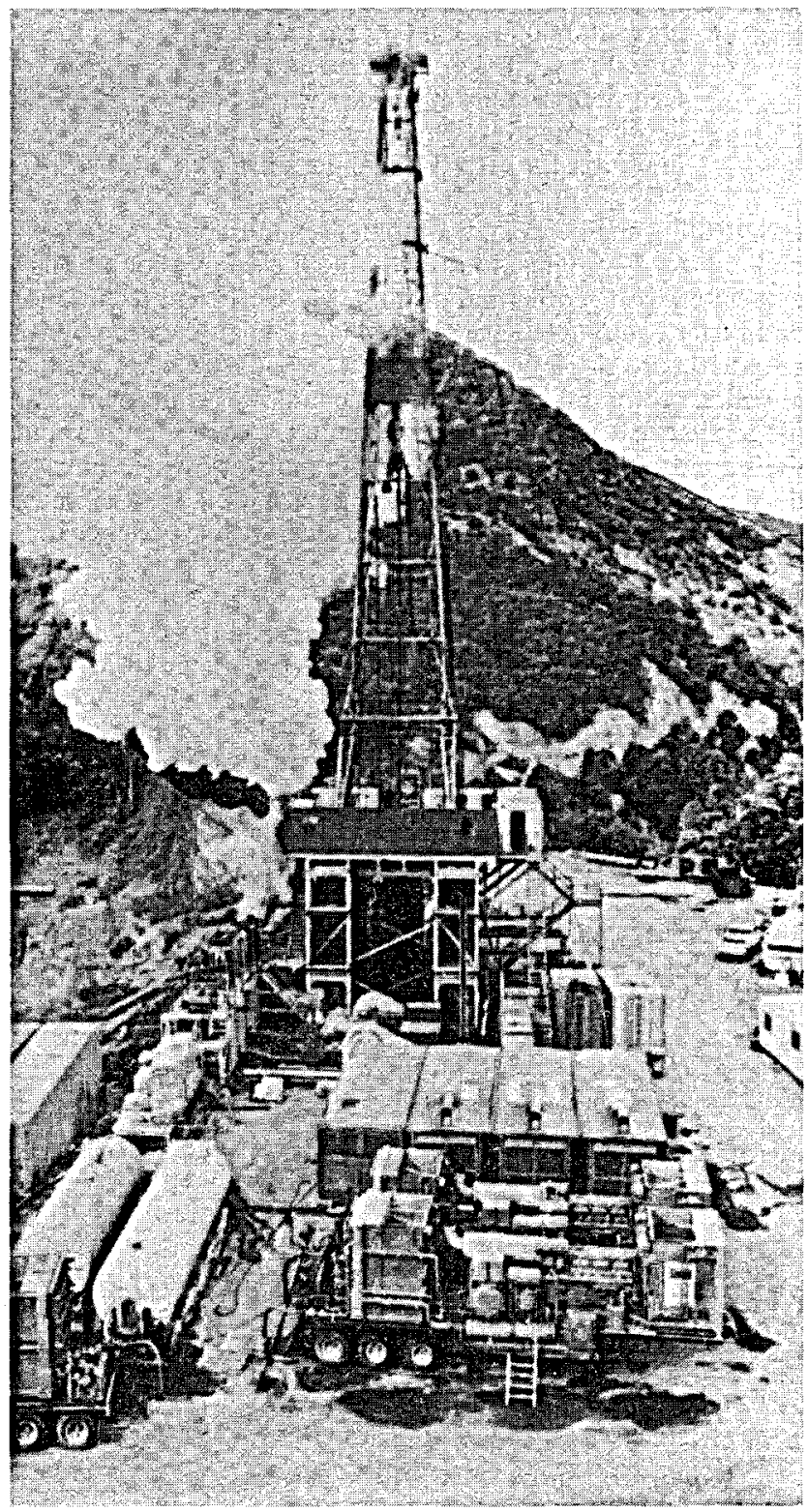

\author{
Drill rig operating at The Geysers \\ using air as the circulating medium. \\ When high temperature and \\ underpressured conditions are \\ encountered as the well enters the \\ reservoir, water-based drilling fluids \\ can solidify and damage the \\ producing formation. To avoid \\ this, air is used as the \\ circulating medium.
}


0 nce an economically exploitable geothermal field is confirmed by drilling, substantial analytical and strategic work is required to plot an optimal path for field development. Reservoir engineering begins at this point and continues as long as the reservoir is in production. Reservoir engineering is a sequence of functions: formation evaluation, reservoir modeling for resource assessment, development of exploitation strategies (reservoir management), and determination of production trends. The goal of these functions is to understand the reservoir's physical geology, hydrology, and geochemistry well enough to design a strategy for producing the reservoir with a good balance of delivered power cost and reservoir longevity.

Reservoir engineering remains an intense area of interest since the investment community requires assurance that the productivity and longevity of reservoirs can be accurately quantified. Until recently, a costly drilling program and/or a definitive operating period of a wellhead generator were the only mechanisms available for such assurance. Today, high technology tools are being developed by U.S. industry for this purpose. While new methods, geoscientific equipment and techniques, and computer software are already seeing some success in field development, long-term production data are needed to confirm and refine the reliability of these predictive tools.

The most recent innovation in reservoir characterization is the consideration of chemical reactions between reservoir fluids and rocks. Formerly, these complex chemical interactions were ignored in reservoir engineering simulations which treated the reservoir fluid as if it were pure water and the reservoir rock as if it were inert. This is not the case, and today's simulations consider the integrated effects of both geochemical and geophysical processes.

\section{Well Test Data}

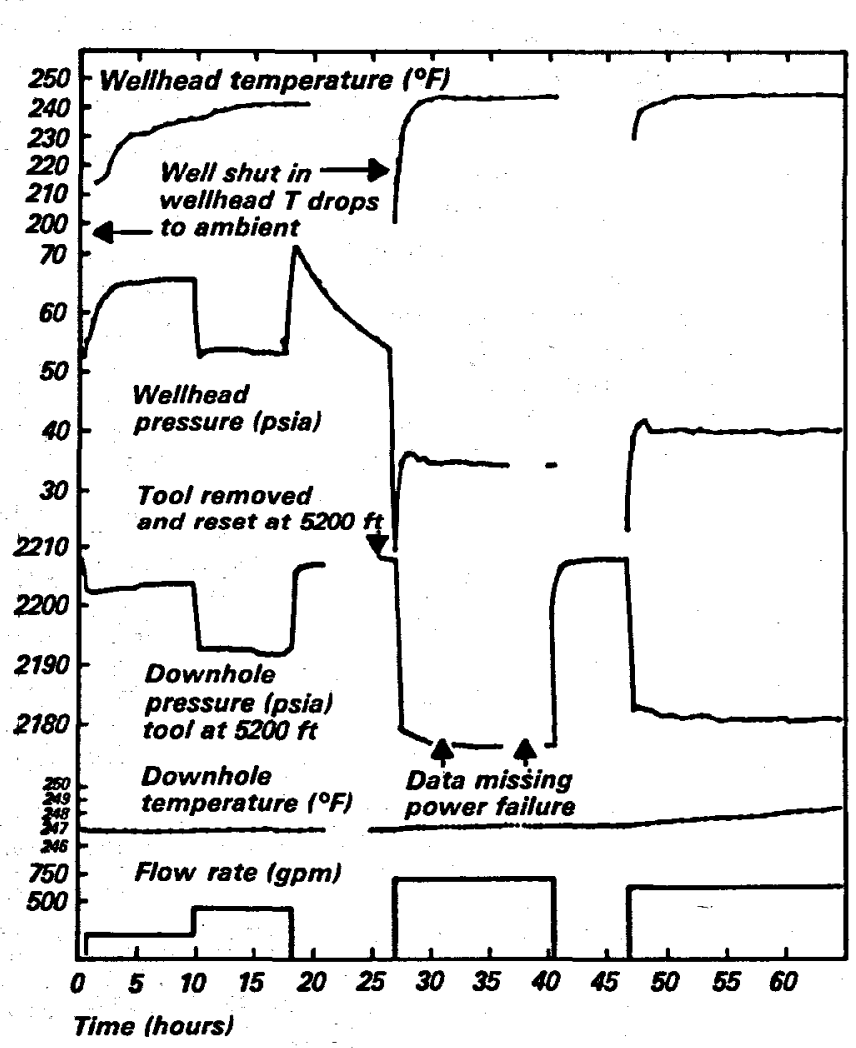

Flow-test data from a geothermal production well. Short-term tests provide information on reservoir conditions. The results affect the siting of subsequent wells, power plant designs, and estimates of the long-term economic value of reservoirs. 


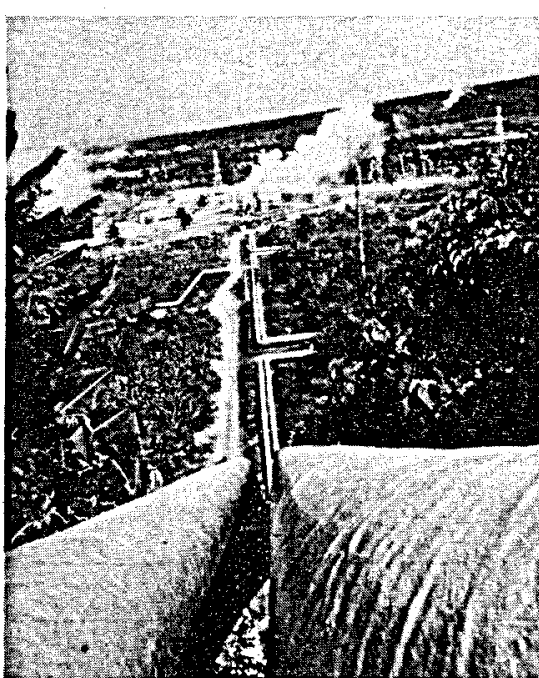

Steam supply lines to a power plant at Tiwi, the Philippines. Geothermal production drilling and power plant construction proceed simultaneously at major projects. Field design and plant design require extensive technical integration to achieve maximum energy output at minimum cost.

\section{Reservoir Engineering Tools and Services Available from U.S. Suppliers}

\section{For Formation Evaluation}

- Well tests to determine the controlling permeability of the formation (fractured or porous), to quantify heat flow, and to estimate heat content

- Pressure transient well tests to delineate reservoir boundaries

- Detection of injected tracers to define the movement of fluids in the reservoir-steam, hot water, and cold recharge

- Analysis of well logs, drill cuttings, and drill cores to derive reservoir parameters such as permeability and porosity

- Borehole televiewer, caliper, and spinner (flowmeter) surveys to confirm the presence of reservoir fractures as major entry points for steam and hot water

- Experimental geophysical and geochemical techniques, both surface surveys and downhole instrumentation for locating and mapping fractures

- Laboratory analyses of fluid chemistry to determine the constituent properties of the reservoir rock and fluid

\section{For Resource Capacity and Reservoir Modeling}

- Conceptual geologic models which define the geometry and physical properties of the reservoir

- Numerical simulation of reservoir behavior under production and injection conditions by means of computer modeling

- Physical models, including laboratory-scale experiments, for measuring and estimating the behavior of reservoir elements

- Conceptual geochemical models to analyze changes in reservoir fluids and rocks and predict the movement of chemical and thermal "fronts" through the reservoir in response to production and recharge

\section{For Field Management and Production Engineering}

- Consulting services on well optiminization-considering appropriate variations in well locations and depths; production rates and methods; fluid injection locations and rates; and production/injection control strategy

- Cost/benefit studies of energy extraction rates versus the costs of flashing flow and pumped production

- Improved injection technologies and injection well replacement strategies

- Injection techniques to enhance production through heat sweep from the reservoir rocks

- Experimental methods for enhancing reservoir permeability

\section{For Determining Reservoir Production Trends and Longevity}

- Long-term monitoring by means of geophysical measurements and geochemical sampling to detect fluid depletion and recharge ratio

- Geophysical monitoring of the ongoing natural fracturing processes

- SHAFT 79 computer code for simulating reservoir behavior (developed by Lawrence Berkeley Laboratory and available from the National Software Center at the Argonne National Laboratory): in use by seven countries outside the U.S. 


\section{Large-Scale Electric Technology}

arge geothermal power plants have a maximum size of about $135 \mathrm{MWe}$. The main reasons are: (1) as single plants get larger, the cost of collection and injection of the fluids increases as more wells (both production and injection) are required, and (2) the fluid transmission heat losses become greater as the resource wells are located further and further from the electric plant.

\section{General Cost and Efficiency}

Geothermal power costs are very sensitive to the wellhead temperature, flow rate, and well cost. These three parameters determine, to a large extent, the economic value of a geothermal resource.

The thermodynamic efficiency of the power cycle increases with resource temperature. The size and cost of many power plant components vary inversely with temperature and directly with well flow rate. Power costs are much more sensitive to flow rates at lower temperatures because the thermodynamic efficiency declines rapidly.

Economies of scale are related to increased brine gathering system (pipe) costs versus reduced turbine-generator costs-per-kW as the size of the system increases. The upper limit is about 135 MWe for dry steam plants, and about 55 MWe for liquid-dominated plants.

\section{The Technologies}

The most common methods for converting geothermal heat into electric power are:

- Dry Steam Process-Naturally occurring dry steam is the least common geothermal resource, but the simplest to use. The steam is fed through insulated pipelines to steam turbines modified for geothermal applications.

- Flash Steam Process-Part of the geothermal fluid is flashed into steam in one or more stages. The steam is used directly in a turbine and generator to produce electric power.

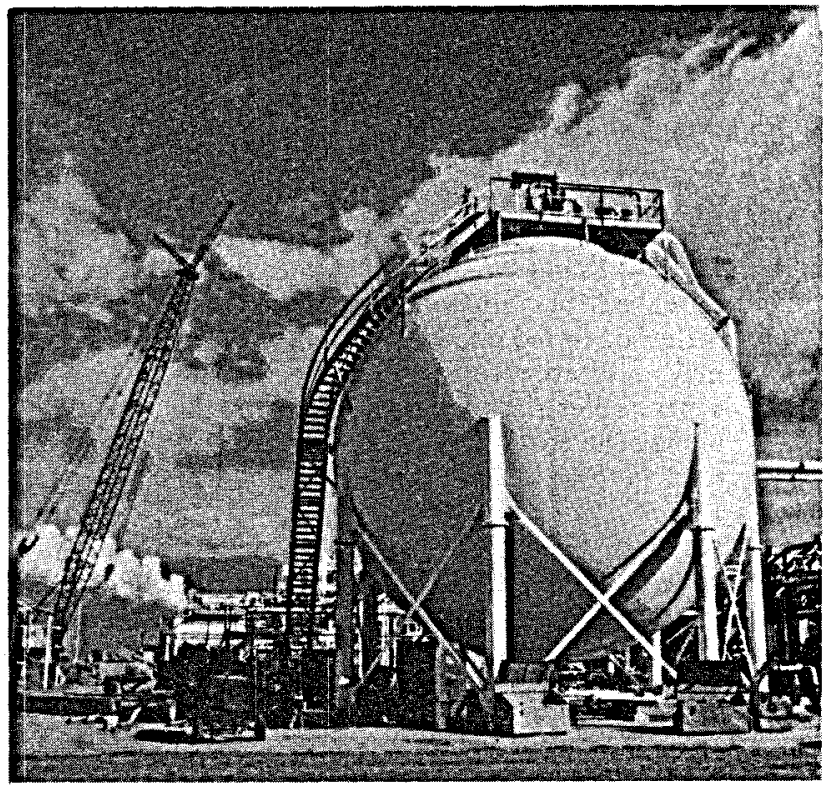

Hydrocarbon storage tank at the Heber 45-MWe binary cycle power plant. Jointly funded by the U.S. Department of Energy and an industrial consortium led by San Diego Gas and Electric, this electric plant is expected to be the vanguard of greatly increased U.S.

geothermal electric power capacity. This research plant is intended to verify environmentally benign technology for exploiting hydrothermal resources at temperatures lower than usually suitable for flash steam technology.

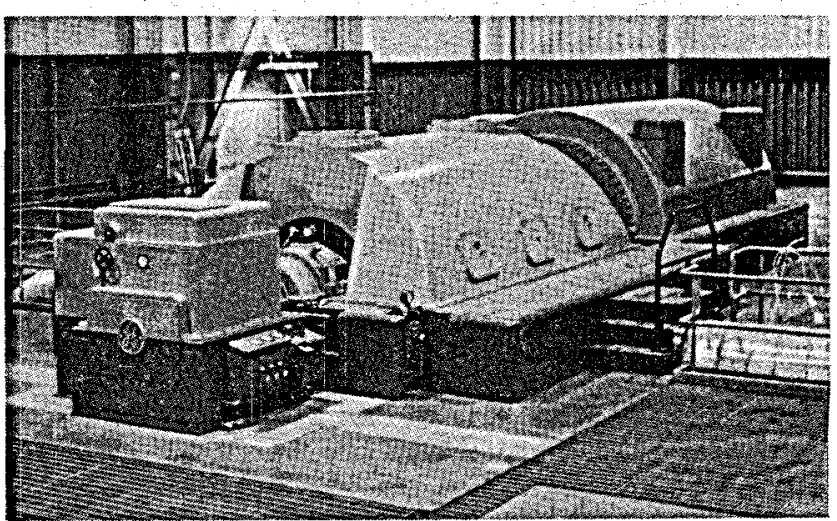

Steam turbine at PG\&E Unit 15, The Geysers. 
- Binary Process-The heat of the brine is transferred in heat exchangers to a pressurized hydrocarbon working fluid, such as isobutane, which is expanded through a turbine to produce power. The working fluid is then condensed and recycled through the heat exchanger.

- Hybrid Process-Fossil or biomass fuel is used to raise the temperature of a geothermal brine before it is flashed or fed into heat exchangers. Hybrid plants may be appropriate for resources too cool to generate electricity economically from the geofluid alone. The geofluid plays an efficient "fuel-saving role" in these plants.

At today's state-of-the-art, flash steam technology is usually used when the resource temperature is over $200^{\circ} \mathrm{C}$. Binary cycles are thermodynamically more efficient than flash cycles in the $150^{\circ} \mathrm{C}$ to $200^{\circ} \mathrm{C}$ range. However, the larger size and higher costs of equipment required for lower temperature resource fluids, and the tendency of some brines to foul binary-cycle heat exchangers and scale downhole pumps, have inhibited the use of binary systems in all but very small units.

Now, however, a 45-MWe proof-of-concept binary plant is in operation at Heber, California, a resource with only moderate fouling and scaling problems. This is the first binary plant with over 10-MWe capacity anywhere in the world. It is a joint effort of the U.S. government and industry. It is expected to lead the way to refinements in binary technology whereby this type of equipment can be used from $\mathbf{3 0}$ to $\mathbf{4 0}$ percent more cost-effectively than flash steam technology on the more abundant moderate-temperature resources of the world.

\section{U.S. Experience}

Twenty-one power plants totaling nearly 1,500 MWe of generation capacity are in operation at The Geysers steam field in California; more large plants are under construction; and still others are planned. Initially the sole domain of a major public utility, The Geysers field is now tapped by plants owned by groups of northern and central California municipalities and the California Department of Water Resources. Recent purchases of properties in this area have involved exchanges of hundreds of millions of dollars.

The U.S. "hot water" geothermal electric industry was born with the installation of a flash and a binary plant in 1980 . It is still small by comparison to the dry steam operations at The Geysers. However, it is more exciting because of the success of less-developed technologies. Plants totaling nearly $300 \mathrm{MWe}$ in capacity, that utilize liquid-dominated reservoirs are in operation or under construction, and a number of others are in planning stages. The larger plants are centered in the Imperial Valley of California. Reservoirs in this area have highly variable temperature and chemical characteristics. The technologies to use them for power generation have successfully met challenges such as fluid salinities 10 times that of seawater in one area and less than optimum temperatures in another. In each case, the technologies were designed to take advantage of the attractive features of the resource-extremely high temperatures and relatively benign chemical composition, respectively-and minimize the problem characteristics.

For example, a 49-MWe dual flash plant is operating almost side-by-side with the Heber binary plant, utilizing the same moderate-temperature $\left(182^{\circ} \mathrm{C}\right)$, low-salinity reservoir. The relatively pure resource, in this case, compensates for the lower temperature. Industry is extremely interested in the performance of this plant as compared to the almost identically sized binary plant.

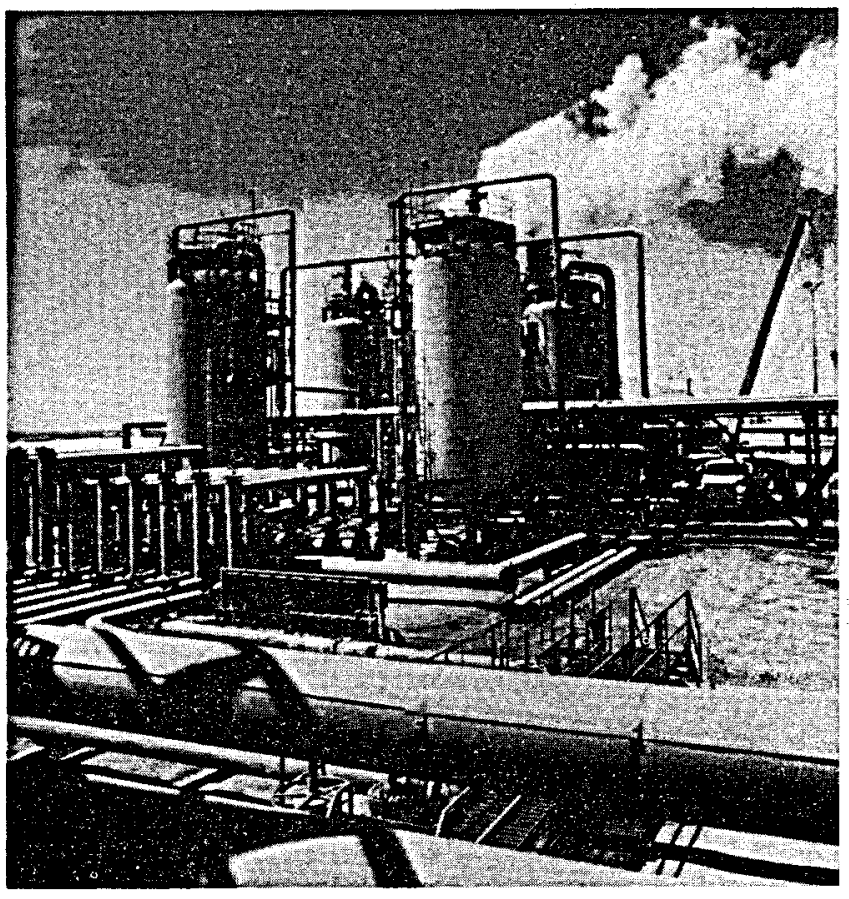

Vertical crystallizer tanks of a flash steam plant at Salton Sea. This technology was developed specifically to tap the Salton Sea reservoir's very desirable high temperatures and 3,000 to 4,000 MWe electric generation potential. The crystallizer/clarifier concept will be used at many other high salinity sites. 


\section{Small Geothermal Generators}

\begin{abstract}
mall scale (10 MWe or less) geothermal power generating units have advantages over their large counterparts in a variety of power development scenarios. Perhaps their greatest utility is to serve as the "ice-breaker" plant in unproven hydrothermal fields. They also perform valuable service later in the development process by providing power to satisfy incremental demands for electricity. Thus, small geothermal generating units can be considered a "before-and-after" technology.
\end{abstract}

The particular advantage of small units as start-up technology is their modular construction and the mobility they provide. A plant can be moved from one reservoir to another or from site to site at the same reservoir. Modular equipment also minimizes construction costs in remote areas where the majority of known geothermal reservoirs capable of power generation are located, and reduces the long non-revenue-producing lead-times associated with larger plants. By adding small incremental units over time, the field development can be staged-a less costly approach and one that generates data with which to refine the reservoir model. Most importantly, the risk element in geothermal development is reduced with the reduction in size and cost, and with the advantages that accrue from mobility.

At the current stage of geothermal development, the "before" role is much more evident worldwide. Only in Italy, where geothermal energy was first used for power generation, can the trend from small plant to large plant to smaller plant be observed-at Larderello, Castelnuovo, and Serrazzano.

\section{Role of the Small Plant in U.S. Industry}

Until 1984, the hot water geothermal power industry in the U.S. consisted of three 10-MWe plants in Imperial Valley, California, and a 3-MWe wellhead unit in Hawaii. All were built as demonstration plants to provide the opportunity to observe technical performance and to evaluate modifications and improvements which could be transferred to other plants. While all four plants suffered some degree of initial difficulties, minor in one case, all are successful, They have achieved considerably higher availability factors than is typical of nuclear and fossil plants, and their power output has been sold commercially since operations began.

Since the four plants employ three different technologies, they have served to provide a very broad geothermal power generating experience base. The Magma Power Co. dual binary plant at East Mesa utilizes its patented Magmamax process which pumps the hot geothermal fluid through a heat

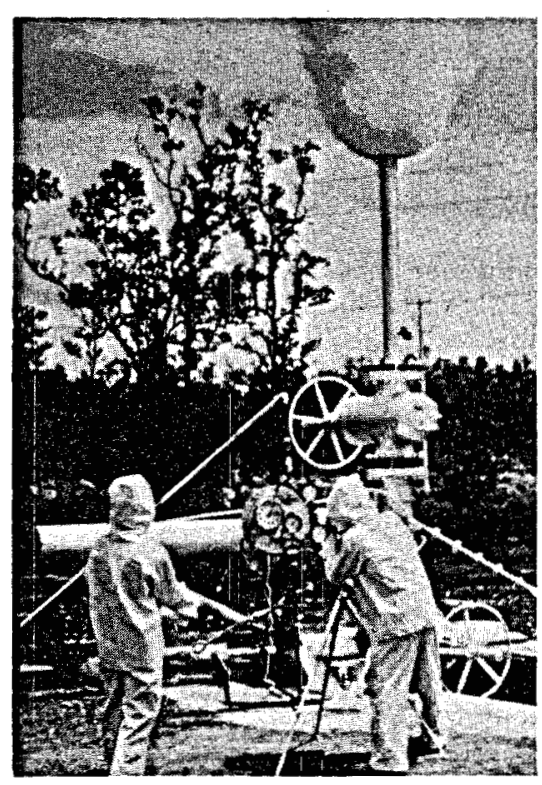

This well at Puna, Hawait, powers a 3-MWe wellhead generator.

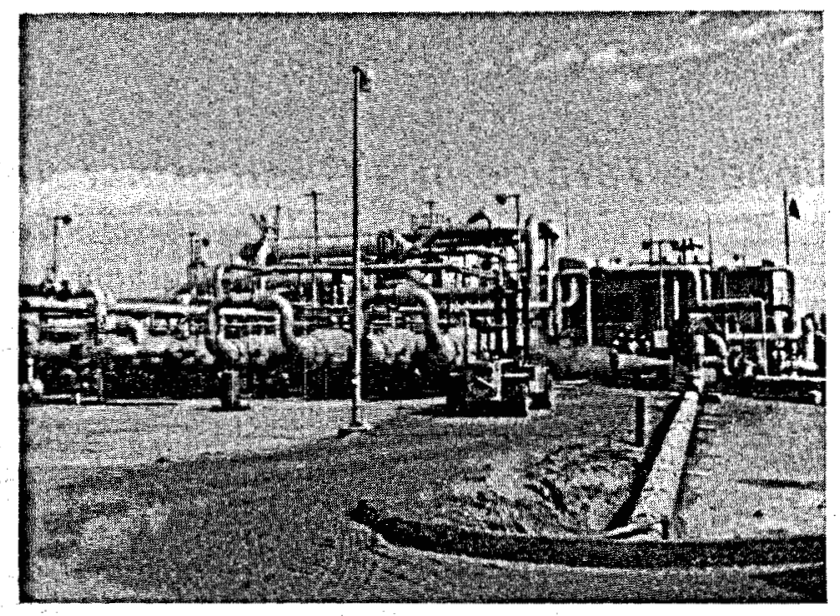

Primary heat exhangers at Magma

Power Company's binary-cycle

Magmamax plant at East Mesa, California. 
exchanger where isobutane working fluid is vaporized to drive a turbine. The vapor is condensed by cooling and returned to the heat exchanger system. The spent geothermal fluid is injected back into the reservoir to complete an environmentally-benign closed cycle. A second parallel power loop uses propane as a working fluid.

Two southern California Edison/Unocal plants employ single flash technology. The Brawley plant utilizes fluids containing over $100,000 \mathrm{mg} / \mathrm{L}$ of dissolved solids. It provided the experience and knowledge needed to design another plant to benefit from the high temperature of the Salton Sea reservoir which contains even more chemically hostile fluids. The Salton Sea plant has performed relatively smoothly from the start of its operation.

The Hawaii Electric Light Co. plant near Pahoa is also a flash plant, but utilizes a wellhead generator-a technology developed with U.S. government research and development funding. Operating at the wellhead, this generator avoids transmission of the fluid through pipelines, resulting in significant energy and cost savings.
A more recent U.S. technology development is a turbine designed to use the heat in both the steam and liquid phases of the resource fluid. After very successful long-term testing of this equipment, Utah Power and Light Co. is using biphase units to boost the output of its 20-MWe stationary plant near Milford, and in conjunction with a dual pressure steam turbine in a new plant, to generate a net power of 14.5-MWe. The Electric Power Research Institute participated in the development of this equipment.

U.S.-manufactured wellhead generators, called power generation modules, are operating at Wendel, California, as the first units of a planned incremental development program. These modules contain their own heat rejection systems, avoiding the need for separate cooling equipment.

Still another type of wellhead unit manufactured in the U.S. permits the use of hydrothermal fluids with a high noncondensable gas content. This is the back pressure turbine which, while less efficient than the condensing turbine, may be more suitable where $\mathrm{H}_{2} \mathrm{~S}$ abatement is not required.

Other types of turbine/generators produced by U.S. manufacturers are either designed for or are adaptable to geothermal use. They incorporate versatilities to accommodate a wide range of hydrothermal resource characteristics.

\section{Biphase Turbine in a Geothermal Application}

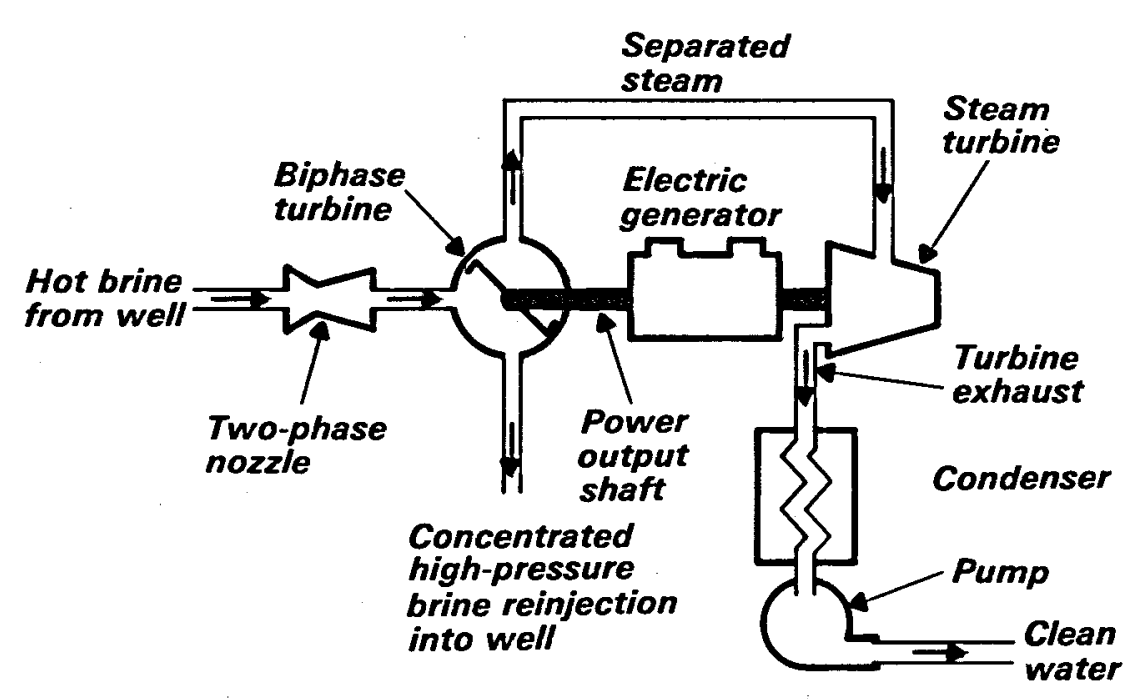

The Biophase rotary-separator turbine converts kinetic and pressure energy in the geothermal brine to shaft power. It is a valuable adjunct to flash steam turbine installations. 


\section{Downhole Pumps}

Downhole pumping, where the pump itself is located deep in the well, may be used as an adjunct to geothermal power generation operations of all sizes. Its purpose is to increase fluid production rates and reduce downhole mineral precipitation and scaling. In addition, for binary technology systems, pumping is usually necessary to prevent fluid flashing and to keep the resource in its liquid state. Both mechanical line-shaft and submersible electric pumps are used in geothermal applications. However, due to depth and other limitations of the line-shaft equipment, current interest centers on the submersible electric pump.

In an electric submersible pump, a downhole electric motor powers the brine pump. Electricity is provided by an electric cable from the surface. The pump is easily emplaced and can be used to depths of several thousand feet. Historically, the problem with this technology in geothermal wells has been degradation of the motor and power cable by intrusion of hot, corrosive brine.

Recent R\&D has resulted in low-horsepower units that can survive a year's operation in $175^{\circ} \mathrm{C}$ brine, a performance expected to be improved and extended to larger systems with the use of a new metal-sheathed power cable. New downhole lubrication systems which prevent brine intrusion and loss of lubricating oil have also been successfully tested.

\section{Submersible Pump Installation}




\section{Direct Use Systems}

\begin{abstract}
$T$ he heat of geothermal resources has been used for district heating, space and water conditioning, industrial processing, hybrid fuel systems, mineral recovery and, since ancient times, cooking, bathing, healing, and recreation. For the most part, these applications all utilize existing technology, whose reliability, economics, and environmental acceptability have been demonstrated throughout the world.
\end{abstract}

Because of increases in prices of conventional fuels over the last decade, nonelectric applications of geothermal energy have become more cost competitive. Such applications are therefore receiving increased attention in the United States and throughout the world.

Direct use applications of geothermal energy generally employ lower temperature, lower heat content, and shallower geothermal waters than used in electric power generation. Cooler, shallower groundwaters are less mineralized, and most direct uses can operate on smaller volume rates of fluid production than is usually required in power generation. In the United States, there are currently over 215 projects using an estimated $902 \times 10^{9}$ Btu's annually for these applications. Many of these projects include multiple structures and/or end users.

\section{Space and Water Conditioning}

Space and water conditioning are two of the most common applications of geothermal energy. Hospitals, schools, churches, and other publicly-supported facilities and commercial buildings are heated in this way. Many individual residences have also benefited from their own geothermal wells. A recent survey indicated 550 homes in Klamath Falls, Oregon, and nearly 200 homes in Reno, Nevada, are heated by geothermal energy. Many of these applications also involve water heating by geothermal hot water heaters. The estimated total annual end use energy supplied by geothermal for space conditioning and domestic hot water prejects in the U.S. is $436 \times 10^{9}$ Btu's. An additional $37 \times 10^{9}$ Btu's annually may be realized from projects that are presently under construction.

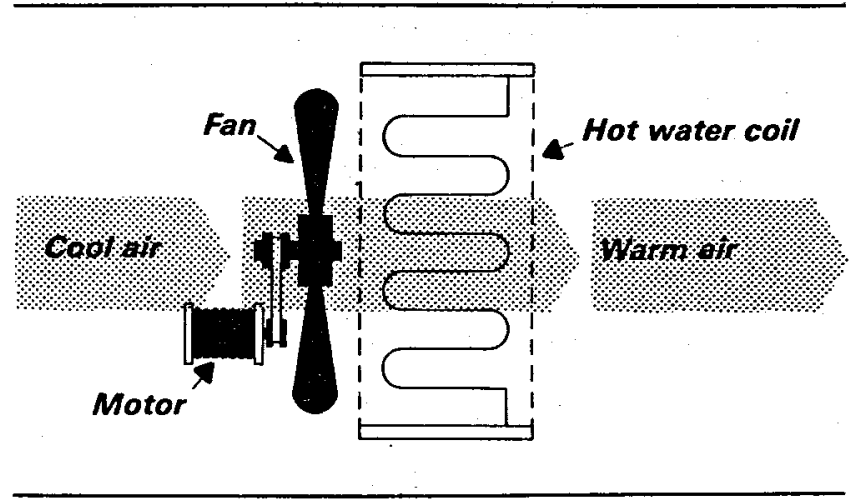

This fan-driven air heater is one of the simplest geothermal direct heat systems. More complex systems cascade geothermal fluid through a series of processes at varying temperatures. 


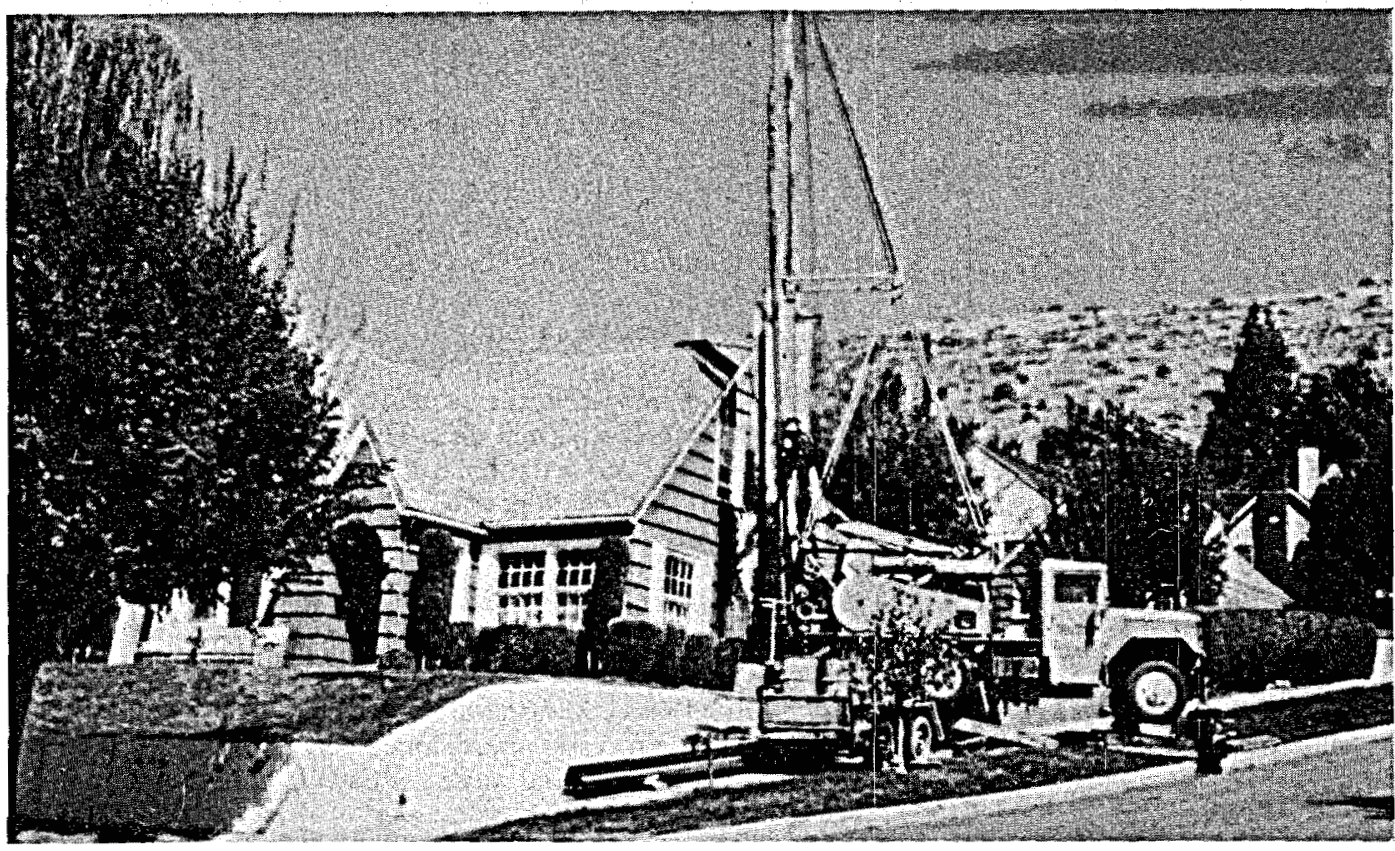

Drilling a geothermal well for residential heating at Klamath Falls, Oregon. Since at least 1900, residents of Klamath Falls have installed their own geothermal wells for space heating.

\section{District Heating Systems}

District heating systems involve a central plant providing space and/or water conditioning to multiple structures representing many end users. Approximately 30 municipal and institutional geothermal district heating systems along with a number of similar systems for resort complexes are currently operational in the U.S. Other projects are under construction.

Boise Warm Springs Water District located in Boise, Idaho, was established nearly a century ago and is the oldest geothermal district heating system in the U.S. The city has upgraded and expanded this residential system and has developed a new district heating system, Boise Geothermal, in the downtown business district. The new system began operating in March 1983, and provides space and water heating to 20 government, institutional, and commercial buildings. The heating capacity is 220 billion Btu's per year. 
Also in Boise, the Idaho Capital Mall district heating system provides space heating to seven state-owned buildings. Nearly 6,700 square meters of building space is heated. Ninety percent or more of the annual heating requirements are supplied by geothermal energy. This results in an annual savings of natural gas of approximately $\$ 150,000$ based on 1981 costs.

The first district heating system to combine heat pumps and municipal water mains is located in Ephrata, Washington. Water ranging from $27^{\circ}-32^{\circ} \mathrm{C}$ is extracted from the water mains and increased to $49^{\circ}-66^{\circ} \mathrm{C}$ by the central heat pump. It is then circulated through the Grant County Courthouse, Courthouse Annex and the County Law and Justice Center. Future expansion of the system will include a high school and several commercial buildings. The system has reduced the County Courthouse fuel bill by 85 percent.

\section{Industrial Process Heat}

Industrial processing generally requires the highest temperature fluids of all the direct uses. Temperatures above $150^{\circ} \mathrm{C}$ are normally desired. However, lower temperatures can be used in some cases, especially for various drying applications. Both steam and superheated water are utilized.

Although attractive in terms of fuel savings, widespread industrial process use of geothermal energy has not occurred. This is due, in part, to the difficulty of relocating commercial enterprises to geothermal sites. The world's two largest industrial users are a diatomaceous-earth drying plant in Iceland and a paper and wood processing plant in New Zealand. The United States has four enterprises using $118 \times 10^{9}$ Btu's annually: sewage digestion plants in San Bernardino, California and Elko, Nevada; a vegetable drying facility in Brady Hot Springs, Nevada; and a copper processing plant in Hurly, New Mexico. The San Bernardino plant, the first U.S. wastewater treatment plant to convert to geothermal, processes approximately 81 million liters of domestic and industrial waste per day.

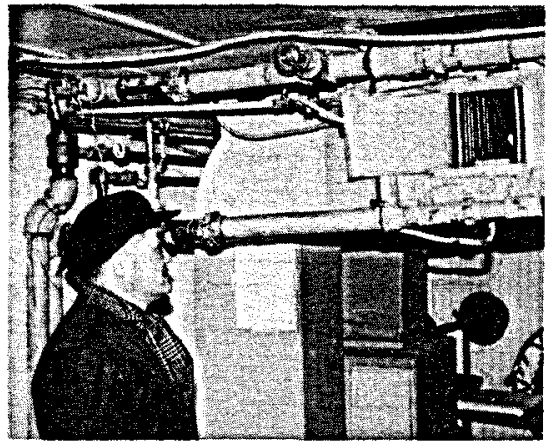

United Nations training program for Chinese fellows at Geo-Heat Center, Oregon Institute of Technology. This engineer is examining a geothermal home heating system. 
Direct Heat Applications Temperatures

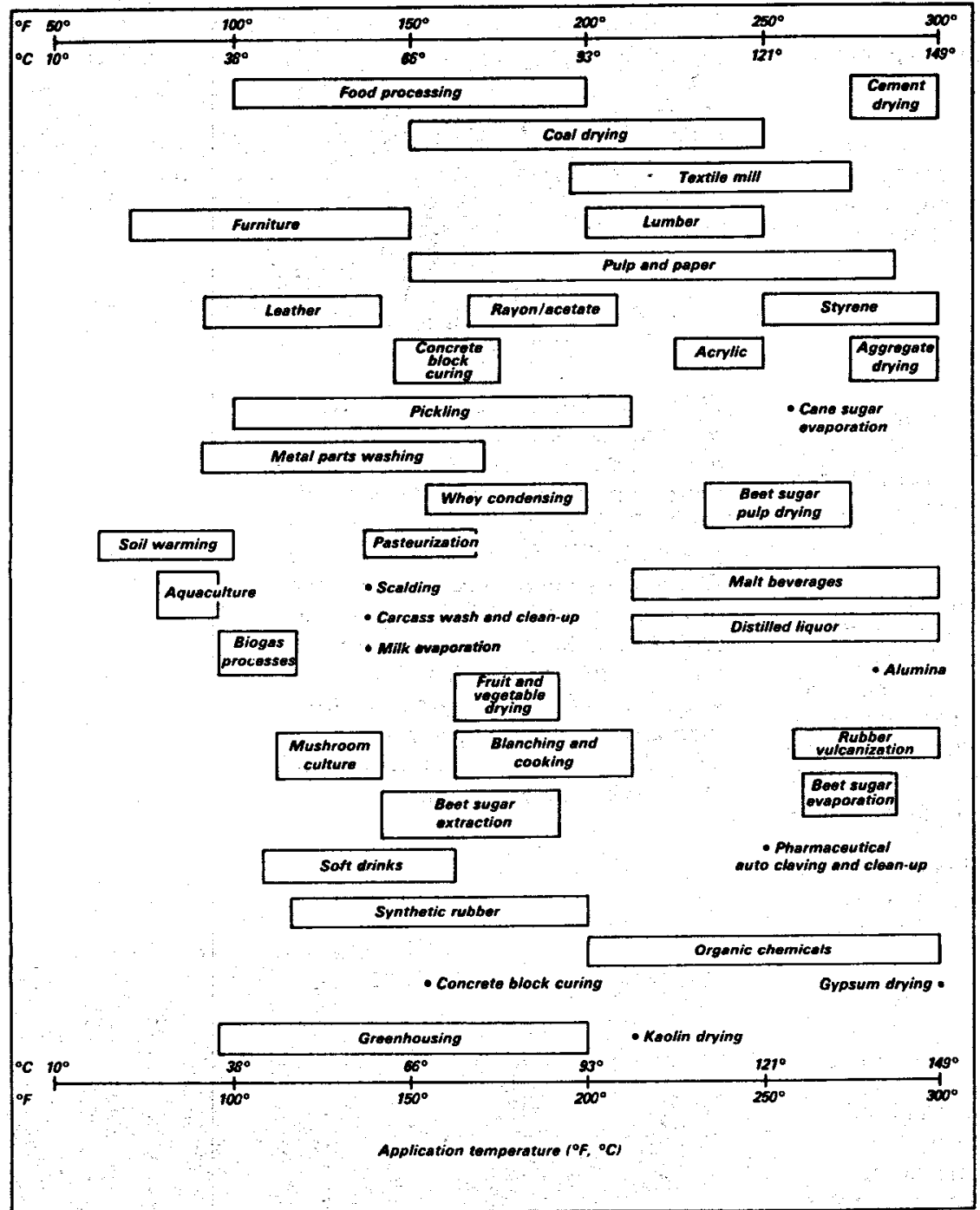

\section{Mineral Recovery}

Many geothermal brines contain metals of commercial interest such as potassium, lithium, manganese, strontium, and zinc at concentrations in excess of $100 \mathrm{ppm}$. A 50-MWe power plant requiring $2.25 \times 10^{6} \mathrm{~kg} /$ hour of brine could possibly yield 1,600 metric tons of metal annually, based on plant operations of 24 hours per day for 300 days per year. Techniques for recovering metals from post-flash geothermal brines have been developed by U.S. researchers and are compatible for use with new power generation systems, or for retrofitting to existing power plants with minor modifications. 


\section{Agriculture and Aquaculture}

\begin{abstract}
$\boldsymbol{T}$ use of geothermal energy for agricultural and aquacultural applications is becoming increasingly attractive, and this trend is likely to continue. These applications cannot always economically justify exploration and reservoir confirmation programs, but they can benefit from the developmental progress of larger, more revenue-intensive industries-i.e., power generation. Some agricultural and aquacultural uses are ideally suited to multi-stage use of geothermal energy and can employ the waste heat of power plants or direct use applications that require a higher-temperature resource.
\end{abstract}

\section{Greenhouses}

Geothermal energy has been reliably heating greenhouses for years. Even in the coldest weather, the temperatures necessary for optimum plant growth are maintained. Geothermal energy can extend short growing seasons to a year-long basis and significantly reduce fuel costs.

Hydroponic farms near Susanville, California, use geothermal fluids to heat $\mathbf{3 1}$ greenhouses where tomatoes and European cucumbers are grown using water as the root medium. In one month, 31,500 kilograms of cucumbers are harvested in a production area of 1.33 acres. The complex is heated with $102^{\circ} \mathrm{C}$ water pumped from a shallow geothermal well. Even when winter ambient temperatures drop to $-29^{\circ} \mathrm{C}$, a temperature of $21^{\circ} \mathrm{C}$ can be maintained in the greenhouses.

The company's cucumbers and tomatoes are in great demand because of their excellent taste and appearance and their unusually long shelf life. This excellent quality brings high prices.

\section{Soil Warming}

Studies have shown that heating the roots of a plant rather than the air above them, results in a 30\% increased growth rate and a $30 \%$ reduction in greenhouse heating costs. Systems designed for soil warming transfer heat from water (at about $55^{\circ} \mathrm{C}$ ) to the plant through a distribution system of synthetic rubber tubing. Because of the low temperature required, many geothermal resources are suitable for this application. Greenhouses using soil warming systems report impressive results. At a greenhouse in New Mexico, a cutting becomes a well-established crysanthemum plant in only 10 to 11 days.

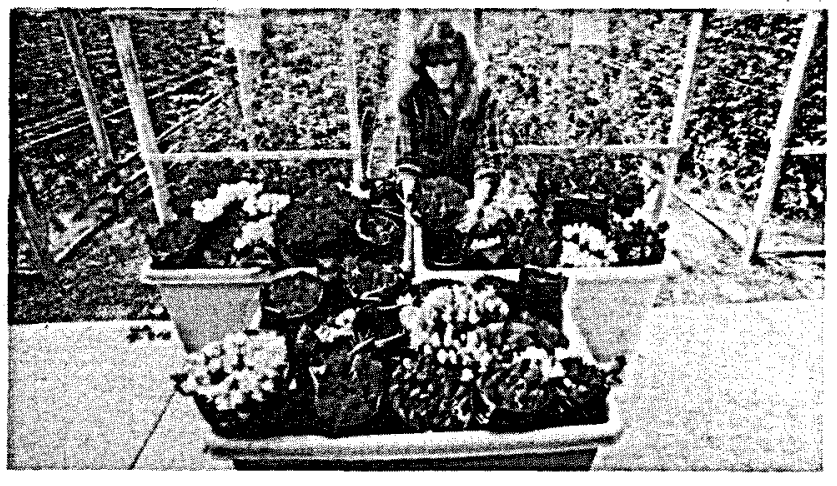

This Utah Roses greenhouse at

Bluffdale, Utah, was specifically

designed to use geothermal energy,

which supplies all of the required

heat. The facility would otherwise

use $\$ 100,000$ of natural gas per year.

The energy system cost, including

production and injection wells, was

about $\$ 90,000$. Thus, the simple

payback period was less than a

year. There is enough heat in the

discharged water to heat a

greenhouse three times the size of

the present 3-acre facility.

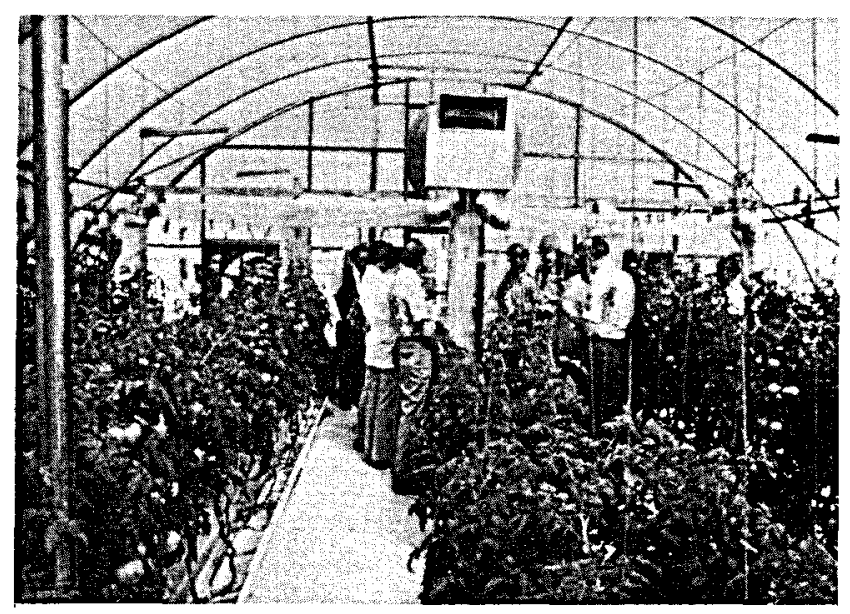

GeoProducts Corporation's vegetable greenhouse, at Wendel Hot Springs, California. This is the largest geothermal heated greenhouse operation in the U.S. 


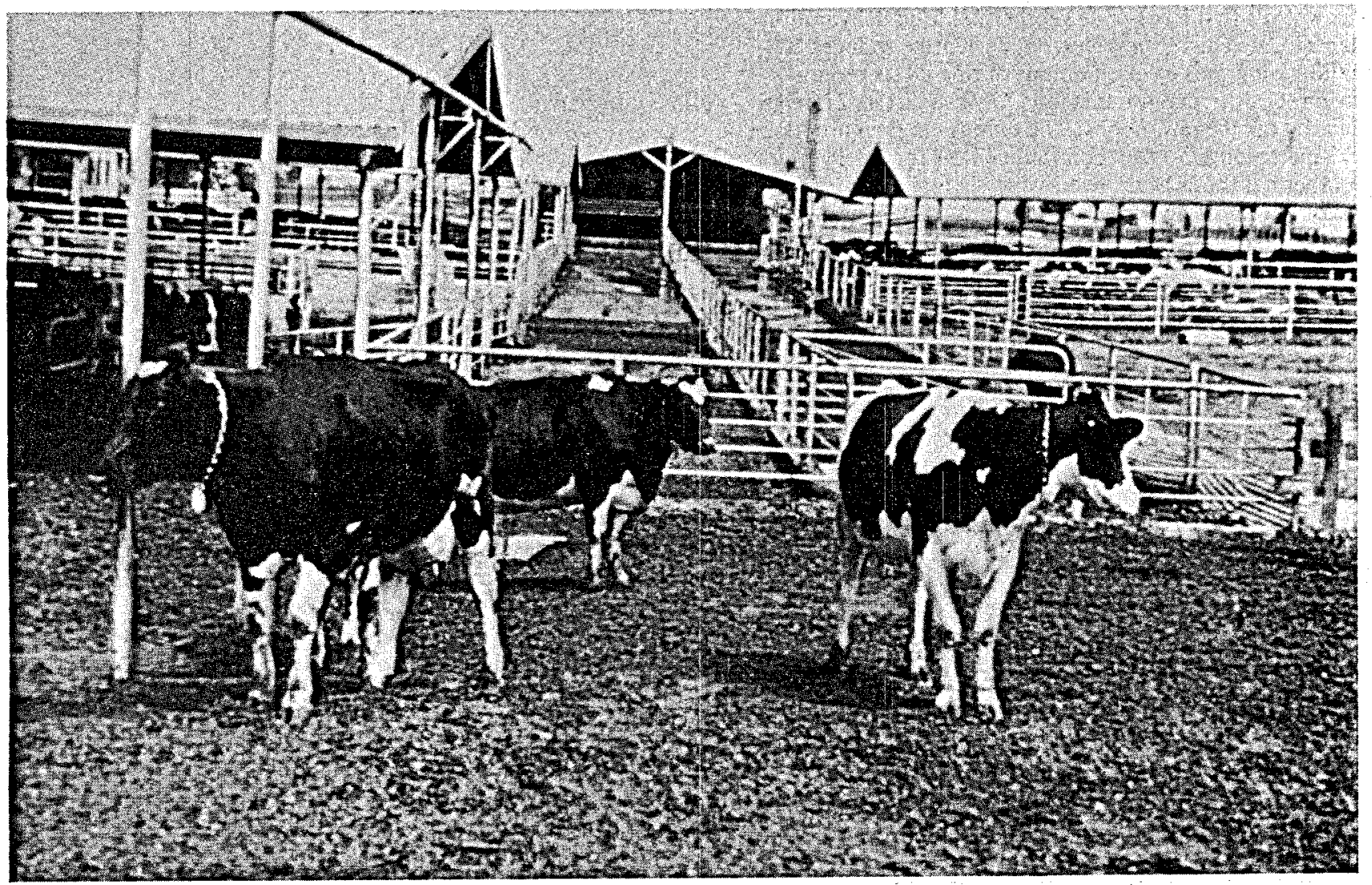

Milk supply for a Klamath Falls, Oregon, geothermal dainy. The Medo-Bell Creamery has been using geothermal hot water for pasteurizing milk for nearly 40 years. A plate-type pasteurizing unit uses 200 liters per minute of $87^{\circ} \mathrm{C}$ fluid to heat the milk to $77^{\circ} \mathrm{C}$ for 15 seconds. The annual operating cost is extremely low.

\section{Mushroom Culture}

Geothermal energy has been used successfully in the cultivation of mushrooms. In December 1984, production began at a semi-automated mushroom-growing facility, in Vale, Oregon, using geothermal energy for both heating and cooling. A yield of 3-1/2 million pounds of mushrooms per year is expected and present production levels are on target.

\section{Processing Agricultural Products}

Food processing, especially vegetable dehydration, is an excellent application of geothermal energy. Vegetable dehydration typically uses fairly low temperatures, from $38-93^{\circ} \mathrm{C}$. Furthermore, combustion products that could either discolor or contaminate the processed produce are absent from the air stream. Because there is no open flame, the use of geothermal energy eliminates the possibility of fire hazards. 
The world's first large-scale geothermal food dehydration plant, located at Fernley, Nevada, currently produces 2.7 million kilograms of dried onions during its six month season. Geothermal water is used to wash dirt and foreign material off the raw onions. The onions are then processed in a 57-meter long, 3-stage, continuous flow food dehydrator. Geothermal fluids heat the air which is forced through the bed of onions as they pass on a perforated stainless steel belt. Geothermal energy replaced a natural gas system at the Fernley plant which consumed 116 million cubic feet of natural gas annually. The savings amount to $\$ 250,000$ per year. The plant has recently been equipped to process celery and carrots between onion seasons.

\section{Aquaculture}

Geothermal waters can produce excellent yields of high quality fish and Crustacea under accelerated growth conditions. Warm water tilapia, catfish, and prawns mature in half the time, and grow larger than their cold water counterparts. Geothermal aquaculture permits breeding in the off-season, allowing fish farmers to harvest their products when market availability is the lowest and prices are the highest.

Aquafarms International, in Mecca, California, raises Malaysian prawns, bass, catfish, Japanese koi, and grass-eating carp in 61 ponds supplied by three geothermal wells and five irrigation wells. Water covers 50 acres, with pond sizes varying from $1 / 10$ acre to 2 acres. Aquafarms fish are available year round and their prawns, raised in fresh water, contain no iodine. Most of the prawns are sold to gourmet restaurants.

At its hatchery near Buhl, Idaho, Fish Breeders of Idaho has been raising channel catfish and other types of fish in geothermal water for over ten years. The $32^{\circ} \mathrm{C}$ water is cooled by spring and stream water to the ideal temperature of $27-29^{\circ} \mathrm{C}$ in which the fish thrive. Fish Breeders is located in southern Idaho, within the Snake River Canyon where the climate is too cold and the growing season too short to breed catfish commercially in unheated ponds. Thus, geothermal water changes a noncommercial area to a 365-day optimum growing season. The quality of channel catfish produced in the clean water is excellent since there are no odor-producing impurities present to impart undesirable taste. These catfish claim high prices in the gourmet market.

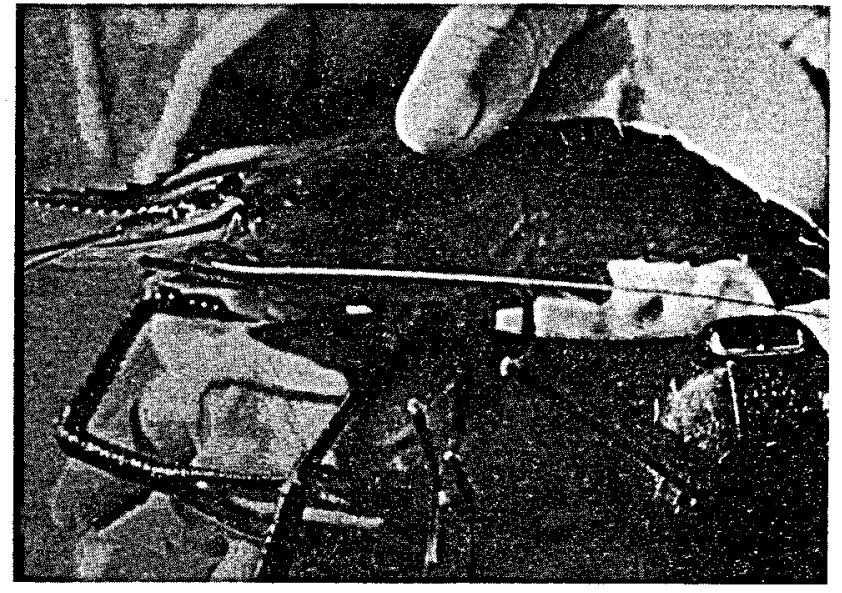

Giant prawn raised in Oregon Institute of Technology aquaculture pond. These ponds use the outflow from the campus' geothermal heating system to raise prawns and trout. The Institute was relocated in 1963 to take advantage of geothermal water to heat eleven buildings, provide domestic hot water, and cool five buildings during the summer. 


\section{Brine Handling}

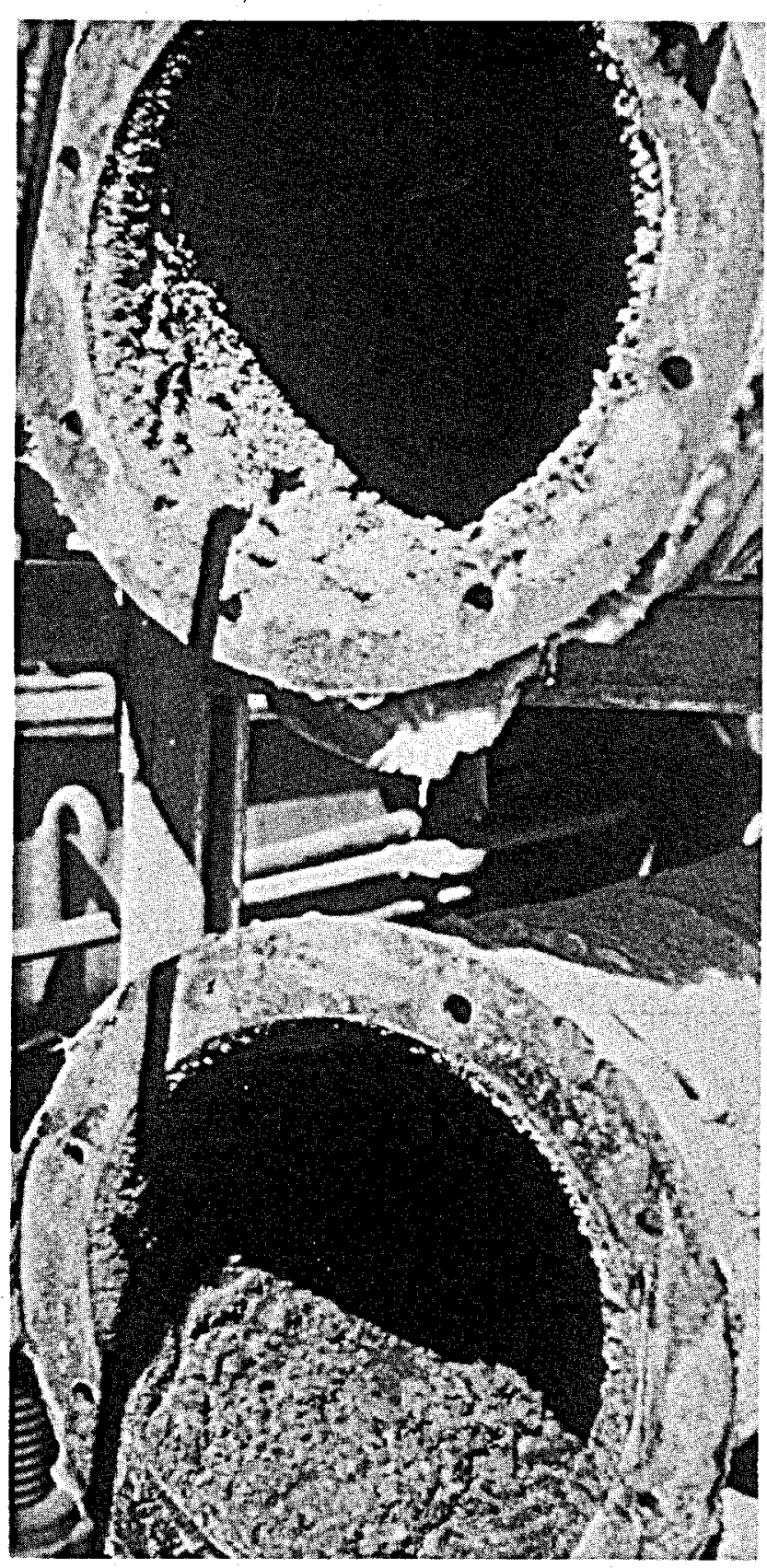

G eothermal brines once had a negative reputation among power engineers. In many instances, this reputation was justified, especially for brines produced from a few major reservoirs. For example, the severe chemical conditions encountered in the Salton Sea and Brawley reservoirs of the Imperial Valley, California (and the adjacent field at Cerro Prieto, Mexico) have been highly visible because these reservoirs are very economically attractive due to their large volume and high temperature.

These visible problems have induced exaggerated fears of brine handling problems at other reservoirs, many of which are, in fact, relatively benign. Nevertheless, brine handling problems are real. Geothermal brines have scaled production wells almost shut, fouled or rapidly eaten through heat exchanger tubes, deposited thick scale in pumps and tanks, corroded and eroded turbine blades, and plugged injection wells. The "worst" brines contain 10 times the dissolved solids of sea water. Chemicals in many brines exhibit high corrosive reactivity with metals at geothermal fluid temperatures.

\section{Most Problems Have Been Solved}

Many of these problems are no longer unmanageable. The brines, of course, are the same as they have always been. In the past decade, however, extensive research and field experience have identified and proven solutions to most of the problematic interactions between geothermal brine constituents and energy extraction equipment and materials. There are now technically satisfactory and economical ways of managing almost all of the problems that appeared intractable in the early 1970's. Some of these are listed in the box on the next page. These results markedly reduce the risks involved in selecting appropriate processes, components, and materials for geothermal systems.

The undesirable interactions differ greatly from reservoir to reservoir. They must be measured, analyzed, and designed-for on a case-by-case basis. Geothermal power system design has achieved "off the shelf" modularity only where the brines are relatively pure.
Geothermal fluid scale in pipes, deposited before current state-of-the-art brine-handling measures were available. 


\section{Brine Handling Need \\ Fluid transport and control systems \\ Production well corrosion, erosion, rupture, collapse}

\section{Available Technologies}

Wellhead separators

Two-phase flow design codes Automated control systems

Selection of casing materials

High-quality cementing job

Minimize thermal shocks to wells

Minimize sand scouring

Production well scaling

Downhole production pumps

Chemical treatment

Cavitation descaling

Surface equipment corrosion

Selection of steels

Elimination of $\mathrm{O}_{2}$ leaks

Chemical treatments

Polymer pipes, linings

Increased part thickness

Dissolved solids handling

Conversion cycle selection

Crystallizer-clarifier

Chemical treatments

Surface coatings, treatments

Noncondensable gases

Gas ejectors

Compressors

Gas turbines

Preboilers

$\mathrm{H}_{2} \mathrm{~S}$ scrubbers

Injection well and

formation plugging
Surface precipitation

Filtering

Downhole chemical treatments

Many of the needs represented

here had no good technical

solutions as late as 1975.

Significant technology research

and practical experience has

produced many methods for

solving these needs. 


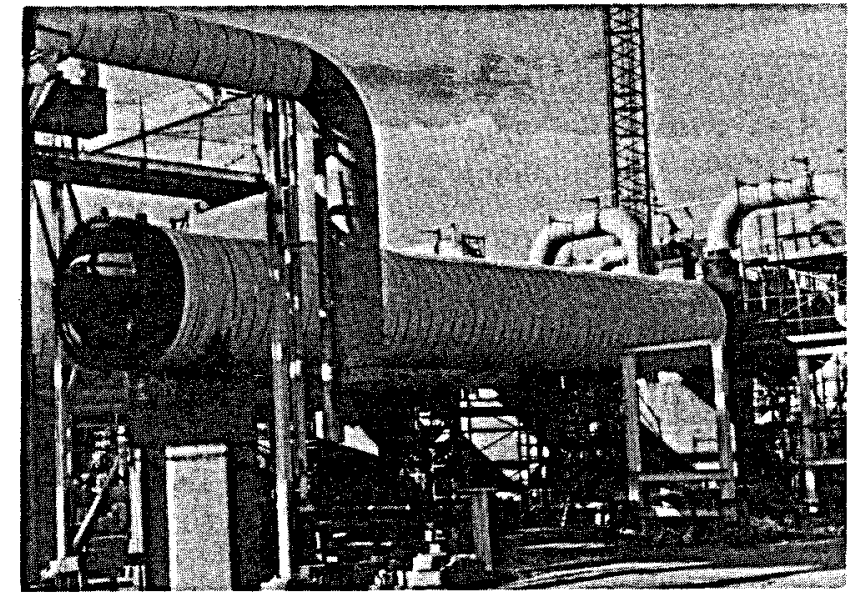

Shell and tube heat exchanger at the Heber 45-MWe binary plant. Eight of these 160-ton, 27-meter long by 2-meter diameter devices are used to transfer geothermal heat to an organic working fluid. The tubes are made of high chromium ferritic stainless steel to minimize corrosion and scaling.

\section{Brine Effects on Materials}

Geothermal waters frequently contain dissolved solids and gases leached from reservoir rocks. These can present chemistry-specific problems, e.g., excess acidity in brines can cause embrittlement of oil-field grade carbon-steel tubular goods. Almost all problematic chemical reactivity is worsened by the temperatures of the brines $\left(150^{\circ}\right.$ to $\left.350^{\circ} \mathrm{C}\right)$.

Intensive integration of what has been learned from on-line systems has been accomplished. For a new brine that falls within certain well-defined bounds of chemical condition, experience and technical approaches used at other sites should be sufficient to identify cost-effective power cycles, equipment, and materials. An aggressive chemical environment created by the brine may dictate which power conversion cycle (e.g., flash, binary) is most acceptable. Component selection criteria must include an estimate of material availability and the form of the material required to survive the anticipated chemical environment. For example, the to-be-expected minor leakage past valve seals may corrode common materials in the valve body.

It should be expected that some aspects of the first few plants at a reservoir will have to be altered after an initial operating period. Perhaps half of the reservoirs opened so far have required modifications of either design or materials in heat exchangers, surface pumps, turbine nozzles, turbine blading, or condenser components.

\section{Precipitation, Scaling, and Plugging}

Precipitation of substances from brine can cause scaling or erosion, and either increase or decrease corrosion rates. The composition and rate of precipitation depend on fluid composition and specific process stream conditions. The chemistry of scaling can be so complex that extensive applied $R \& D$ is sometimes required to prevent scaling. But most scaling problems are dominated by silicate or carbonate compounds in brines, and these are now understood and can be dealt with effectively.

\section{Scaling in Surface Equipment}

Some brines contain high concentrations (up to 30 percent by weight) of chemicals that precipitate as temperatures decrease. Such brines were notorious for fouling heat exchangers, scaling flash tanks and surface pipes, and precipitating in injection wells and eventually plugging the injection formations. 


\section{Crystallizer-Clarifier for Scale Control}

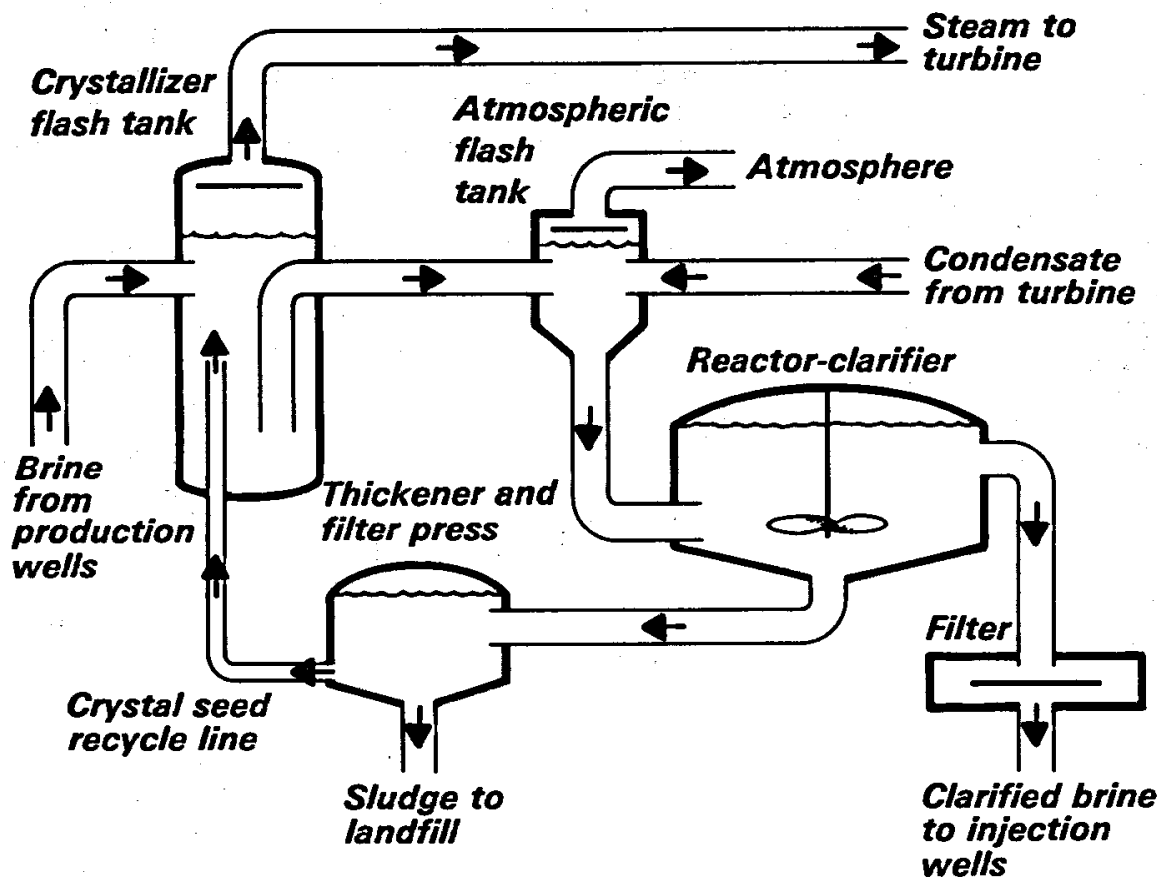

The crystallizer-clarifier controls most scaling and fouling of surface equipment, and prevents the plugging of injection formations. Seed crystals, taken from the solid effluent stream, are injected into the first flash tanks, at one percent by weight in the tank. Essentially all precipitation of brine solids occurs on the seeds, rather than on equipment surfaces. The clarifier tank allows precipitation to run to completion. All solids are eventually removed as compacted sludge. The crystallizer-clarifier was developed by a consortium of industrial firms and DOE representatives.

Modifications of the process are now incorporated into the Unocal/Southern California Edison 10-MWe flash plant at Salton Sea, and the Magma Power Company 34-MWe plant currently under construction near Niland, California.

Precipitation from these brines is now controlled using the "crystallizer-clarifier" technique. This process forces the inevitable precipitates to form and remain in the brine stream rather than on equipment surfaces. Plant shutdowns for scale removal are essentially eliminated, and injection well life is markedly improved (see the figure).

\section{Production Well Scaling}

Many brines are close to saturation with calcium carbonate. These carbonates tend to precipitate wherever brines are flashed. When this happens in production wells, scaling can choke off the flow very rapidly. The proven technical solution is to maintain pressure in the well, using a downhole pump. Both line-shaft pumps and downhole motor pumps have been used. Downhole pumps for this purpose are so effective that their use in conjunction with binary power plants in the U.S. is covered by industry patents. 


\section{Environmental Technology}

$\boldsymbol{T}$ he use of geothermal energy is one of the cleanest and safest means for generating electric power. It provides a natural heat source, requiring no attendant combustion with its inherent strains on the environment. There are no nuclear radiation concerns.

In addition, geothermal development involves minimal land disturbance as compared to the large areas required for the mining, refining, transportation, fuel processing, and waste disposal needed to support coal and nuclear plants.

Geothermal energy must be used in the immediate vicinity of the resource in order to prevent excessive heat loss, so the entire cycle from extraction to transmission is located at one site.

At today's state-of-the-art, the challenges of the environmental implications of geothermal development have been met with U.S. technology. Solutions are available, for use where problems exist, that permit geothermal operations to comply with the most rigid environmental regulations in the world. California, the bellwether state for stringent environmental protection, is host to the largest geothermal power complex in the world at The Geysers and the hot-water industry developing in the Imperial Valley and elsewhere in the state. In addition, California is encouraging and financially assisting increased direct use of its geothermal resources.

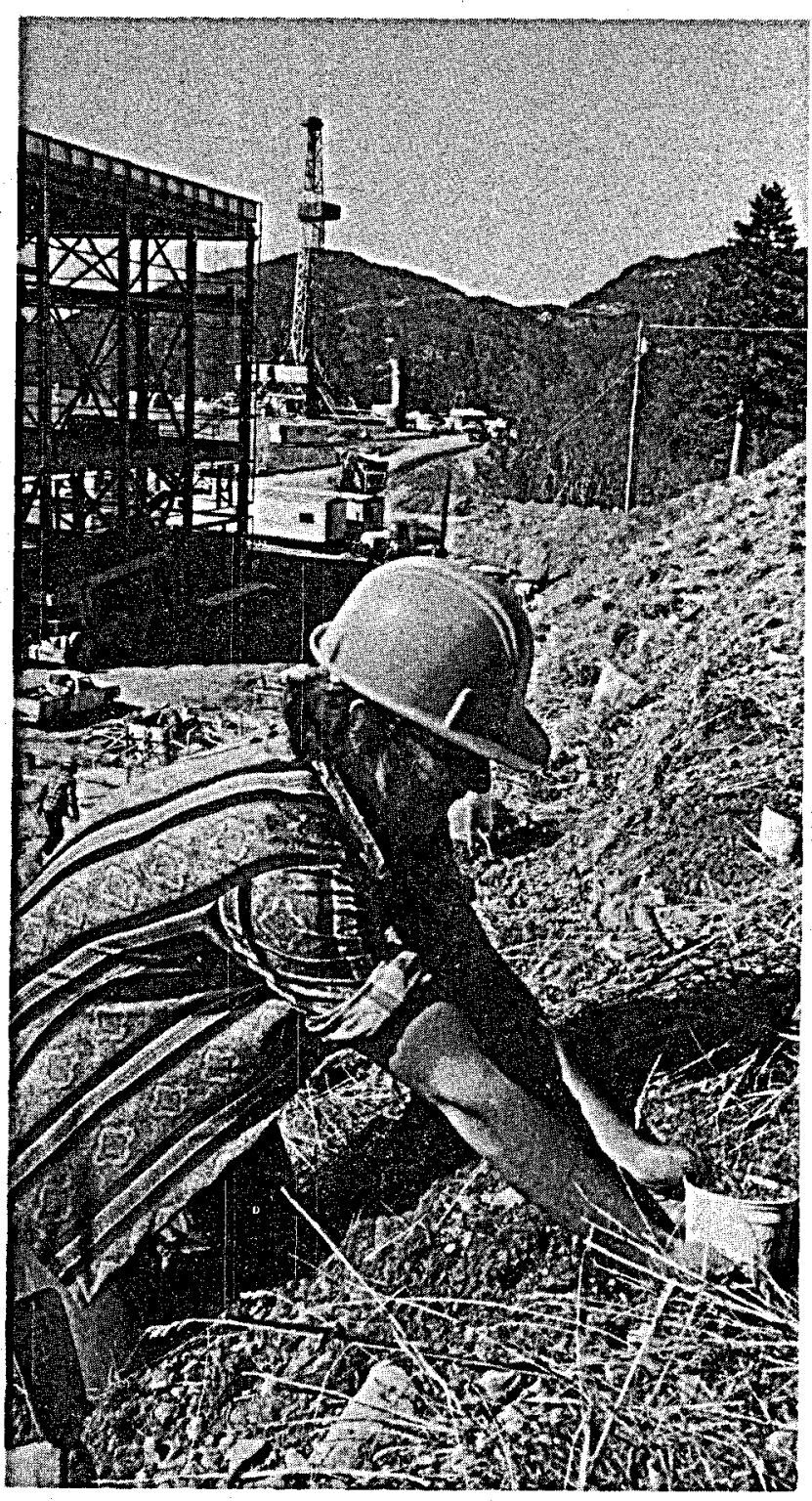




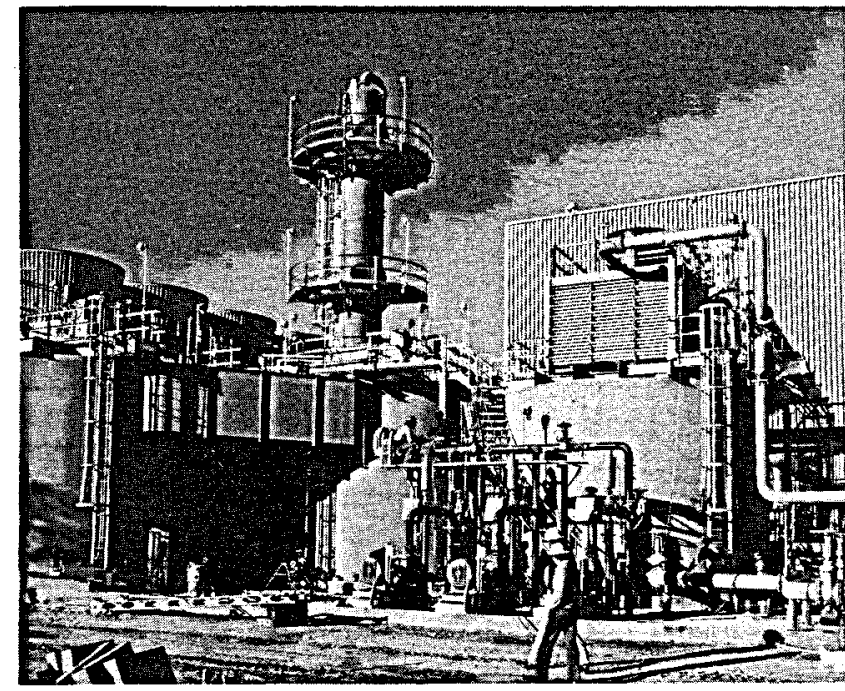

Stretford $\mathrm{H}_{2} \mathrm{~S}$ control system at The Geysers. The tall tower is the scrubber column for the system. It prevents more than 90 percent of the $\mathrm{H}_{2} \mathrm{~S}$ present in the inlet steam from leaving the plant as air emissions.
This development has occurred in spite of the highly publicized hydrogen sulfide content of the steam at The Geysers; the potential for subsidence in Imperial Valley that would damage its agricultural economy; and the threat of land and water contamination by the highly saline fluids of the Salton Sea and Brawley reservoirs.

Mitigating technologies have been developed over the past decade that have resulted in environmental success stories at both The Geysers and Imperial Valley. Development of California's geothermal assets is progressing harmoniously with conservation of its other natural resources.

This is particularly notable since the levels of hydrogen sulfide at The Geysers and the uniquely high salinities of the Salton Sea and Brawley reservoirs represent geothermal energy's "worst case" environment problems. These problems are not generally characteristic of the more prevalent types of reservoirs with lower temperatures and salinities. In some cases, the chemistry is within the criteria for drinking water quality and hydrogen sulfide is virtually not a factor. In addition, since closed-system binary cycles are the technology of choice for these resources, such operations are essentially pollution-free.

Approximately 700 acres of land are required for a $100-\mathrm{MWe}$ geothermal power plant. Ten to twenty percent is typically used for access roads, well locations, pipelines, and plant site, while the rest is undisturbed. Based on this, the total land use per $10^{12}$ Btu's annual output is approximately 275 acres with only 28 to 55 acres disturbed.

It is during the construction phases that land disruption is most noticeable and probably most significant. Once the wells have been drilled and the construction phase completed, the effects on the land begin to diminish and farming, for example, could continue between pipelines and power plants.

The impact of geothermal development on land fertility has, to date, been minimal. During most of the 60 years of field development at Larderello, Italy, the surrounding land has been used for various agricultural purposes, and today irrigated crops are grown up to power plant property lines in Imperial Valley.

The U.S.-developed technologies for mitigating the environmental problems associated with geothermal development in some areas are described briefly in the table on the next page. 


\section{Potential Problem}

Suspended particulate matter during air drilling

Runoff and siltation due to land disturbance

Rock cuttings, spent drilling fluids, oils from wells

\section{$\mathrm{H}_{2} \mathrm{~S}$ emissions from} production areas

$\mathrm{H}_{2} \mathrm{~S}$ emissions from power plants

Mineral particles in cooling tower drift

Spent geothermal brine and cooling water

\section{Technologies Available}

Efficient wellhead particulate separators

Modern erosion control techniques such as seeding, mulching, drains, and matting

Impermeable sumps; site cleanup

Minimizing venting through techniques such as shorter well tests, testing into a pipeline, vent gathering systems

Patented abatement systems available from U.S. manufacturers

Mechanical drift eliminators; acceptable guaranteed drift rate from tower manufacturer

Usually subsurface injection with prior surface treatment if needed; surface discharge of innocuous direct use fluid when suitable water body is available

Residues from brine Chemical analysis to determine nature if unknown; disposal in approved hazardous disposal facility if required; land-fill disposal if innocuous

and $\mathrm{H}_{2} \mathrm{~S}$ abatement systems

Proper site selection; appropriate well spacing; controlled fluid extraction and injection rates; effective monitoring

Subsidence from large volume withdrawal of geothermal fluids and hydrological changes

Careful siting; knowledge of local seismic

Seismicity due to fluid extraction or injection history; controlled fluid extraction and injection rates; effective monitoring 


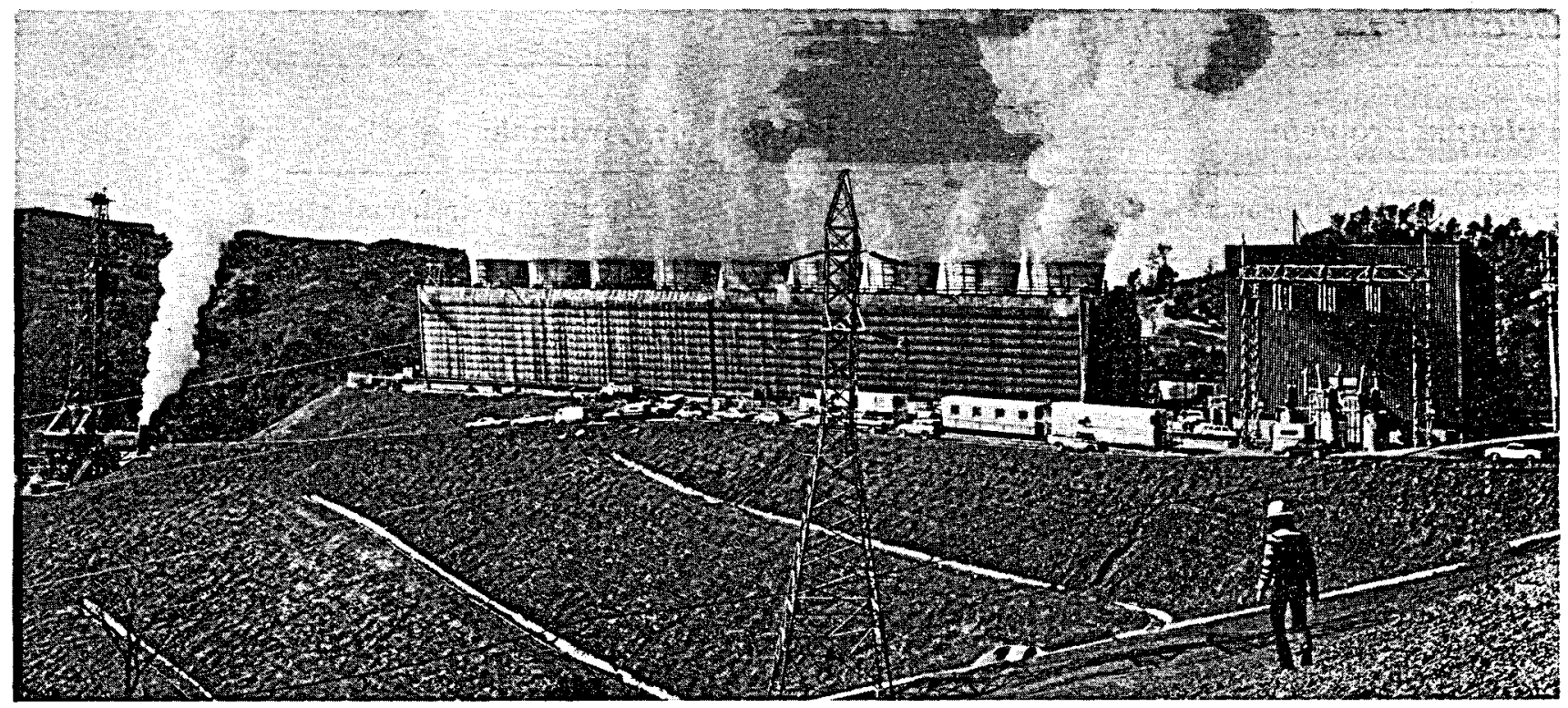

\section{$\mathrm{H}_{2}$ Removal}

Erosion and siltation control at The Geysers. Terracing and reseeding are essential in this hilly terrain.

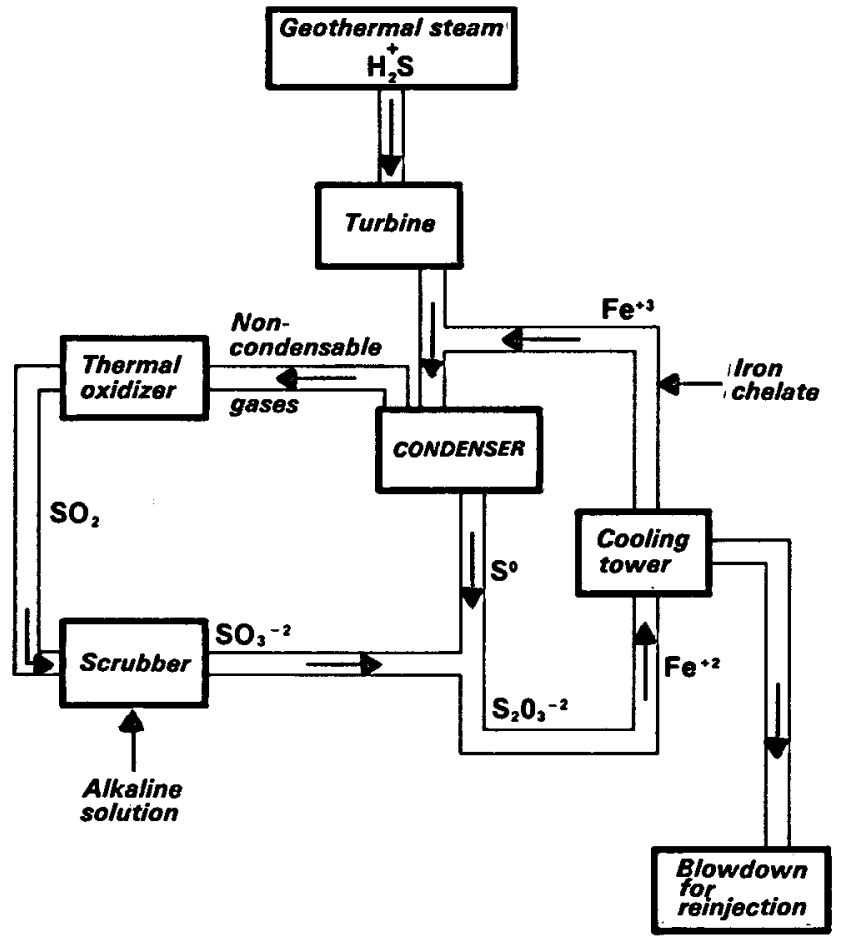

Dow RT-2 $\mathrm{H}_{2} \mathrm{~S}$ removal system. This is the newest $\mathrm{H}_{2} \mathrm{~S}$ abatement system in use at The Geysers. The process converts the gas to a soluble sulfur compound that is injected back into the formation. and produces no toxic wastes. 


\section{Socio-Economics}

\begin{abstract}
D uring the past two decades, U.S. firms have built up an impressive experience base regarding the costs, financial risks, and the general socio-economic impacts of geothermal energy used for electricity generation and direct heat applications. These impacts are, in most respects, similar to systems that use other fuels, e.g., coal or oil. The main difference is that geothermal energy systems substitute capital investments for long-term annual fuel costs.
\end{abstract}

\section{Electric Systems}

Reservoir temperature is the greatest variable in the cost of geothermal energy. There is less variation due to reservoir depth although its effects are still significant as shown in the figure on this page. The equivalent fuel cost for coal-fired electricity in the U.S. is about $\$ 4$ to $\$ 8$ per million Btu's, or on the order of 2 to 4 cents per $\mathrm{kWh}$.

Electric conversion equipment cost is affected by temperature, but not much by well depth. Current technology, binary or two-stage flash, is cost effective if the well head brine temperature is at least $170^{\circ} \mathrm{C}$ or $200^{\circ} \mathrm{C}$ respectively, and increasingly economic at higher temperatures. Conversion system costs are on the order of 3 cents $/ \mathrm{kWh}$ at $200^{\circ} \mathrm{C}$ and 2 cents $/ \mathrm{kWh}$ at $300^{\circ} \mathrm{C}$.
At U.S. hydrothermal reservoirs now being developed, the resulting cost of electricity is about the same as coal-fired electricity. This presumes a reservoir temperature of not less than $200^{\circ} \mathrm{C}$, well depths of about $2 \mathrm{~km}$, and average flow rates on the order of $200 \mathrm{~kg} / \mathrm{hr}$ per well. The first year busbar cost, including conversion equipment, is on the order of 3 to 5 cents $/ \mathrm{kWh}$.

\section{Cost of Geothermal Heat}

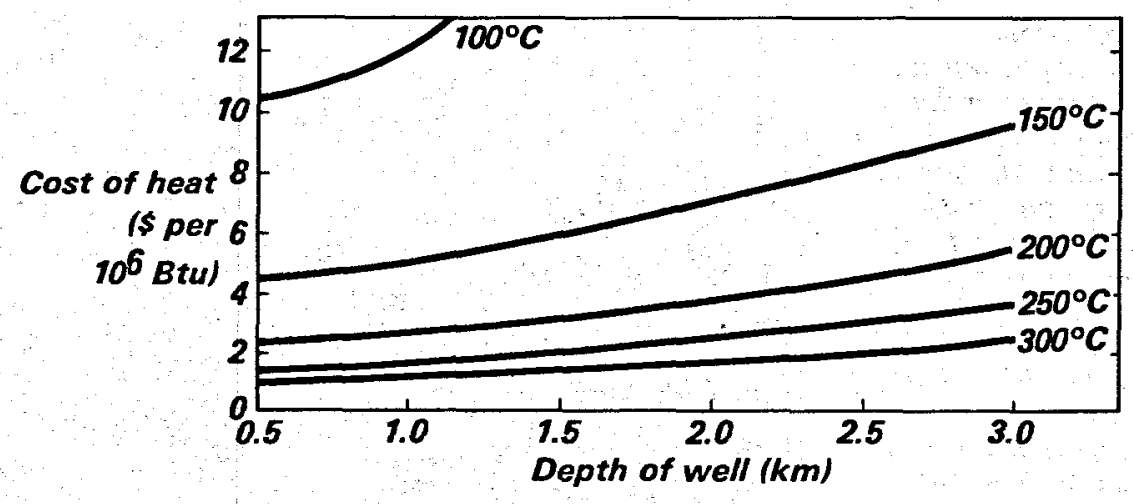

The cost of useful heat from geothermal reservoirs varies with resource temperature and depth. These are 1985 first year costs (capital recovery p/us O\&M) of typical U.S. field equipment-including wells, downhole pumps, and collection piping, but no energy conversion or end use equipment. The field is sized to power a 50-MWe (net) electric plant operating at 60 percent of maximum thermodynamic efficiency. The utilization (capacity) factor is 0.80 . The financing is public, at 10 percent discount rate and no taxes. These costs ( $+1-20$ percent) are relevant to either electric or large-scale direct heat projects. For example, you can muftiply the shown cost by 0.3413 to get the geothermal fuel contribution to electric busbar costs in cents/kWh. 


\section{Direct Heat Systems}

Conversion equipment costs for direct heat uses vary with system size, fluid temperature, and end use applications. For district heating systems, the local distribution system and heat exchanger amortized costs will range from about $\$ 3.5$ to $\$ 7.5$ per million Btu's, depending on population density and resource temperature. Conversion equipment costs for agricultural, aquacultural, and industrial process heat will be much less, especially when brine temperatures are higher.

Two natural factors have retarded the growth of geothermal direct heat applications in the U.S. One factor is the distance between certain reservoirs and population/industrial centers. Heat can be moved economically over large distances only at very large flow rates, and entrepreneurs are unlikely to site new plants far from labor forces, industrial service centers, and/or sources of raw materials and markets. The second critical factor is that the low utilization factors sometimes encountered in direct heat applications markedly increase the delivered energy cost from these capital intensive systems. For example, a crop drying process that operates 1,500 hours per year will experience a geothermal heat cost per unit three to four times that of a plant that runs 6,000 hours per year.
Irrigated fields at the Salton Sea electric plant boundary. The onset of geothermal development in the Imperial Valley created much concern about the effect it might ${ }^{*}$ have on the Valley's agricultural economy. Many local organizations, government agencies, and individuals participated in the five-year Imperial Valley Environmental Project, initiated in 1975 and funded by the U.S. government. The project developed the impartial information needed for geothermal development to proceed without damage to the Valley's ecology or economy.

\section{Social Acceptance of Projects}

Generally, for geothermal development, social concerns, positive and negative interests, and behaviors are similar to those encountered with any new moderate-sized industrial project. But certain aspects of geothermal projects take on heightened visibility and concern when they are sited near cities or valuable agricultural areas.

One major concern is effluents. Hydrogen sulfide has a noxious odor and is toxic to plants at low concentrations. Another concern is that industrial development of a reservoir might reduce the fluid flow available to preexisting small projects or detract from beautiful scenery. Spa owners in Japan, for example, have recently forced a slow-down of geothermal electric projects.

Social acceptance of projects is markedly enhanced if local participative planning is included early and throughout the project cycle. For example, the U.S. Department of Energy granted funds to the local government of Imperial County, California, which is both a major agricultural region and the most promising liquid-dominated geothermal region in the U.S. These funds made it possible for the local authorities and farmers to satisfy themselves that large scale geothermal electric development would not damage this highly productive and sensitive agricultural region. Hearings and technical analyses began long before citizen concerns could escalate to a level that impeded geothermal energy development.

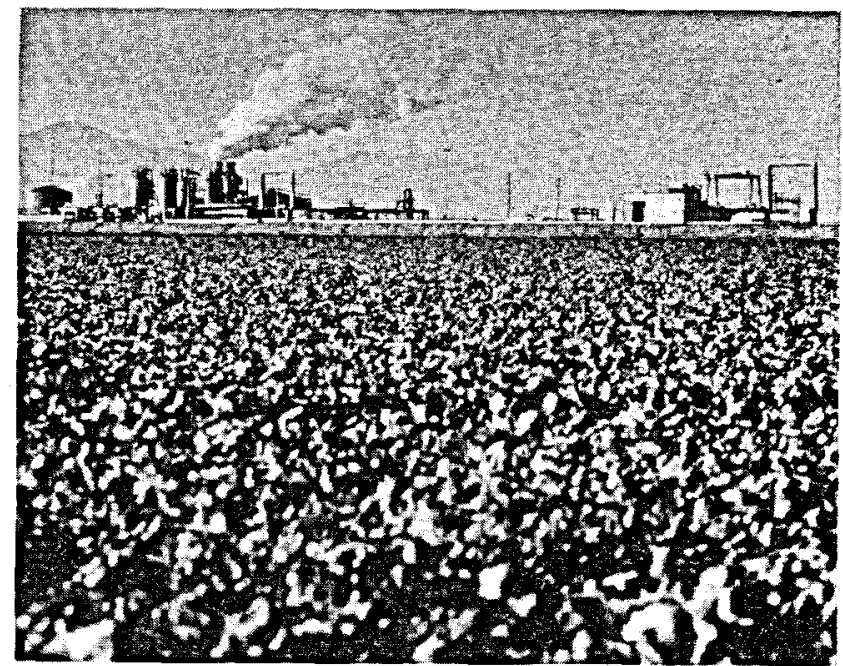




\section{Financial Risks and Advantages}

The financial risks associated with geothermal development are dominated by the risks of exploration and reservoir confirmation. But these risks are highly leveraged compared to the total cost of a typical major geothermal project. For example, exploration plus confirmation costs might comprise $\$ 5$ to $\$ 15$ million, compared to a total project cost on the order of $\$ 120$ million for a $50-\mathrm{MWe}$ electric plant. The risk here, when the potential reservoir is found to be dry or too cool, is a very small fraction of the total development costs.

For developing countries, the risks related to borrowing capital for geothermal projects is similar to the risks for other infrastructural development. Geothermal energy will not, in itself, generate foreign exchange. Its great promise is that it can reduce expenditures for fossil fuels. The point of net advantage is where debt service on the geothermal energy system is less than the costs (both debt service and fuel) of equivalent energy from conventional fuels. The savings of hard currency will sometimes dictate the use of systems that are less than technically optimal.

Thus, the capital investments for geothermal projects should be evaluated in the context of a trade-off against the future costs of other fuels, and especially the mid- to long-term price escalations for petroleum. The evaluation should include consideration of the contribution of local labor in drilling and construction, since this will further improve the equation.

If a country engages in a geothermal development program, in the long run, local reservoir analysis and power system engineering expertise will emerge and replace the purchased expertise in the program's early projects. For example, with about 20 years of experience in geothermal energy projects, Mexico is now installing wellhead geothermal electric systems which are 80 percent domestically produced.

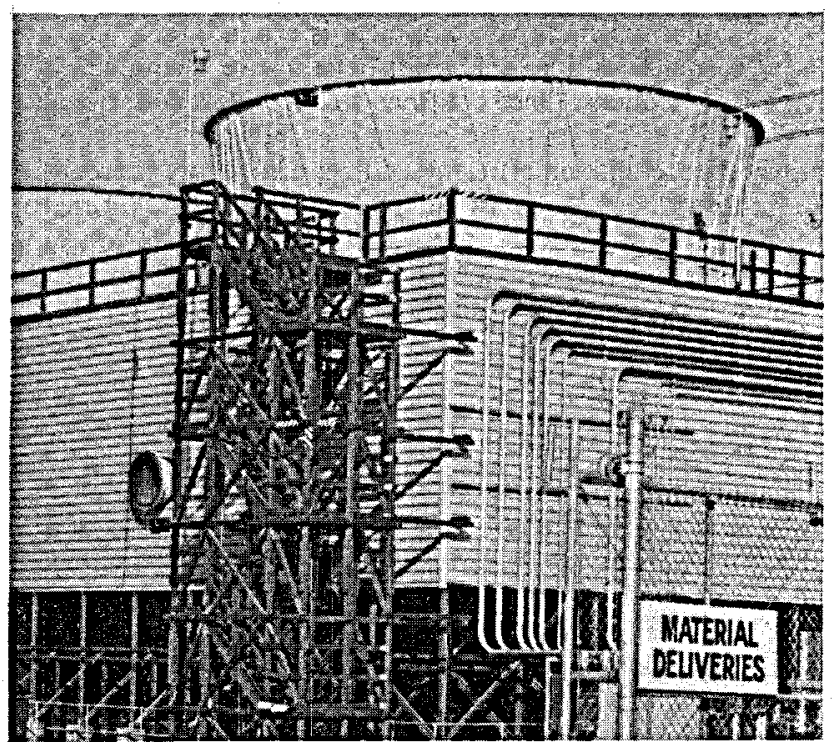

$\$ 85$ million dual-flash plant of the Heber Geothermal Corporation. This plant is the first commercially-funded large size hot water geothermal power plant in the U.S. Risks are contained and assigned to Chevron Resources, field developer, Heber Geothermal, and General Electric Credit Corporation, the lender, by means of long-term input and output contracts, performance bonds, and a comprehensive insurance package, including systems performance insurance. 


\section{International Scene}

\begin{abstract}
4 eothermal energy development is expanding throughout the world as its benefits are becoming increasingly evident. Once confined to only a few countries, geothermal energy is now becoming prominent in many nations that require an efficient, indigenous energy source. U.S. industry has in the past and will continue in the future to provide technology which supports geothermal expansion worldwide. The following descriptions offer a brief scenario of countries that are currently expanding their geothermal markets.
\end{abstract}

\section{China}

China is very rich in geothermal resources, with about 2,500 surface manifestations spread over 30 provinces, urban areas, and autonomous regions. Since most explored reservoirs contain low-temperature fluids, current use of geothermal energy is mostly in direct use applications. A number of very small flash and binary plants are in operation, with the largest-a $7 \mathrm{MWe}-$ at Yangbajing in Tibet. The addition of five 3-MWe generators at this site by 1990 has been announced, along with another 3-MWe plant near Ali to serve Shiquanbe township. Current interest is centered on innovative direct uses in Tianjin, the second largest commercial and industrial city in China.

\section{El Salvador}

El Salvador was an early entrant into the use of geothermal power generation technology. The construction of the first unit at Ahuachapan began in 1971, with commercial operation beginning in 1975. A second unit soon followed, and by 1981, a third unit, compiling a total of $95 \mathrm{MWe}$, came on line. Within a month, all three units were paid for in oil savings. An additional $85 \mathrm{MWe}$ is tentatively planned at some time in the future.

\section{France}

France is now a major direct geothermal heat user. The main application is in space heating for buildings, a particularly suitable and economic use where metropolitan areas are located above productive aquifers. Other direct uses include greenhouses, fish farms, and the heating of swimming pools. At the end of 1984, the equivalent of about 130,000 dwellings were on-line. In addition, a 4.2 MWe geothermal power plant is in operation on the island of Guadeloupe.

\section{Greece}

A 2-MWe portable turbine generator, Greece's first geothermal power plant, is scheduled for installation on the island of Milos in October 1985. A 60-MWe plant was scheduled to follow the pilot unit by 1990 to permit expansion of the island's mining industry, and export of excess power to other islands via an underwater cable. However, the plant is not included in a recent 10-year energy plan issued by the Greek Public Power Corporation.

\section{Iceland}

Approximately 80 percent of all homes in Iceland are heated by geothermal district heating systems, with approximately half the population served by the Reykjavik District-Heating Service. Geothermal energy is also used in fish farms, drying of diatomaceous earth, seaweeds, and fish meal, extraction of

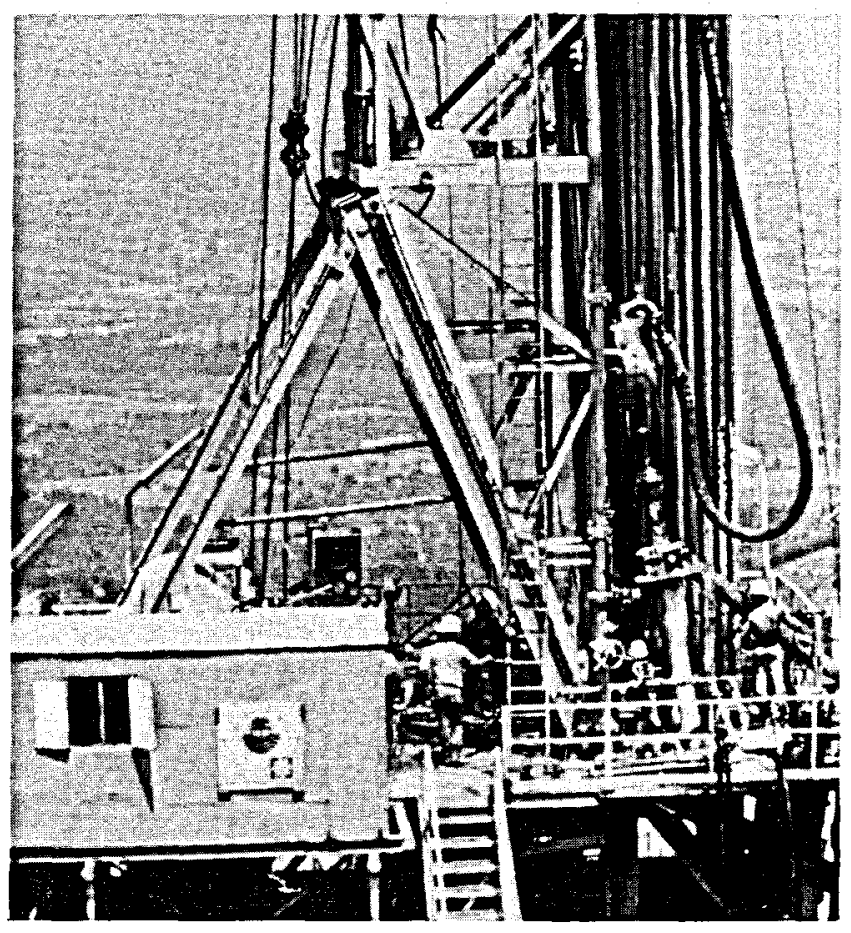

Unocal Corporation drilling operation at the Makiling-Banahao geothermal field in the Philippines. Unocal's wells supply $660 \mathrm{MWe}$ of steam capacity to government owned electric power plants in the Philippines. 
salts, drying and curing of light aggregate cement slabs, washing and drying of wool, mushroom growing, soil warming, heating swimming pools, and deicing. A 30-MWe dual flash geothermal power plant is in operation at Krafla, and smaller single flash units are on-line at Namafjall and Svartsengi.

\section{Indonesia}

Indonesia opened its first geothermal power station at Kamojang, West Java, in 1983 with a capacity of $30 \mathrm{MWe}$ operating on dry steam. The plant is currently being expanded to $140 \mathrm{MWe}$, and will generate three percent of the electric power in Java. Plans have been announced for the installation of an additional 745 MWe capacity by 1994, at seven other fields, all of them liquid-dominated, where exploration and development are currently proceeding. Three U.S. resource development firms are actively involved in these projects.

\section{Italy}

While Italy is most noted in the international geothermal community for power generation, important advances in direct use have occurred in recent years. Eight new district heating systems are operational with a total space heating volume of over 2.5 million cubic meters. Major commercial greenhouses are in operation and in the planning stage. Geothermal power plants have a combined capacity of 519 MWe, with the major development still centered in the Larderello, Travale/-Radicondoli, and Monte Amiata areas.

\section{Japan}

Nine geothermal power plants accounting for $215 \mathrm{MWe}$ are in operation. The technologies employed include dry steam, single flash, and dual flash. Another 55-MWe unit is to be constructed at Hatchobaru, and other plant expansions are under consideration. U.S. firms and universities have been employed for resource surveys and field development services. In addition to power generation, many direct use applications are employed in Japan, especially in resort areas. Two national projects utilize geothermal fluids from power plant production wells to heat river water which is transported to neighboring towns for several cascaded uses. The most exotic geothermal use in Japan is a unique botanical garden featuring tropical plants and nearly 500 crocodiles and alligators representing 27 species.
Kenva

Kenya currently has $45 \mathrm{MWe}$ of geothermal capacity in operation at Olkaria, and an additional capacity of $60 \mathrm{MWe}$ is expected to be completed by 1992 . Exploratory and confirmation drilling is also under way at Eburru, and exploration will continue in several areas of the Rift Valley to inventory resources for future development.

\section{Mexico}

Mexico has moved into third place in geothermal development-behind the U.S. and the Philippines-with a total of $710 \mathrm{MWe}$ of capacity operational or under construction at Cerro Prieto, Los Azufres, and Los Humeros. U.S. researchers have been actively involved in the reservoir engineering at Cerro Prieto. The Mexican government hopes to realize 2,440 MWe geothermal capacity by the year 2000 . In addition, a new plant to extract potassium chloride from separated brines at the Cerro Prieto flash plant will produce 200,000 tons per year, or 85 percent of the national demand. Prototype greenhouses at Cerro Prieto have been successful, and commercial direct uses are planned for the future.

\section{New Zealand}

Wairakei, New Zealand, is the site of the world's first geothermal power plant using liquid-dominated resources. Eleven of the original 13 units are still in operation with a combined capacity of $157 \mathrm{MWe}$; this may be increased by a 5-MWe bottoming binary cycle powered by waste hot water. Two units will be moved from the Wairakei field to be used along with new units at Ohaaki (Broadlands) to generate a total of $116 \mathrm{MWe}$. Another $10 \mathrm{MWe}$ are operational at Kawerau. New Zealand was also a pioneer in major direct uses of geothermal energy. A large pulp and paper mill was sited at Kawerau to make use of the natural steam available there, and an international hotel at Rotorua was the first to use geothermal cooling in addition to space heating.

\section{Nicaragua}

The first geothermal power plant in Nicaragua, a 35-MWe single flash plant at Momotombo, began operation in 1983. A resource potential is available for direct uses to fill needs such as desalting, commercial and industrial air conditioning, refrigeration for fish, and timber drying. 


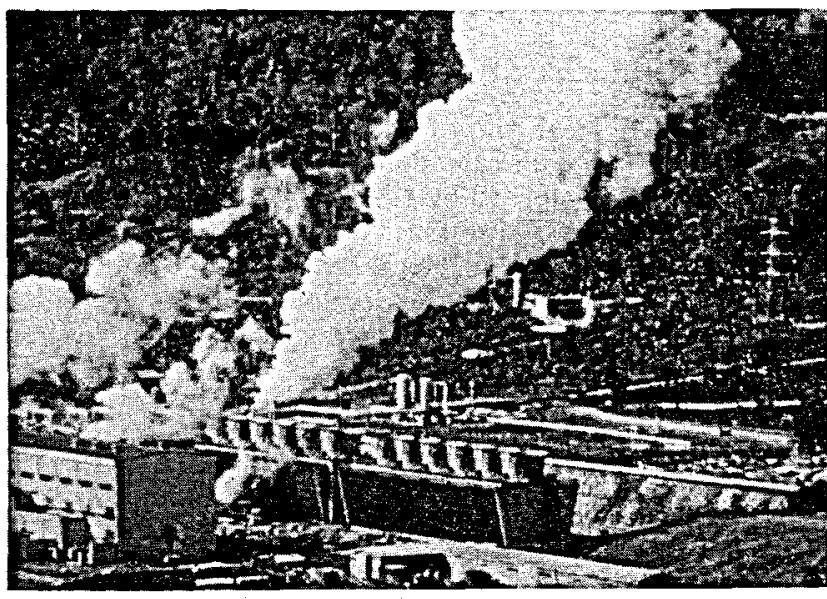

Geothermal power plants at Tiwi in the Philippines. The combined output at Twi and MakilingBanahao provides nearly 20 percent of the Philippines' electricity.

\section{Philippines}

With 894 MWe of geothermal power on-line, the Philippines rank second only to the U.S. in geothermal electricity production. Another $55 \mathrm{MWe}$ is planned for completion in 1988, and 92.5 MWe in 1989. The four fields now being exploited are Tiwi, Makiling-Banahao, Tongonan and Palimpinon. At the first two of these fields, a U.S. resource development firm supplies all of the steam-a total of 660 MWe. Nine other areas are considered prime candidates for additional plants, with Daklan and Bacon-Manito currently in developmental phases. Geothermal energy accounts for about one-fourth of the electric power produced in the Philippines.

\section{Portugal}

Since most of the reservoir temperatures are less than $100^{\circ} \mathrm{C}$, the potential for geothermal energy in mainland Portugal is confined to direct use of low-temperature fluids. However, a 3-MWe single flash power generation unit is in operation in the Azores on the island of San Miguel.

\section{Soviet Union}

While the 11-MWe plant at Pauzhetka in Kamchatka is the only geothermal plant reported to be operating in the USSR, Soviet scientists estimate that geothermal power stations will provide five percent of the country's electrical energy by the year 2000. A 50-MWe plant at Mutnovsky in eastern Kamchatka will become operational between 1986 and 1990 , and is expected to be expanded to $200 \mathrm{MWe}$. Three small experimental power plants, less than $10 \mathrm{MWe}$, are under construction to utilize the energy recovered from hot dry rock on the west coast of the Caspian Sea.

\section{Turkey}

Turkey has substantial high-temperature and low-temperature geothermal resources. From the $\mathbf{1 0}$ areas investigated so far, there is possibly a resource potential of $4,000 \mathrm{MWe}$. Turkey currently has $20.6 \mathrm{MWe}$ of geothermal power generating capacity on-line with a number of direct heat projects such as greenhouses and space heating, in operation. Consideration is being given to contracting with foreign industry to develop the country's geothermal fields, with Turkey purchasing the energy when it is produced. 


\section{Advanced Technology}

\begin{abstract}
$\boldsymbol{T}$
he goal of the geothermal program of the U.S.

Department of Energy is to establish a scientific and engineering technology base, from which the U.S. geothermal industry can develop specific processes and products in response to market demands.

The strategy of the program is to support R\&D projects that will (1) provide tangible technological payoff to the geothermal industry in meeting critical near-term objectives, and (2) provide a technology base for continued growth of geothermal energy utilization through longer-range R\&D needed to exploit all forms of geothermal energy.
\end{abstract}

Research efforts related to hydrothermal resources focus on developing better technologies and procedures for defining the characteristics of hydrothermal reservoirs and achieving significant improvements in the performance of drilling technologies and binary cycle electric technologies for moderate-temperature reservoirs.

Government research on hydrothermal technologies is quite interactive with industry's field experience in using the technologies. The recent "flowering" of flashed-steam and small binary power plants in the southwestern U.S. has occurred because of effective interactions between industry and government.

Longer-term research is focused on "advanced" and technically more demanding nonhydrothermal resources: geopressured, hot dry rock, and magma. Here the payoffs will be longer-term, and the Government sponsors most of the ongoing $R \& D$.

Geopressured production wells are being tested to determine the magnitude, availability, and productivity of geopressured resources for recovery of methane and thermal and hydraulic energy. Experiments will be undertaken to determine the efficiencies that can be achieved in electric power generation with hybrid units utilizing more than one form of energy in the process. The feasibility of direct use applications, such as space heat or industrial steam supply, with the heat of the brines will also be tested.
Experiments to determine the technical and economic feasibility of commercial-scale use of the heat of hot dry rock resources are under way at a large man-made reservoir at Fenton Hill, New Mexico. The reservoir will be subjected to long-term flow tests to establish production rates and longevity during which power generation experiments will be carried out.

Preliminary studies are in progress to investigate the engineering and economic feasibility of penetratíng and extracting energy from magma bodies. Geophysical studies of sites potentially amenable to drilling into magma are being carried out, and equipment and materials that can withstand the magma environment (temperatures up to $1,100^{\circ} \mathrm{C}$ ) are being developed. Depending on the results of these preliminary investigations, drilling could occur in the late 1980's.

The geothermal "accessible resource base" will grow as technology advances for extraction of energy from hydrothermal, geopressured, hot dry rock, and magma resources. These resources will increase the electrical energy potential available and will also increase direct utilization. Development of only a small fraction of the remaining resources could significantly increase the worldwide use of geothermal energy. 


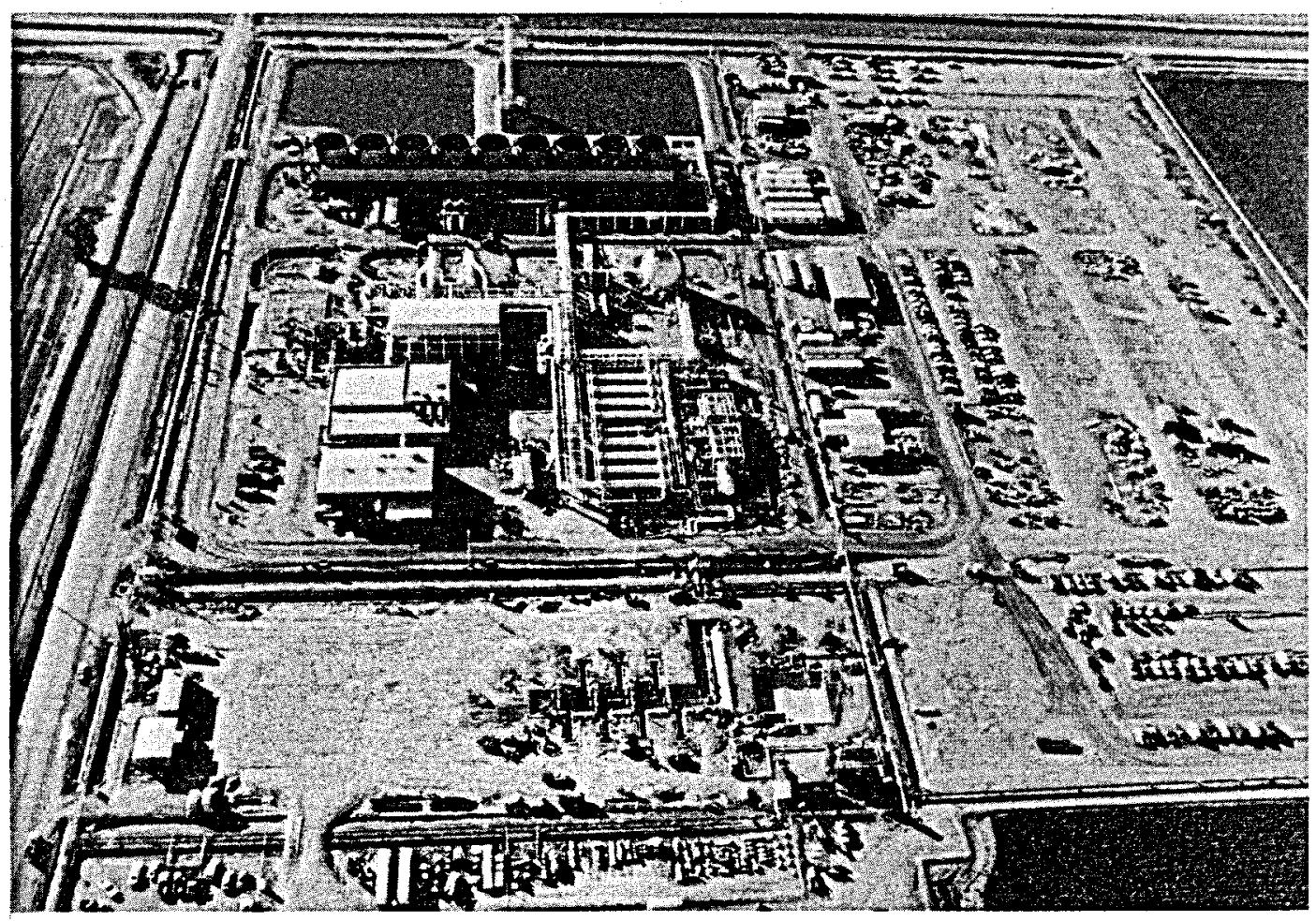

\author{
Aerial view of 45-MWe Heber \\ proof-of-concept binary plant. The \\ performance of this plant, \\ cost-shared by the U.S. Department \\ of Energy and a consortium headed \\ by San Diego Gas and Electric \\ Company, will be monitored closely \\ for two years. All data and analyses \\ will be made public to encourage \\ greater use of this technology for \\ moderate-temperature \\ hydrothermal fluids.
}




\section{Photo credits:}

P. 5/The Geysers/Pacific Gas and Electric Company

P. 6/Utah Roses/Geo-Heat Center, Oregon Institute of Technology

P. 8/Drill Rig/Longyear Company

P. 15/Core Semples/Longyear Company

P. 20/Drill Rig/Dresser Industries

P. 22/Steam Lines/Unoca/ Corporation

P. 23/Generator/General Electric Company

P. 24/Crystallizer Tanks/Goslin-Birmingham, inc.

P. 24/Steam Lines/Pacific Gas and Electric Company

P. 25/Single Wellhead/Hawaïan Electric Company, Inc.

P. 29/Household Well/Geo-Heat Center, Oregon Institute of Technology

P. 30/Direct Use/Geo-Heat Center, Oregon Institute of Technology

P. 32/Utah Roses/Utah Roses, Inc.

P. 34/Prawn/Geo-Heat Center, Oregon Institute of Technology

P. 37/Heat Exchanger/The Meridian Corporation

P. 39/Planting Techniques/Pacific Gas and Electric Company

P. 40/Stretford Plant/Pacific Gas and Electric Company

P. 42/Terraced Hillside/Pacifte Gas and Electric

$$
\text { Company }
$$

P. 44/Plant Financing/Gibbs \& Hill /nc.

P. 45/Fields/Unocal Corporation

P. 46. Drill Rig/Unocal Corporation

P. 48/Tiwi Plant/Unoca/ Corporation

P. 49/Heber Binary/San Diego Gas and Electric Company 